EDWIN JOSÉ CASTILLO ZURITA

AVALIAÇÃO DA INVERSÃO DA SACAROSE EM UM SISTEMA DE EVAPORAÇÃO (EVAPORADOR DE FILME DESCENDENTE COM PROMOTOR DE PELÍCULA) 
EDWIN JOSÉ CASTILLO ZURITA

\title{
AVALIAÇÃO DA INVERSÃO DA SACAROSE EM UM SISTEMA DE EVAPORAÇÃO (EVAPORADOR DE FILME DESCENDENTE COM PROMOTOR DE PELÍCULA)
}

\author{
Dissertação apresentada à Escola \\ Politécnica da Universidade de São Paulo \\ para obtenção de titulo de Mestre em \\ Engenharia
}


EDWIN JOSÉ CASTILLO ZURITA

\title{
AVALIAÇÃO DA INVERSÃO DA SACAROSE EM UM SISTEMA DE EVAPORAÇÃO (EVAPORADOR DE FILME DESCENDENTE COM PROMOTOR DE PELÍCULA)
}

\author{
Dissertação apresentada à Escola \\ Politécnica da Universidade de São Paulo \\ para obtenção de titulo de Mestre em \\ Engenharia \\ Área de Concentração: \\ Engenharia Química \\ Orientador: Prof. Dr. \\ Cláudio Roberto de Freitas Pacheco \\ Co-Orientador: Prof. Dr. \\ José Luis de Paiva
}


Este exemplar foi revisado e alterado em relação à versão original, sob responsabilidade única do autor e com a anuência de seu orientador.

São Paulo, de junho de 2008.

Assinatura do autor

Assinatura do orientador

FICHA CATALOGRÁFICA

Zurita, Edwin José Castillo

Avaliação da inversão da sacarose em um sistema de evaporação (evaporador de filme descendente com promotor de película) / E.J.C. Zurita. --ed.rev.-- São Paulo, 2008.

$92 \mathrm{p}$.

Dissertação (Mestrado) - Escola Politécnica da Universidade de São Paulo. Departamento de Engenharia Química.

1.Inversão de sacarose 2.Evaporação 3.Evaporadores I.Universidade de São Paulo. Escola Politécnica. Departamento de Engenharia Química II.t. 
Dedico este trabalho a Deus, aos meus Pais José e Virginia e a minha esposa Litzi que me deram a confiança e a força para poder conclui-lo 


\section{AGRADECIMENTOS}

Agradeço:

Aos professores Cláudio Pacheco e José Luis de Paiva pela orientação, pelo constante estimulo transmitido durante todo o trabalho e pela amizade entregue no desenvolvimento do mesmo.

Ao professor Aldo Tonso do Departamento de Engenharia Bioquímica e a Sra. Orlinda Rodrigues por facilitar o uso dos equipamentos do laboratório do Bloco 20 e pela ajuda nas análises das amostras.

Ao professor Wilson Salvagnini pela ajuda na montagem do sistema de evaporação e na introdução da operação do evaporador.

Aos Professores Carmen Tadini e Jorge Gut e ao pessoal do LEA.por permitir-me ser parte de seu laboratório

Aos meus amigos Eduardo, Julio, Marcelo, Marcio, Carola, Carolina, Litzy e a todos que colaboraram direta ou indiretamente, na execução deste trabalho. 


\section{RESUMO}

Neste trabalho é apresentada a avaliação da inversão da sacarose em um sistema constituído de um Evaporador de filme descendente com promotor de película. Foi feita a modelagem da inversão considerando-se os balanços de massa e de entalpia e a cinética de inversão no tubo de evaporação. Os principais parâmetros considerados foram: constante cinética $(k)$, taxa de evaporação $\left(m_{v}\right)$, concentração de açúcares totais $(C)$, vazão do líquido no tubo de evaporação $(q), p H$, temperatura ( $T$ ) e tempo de residência no tubo de evaporação $(\tau)$. Usaram-se dois métodos para a resolução do modelo, a primeira através da integração numérica do modelo (Runge Kutta de $4^{\text {ta }}$ ordem) e a outra através de equacionamento simplificado a partir valores médios das propriedades, $\mathrm{pH}$, e calculando as constantes cinéticas nas temperaturas efetivas em cada zona do tubo de evaporação, $T_{\text {efa }}$ (zona de aquecimento) e $T_{\text {efe }}$ (zona de evaporação), possibilitando assim, a integração analítica do modelo. Foram calculados os valores do volume do líquido ( $V$ ) através dos dois métodos. Os resultados foram expressos em função da vazão do líquido (q). Verificou-se que os resultados calculados pelos dois métodos foram muito próximos. Os modelos desenvolvidos podem ser aplicados para a otimização do processo de evaporação visando à minimização da inversão da sacarose. O método desenvolvido possibilita a determinação do tempo de residência no tubo de evaporação.

Palavras-chave: Cinética de inversão da sacarose. Açúcar invertido. Sistema de evaporação. Evaporador de filme descendente.Tempo de residência. 


\begin{abstract}
In this work the evaluation of sucrose inversion in a system formed by falling film Evaporator with Promoter of film is presented. The modeling was made considering: mass and enthalpy balances and the kinetic of inversion in the evaporation tube. The mean parameters investigated were: kinetic constant $(k)$, evaporation rate $\left(m_{v}\right)$, concentration of total sugars $(C)$, volumetric velocity of the liquid in the evaporation tube $(q), p H$, temperature $(T)$ and residence time in the evaporation tube $(\tau)$. Two methods was used to solve the model, the first by numeric integration (Runge Kutta $4^{\text {th }}$ Order) and the other by analytic integration of simplified model considering mean values of properties and $\mathrm{pH}$, and the kinetic constant calculates at effective temperatures in each zone of the evaporation tube, $T_{\text {efa }}$ and $T_{\text {efe, }}$, allowed the analytic integration of the model. The volume of liquid in the evaporation tube $(V)$ was calculated by the two methods. The results were expressed as a function of liquid flow rate $(q)$. It was verified that the values obtained by the two methods were very closed. These models can be used for the optimization of the evaporation process emphasizing the minimization of the sucrose inversion. The methodology could be used for the determination of the residence time in the evaporation tube.
\end{abstract}

Keywords: Inversion of sucrose kinetic. Sugar invert. Evaporation system. Falling film evaporator. Residence time. 


\section{LISTA DE FIGURAS}

Figura 1.1 Fluxograma da produção de açúcar..................................................21

Figura 4.1 Esquema do sistema de evaporação......................................................39

Figura 4.2 Sistema de evaporação simplificado.....................................................41

Figura 4.3 Divisão do tubo de evaporação...........................................................43

Figura 4.4 Balanço diferencial do tubo de evaporação..............................................43

Figura 4.5 Perfil de temperatura na direção radial.................................................47

Figura 4.6 Perfil de temperatura na direção axial "z"..............................................48

Figura 4.7 Algoritmo de cálculo de $\mathrm{x}_{\mathrm{f}(\mathrm{s})}$ por integração numérica................................49

Figura 4.8 Roteiro do cálculo de $\mathrm{V}$ pelo método rigoroso........................................51

Figura 4.9 Roteiro do calculo de $\mathrm{V}$ com equacionamento simplificado........................57

Figura 4.10 Transferência de calor no tubo de evaporação, KUROKAWA (2002).......60

Figura 4.11 (a) vazão de alimentação como líquido subresfriado e formação das zonas de aquecimento e de evaporação. (b) vazão de alimentação com líquido na temperatura de saturação e formação da zona de evaporação......................................................................................63

Figura 5.1 Influência da Temperatura $T_{c}$ no grau inversão para $q=1,1 \mathrm{ml} / \mathrm{s} \ldots \ldots \ldots \ldots . .71$

Figura 5.2 Influência da Temperatura $T_{c}$ no grau inversão para $q=1,6 \mathrm{ml} / \mathrm{s} \ldots \ldots \ldots \ldots . .71$

Figura 5.3 Influência da Temperatura $T_{c}$ no grau inversão para $q=2,0 \mathrm{ml} / \mathrm{s} \ldots \ldots \ldots \ldots . .72$

Figura 5.4 Influência da vazão do líquido no grau inversão para $T_{c}=70^{\circ} \mathrm{C} \ldots \ldots \ldots \ldots . . .72$

Figura 5.5 Influência da vazão do líquido no grau inversão para $T_{c}=75^{\circ} \mathrm{C} \ldots \ldots \ldots \ldots . . . .73$

Figura 5.6 Influência da vazão do líquido no grau inversão para $T_{c}=80^{\circ} \mathrm{C} \ldots \ldots \ldots \ldots . . .73$

Figura 5.7 Análise estatística da influência da vazão sob o grau inversão para $T_{c}=$

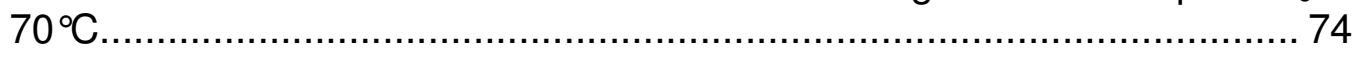


Figura 5.8 Análise estatística para a Influência da vazão sob o grau inversão para $T_{c}$

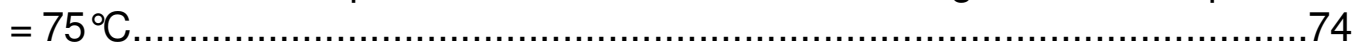

Figura 5.9 Análise estatística para a Influência da vazão sob o grau inversão para $T_{c}$

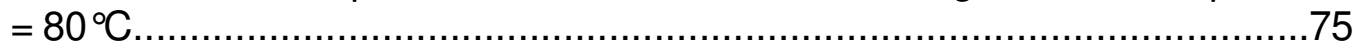

Figura 5.10 Fração invertida em função do tempo para $80^{\circ} \mathrm{C}$ e pH igual a $2,50 \ldots \ldots \ldots . .76$

Figura 5.11 Fração invertida em função do tempo para $75^{\circ} \mathrm{C}$ e pH igual a $2,25 . \ldots \ldots \ldots . . .76$

Figura 5.12 Influência da vazão do líquido sob Volume calculado (V).........................83

Figura 5.13 Influência da vazão do líquido sob o tempo de residência médio $(\bar{\tau}) \ldots \ldots . . .83$

Figura 5.14 Ajuste do volume (V) médio com a vazão média do líquido (q).................86

Figura A.1 Planilha usada para o registro das mudanças nas variáveis do processo

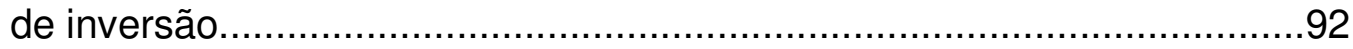

Figura B.1 Tubo de evaporação conectado com a câmara de vapor..........................93

Figura B.2 Distribuidor de alimentação. Situado na parte superior do tubo de evaporação, este consistente de vários furos envolta da entrada do tubo interno que ajudam na formação do filme líquido no tubo de

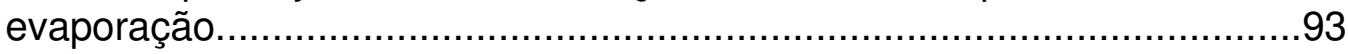

Figura B.3 Promotor de película. Situado dentro do tubo interno do evaporador, consistente de uma tela metálica pegada à parede do tubo que ajuda na estabilidade do filme.............................................................................94

Figura B.4 Câmara de vapor em funcionamento. Conectado na parte inferior do tubo de evaporação. Em teoria esta câmara deve funcionar sem acumulo de líquido como pode ser observado na figura. 


\section{LISTA DE TABELAS}

Tabela 3.1 Porcentagens de sacarose invertida por hora....................................27

Tabela 3.2 Parâmetros cinéticos para a inversão da sacarose.................................28

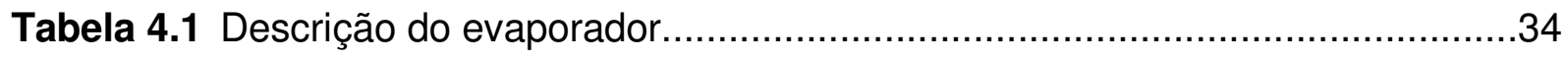

Tabela 4.2 Planejamento fatorial para a determinação da fração de volume ocupada pela zona de evaporação..................................................................66

Tabela 4.3 Planejamento fatorial para a avaliação da inversão da sacarose...............67

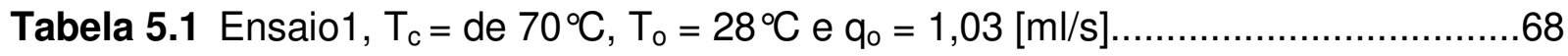

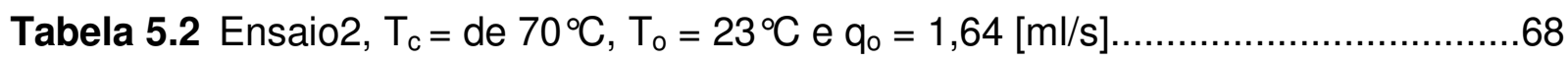

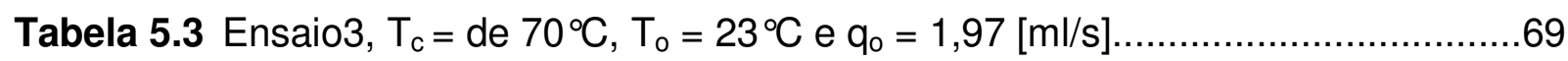

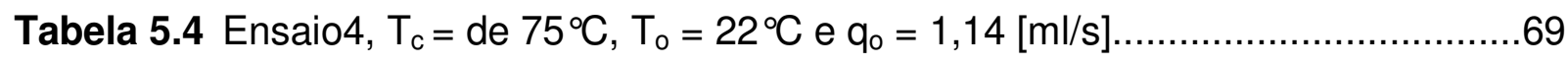

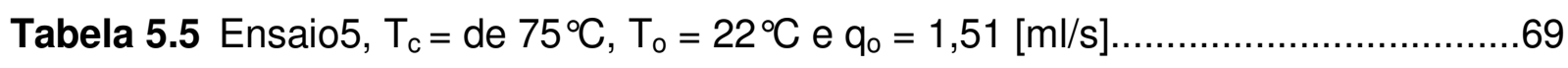

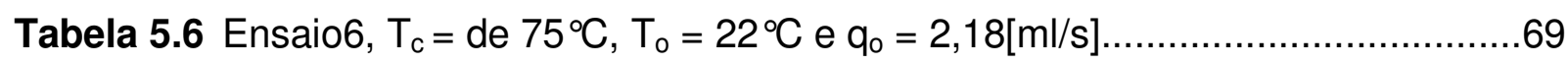

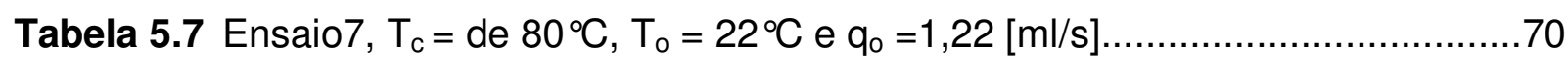

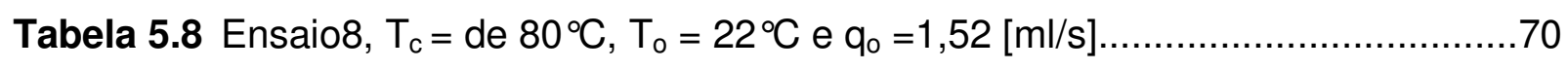

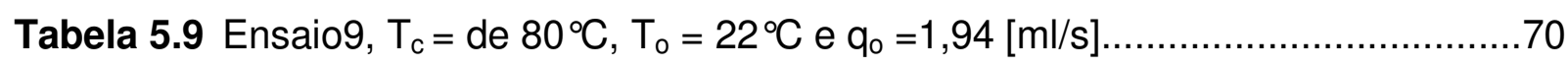

Tabela 5.10 Medições das taxas de evaporação para a alimentação com líquido subresfriado $\left(m_{\mathrm{v}}\right)$ e as taxas de evaporação com alimentação de liquido saturado

$\left(m_{v}^{\prime}\right)$

Tabela 5.11 Cálculo das frações do volume ocupado pela zona de evaporação..........78

Tabela 5.12 Resultados dos cálculos Ensaio1, $\mathrm{T}_{\mathrm{c}}=$ de $70^{\circ} \mathrm{C}$ e $\mathrm{q}_{0}=1,03[\mathrm{ml} / \mathrm{s}] \ldots \ldots \ldots . . .79$

Tabela 5.13 Resultados dos cálculos Ensaio2, $\mathrm{T}_{\mathrm{c}}=$ de $70^{\circ} \mathrm{C}$ e $\mathrm{q}_{\mathrm{o}}=1,62[\mathrm{ml} / \mathrm{s}] \ldots \ldots \ldots . . .79$

Tabela 5.14 Resultados dos cálculos Ensaio3, $\mathrm{T}_{\mathrm{c}}=$ de $70^{\circ} \mathrm{C}$ e $\mathrm{q}_{0}=1,93[\mathrm{ml} / \mathrm{s}] \ldots \ldots \ldots . .79$ 
Tabela 5.15 Resultados dos cálculos Ensaio4, $\mathrm{T}_{\mathrm{c}}=$ de $75^{\circ} \mathrm{C}$ e $\mathrm{q}_{\mathrm{o}}=1,14[\mathrm{ml} / \mathrm{s}] \ldots \ldots \ldots . .80$

Tabela 5.16 Resultados dos cálculos Ensaio5, $\mathrm{T}_{\mathrm{c}}=$ de $75^{\circ} \mathrm{C}$ e $\mathrm{q}_{\mathrm{o}}=1,51[\mathrm{ml} / \mathrm{s}] \ldots \ldots \ldots . . .80$

Tabela 5.17 Resultados dos cálculos Ensaio6, $\mathrm{T}_{\mathrm{c}}=$ de $75^{\circ} \mathrm{C}$ e $\mathrm{q}_{\mathrm{o}}=2,18[\mathrm{ml} / \mathrm{s}] \ldots \ldots \ldots \ldots . .80$

Tabela 5.18 Resultados dos cálculos Ensaio7, $\mathrm{T}_{\mathrm{c}}=$ de $80^{\circ} \mathrm{C}$ e $\mathrm{q}_{\mathrm{o}}=1,22[\mathrm{ml} / \mathrm{s}] \ldots \ldots \ldots \ldots . . . .1$

Tabela 5.19 Resultados dos cálculos Ensaio8, $\mathrm{T}_{\mathrm{c}}=$ de $80^{\circ} \mathrm{C}$ e $\mathrm{q}_{\mathrm{o}}=1,52[\mathrm{ml} / \mathrm{s}] \ldots \ldots \ldots \ldots . . . .81$

Tabela 5.20 Resultados dos cálculos Ensaio9, $\mathrm{T}_{\mathrm{c}}=$ de $80^{\circ} \mathrm{C}$ e $\mathrm{q}_{0}=1,94[\mathrm{ml} / \mathrm{s}] \ldots \ldots \ldots . . .81$

Tabela 5.21 Cálculo dos erros dos volumes médios para os ensaios a $T_{c}=$ de $70^{\circ} \mathrm{C} . .85$

Tabela 5.22 Cálculo dos erros dos volumes médios para os ensaios a $T_{C}=$ de $75^{\circ} \mathrm{C} . .85$

Tabela 5.23 Cálculo dos erros dos volumes médios para os ensaios a $T_{c}=$ de $80^{\circ} \mathrm{C} . .85$ 


\section{LISTA DE SÍMBOLOS}

\begin{tabular}{|c|c|c|}
\hline Símbolo & Descrição & Unidade \\
\hline$\alpha$ & Adimensional definido pela equação 4.46 & \\
\hline$\beta$ & Adimensional definido pela equação 4.44 & \\
\hline$\delta$ & Espessura do filme líquido & $\mathrm{m}$ \\
\hline$\delta_{w}$ & Espessura da parede do tubo de evaporação & $\mathrm{m}$ \\
\hline$\lambda$ & Calor latente de evaporação da água & J. $\mathrm{Kg}^{-1}$ \\
\hline$\rho$ & Densidade da solução de açúcar & $\mathrm{kg} \cdot \mathrm{m}^{-3}$ \\
\hline$\mu$ & Viscosidade dinâmica do líquido & Pa.s \\
\hline$\theta_{\mathrm{ev}}$ & $\begin{array}{l}\text { Fluxo de calor na zona de evaporação para } \\
\text { alimentação com líquido subresfriado }\end{array}$ & J.m $m^{-2}$ \\
\hline$\theta_{\mathrm{ev}}^{\prime}$ & $\begin{array}{l}\text { Fluxo de calor na zona de evaporação para } \\
\text { alimentação com líquido subresfriado }\end{array}$ & J.m $\mathrm{m}^{-2}$ \\
\hline$A$ & Área superficial de troca térmica de um evaporador & $m^{2}$ \\
\hline$A_{e v}$ & $\begin{array}{l}\text { Área superficial de troca térmica da zona de } \\
\text { evaporação do tubo para alimentação com líquido } \\
\text { subresfriado }\end{array}$ & $m^{2}$ \\
\hline$A_{e v}^{\prime}$ & $\begin{array}{l}\text { Área superficial de troca térmica da zona de } \\
\text { evaporação do tubo para alimentação com líquido } \\
\text { na temperatura de saturação }\end{array}$ & $m^{2}$ \\
\hline C & Concentração de açúcares totais & $\mathrm{Kg} .\left(\mathrm{m}^{3}\right)^{-1},{ }^{\circ}$ Brix \\
\hline$C_{0}$ & $\begin{array}{l}\text { Concentração de açúcares totais na entrada do } \\
\text { tubo de evaporação }\end{array}$ & ${ }^{\circ}$ Brix \\
\hline$C_{1}$ & $\begin{array}{l}\text { Concentração de açúcares totais na saída da zona } \\
\text { de aquecimento }\end{array}$ & 'Brix \\
\hline$C_{f}$ & $\begin{array}{l}\text { Concentração de açúcares totais na saída do tubo } \\
\text { de evaporação }\end{array}$ & ${ }^{\circ}$ Brix \\
\hline$C_{S A C}$ & Concentração de sacarose & ${ }^{\circ}$ Brix \\
\hline
\end{tabular}




\begin{tabular}{|c|c|c|}
\hline Símbolo & Descrição & Unidade \\
\hline$C_{S A C(0)}$ & $\begin{array}{l}\text { Concentração de sacarose na entrada do tubo de } \\
\text { evaporação }\end{array}$ & ${ }^{\circ}$ Brix \\
\hline$C_{S A C(1)}$ & $\begin{array}{l}\text { Concentração de sacarose na saída da zona de } \\
\text { aquecimento }\end{array}$ & ${ }^{\circ}$ Brix \\
\hline$C_{S A C(f)}$ & $\begin{array}{l}\text { Concentração de sacarose na saída do tubo de } \\
\text { evaporação }\end{array}$ & ${ }^{\circ}$ Brix \\
\hline$c_{p}$ & Calor específico de uma solução de açúcar & $J .\left(\mathrm{kg} .{ }^{\circ} \mathrm{C}\right)^{-1}$ \\
\hline$D$ & $\begin{array}{l}\text { Diâmetro interno de um dos tubos de um } \\
\text { evaporador }\end{array}$ & $\mathrm{m}$ \\
\hline$e_{T c}$ & Erro na medição da Temperatura de saturação $T_{c}$ & ${ }^{\circ} \mathrm{C}$ \\
\hline$e_{T O}$ & Erro na medição da Temperatura $T_{o}$ & ${ }^{\circ} \mathrm{C}$ \\
\hline$e_{T w}$ & Erro no cálculo de $T_{w}$ & ${ }^{\circ} \mathrm{C}$ \\
\hline$e_{H}$ & Erro na medição de $[H]$ & ${ }^{\circ} \mathrm{C}$ \\
\hline$e_{\text {Laq }}$ & Erro no cálculo de $L_{a q}$ & ${ }^{\circ} \mathrm{C}$ \\
\hline$e_{V}$ & Erro no cálculo de $V$ & ${ }^{\circ} \mathrm{C}$ \\
\hline$E_{a}$ & Energia de ativação & J.(mol) $)^{-1}$ \\
\hline$F_{S A C}$ & Vazão molar da sacarose & mol.s $s^{-1}$ \\
\hline$h_{v}$ & $\begin{array}{l}\text { Coeficiente de filme do lado do vapor de } \\
\text { aquecimento }\end{array}$ & J. $\left(m^{2} \cdot s \cdot{ }^{\circ} \mathrm{C}\right)^{-1}$ \\
\hline$[H]$ & Concentração de hidrogênio & $\left(\mathrm{mol} \cdot \mathrm{L}^{-1}\right)$ \\
\hline$[H]_{0}$ & $\begin{array}{l}\text { Concentração de hidrogênio na entrada do tubo de } \\
\text { evaporação }\end{array}$ & $\left(\mathrm{mol} . \mathrm{L}^{-1}\right)$ \\
\hline$[H]_{f}$ & $\begin{array}{l}\text { Concentração de hidrogênio na saída do tubo de } \\
\text { evaporação }\end{array}$ & $\left(\mathrm{mol}^{-1} \mathrm{~L}^{-1}\right)$ \\
\hline$k$ & Constante cinética da inversão da sacarose & $\mathrm{s}^{-1}$ \\
\hline$k_{0}$ & Fator pré-exponencial da constante cinética & {$\left[\mathrm{H}^{+}\right] . \mathrm{s}^{-1}$} \\
\hline$k_{a q}$ & $\begin{array}{l}\text { Constante cinética da inversão da sacarose na } \\
\text { zona de aquecimento }\end{array}$ & $s^{-1}$ \\
\hline$k_{e v}$ & $\begin{array}{l}\text { Constante cinética da inversão da sacarose na } \\
\text { zona de evaporação }\end{array}$ & $s^{-1}$ \\
\hline$K_{W}$ & $\begin{array}{l}\text { Condutividade térmica da parede do tubo do } \\
\text { evaporador (vidro) }\end{array}$ & $W .(m . \stackrel{\circ}{ })^{-1}$ \\
\hline
\end{tabular}




\begin{tabular}{|c|c|c|}
\hline Símbolo & Descrição & Unidade \\
\hline$L$ & Comprimento do evaporador & $\mathrm{m}$ \\
\hline$L_{a q}$ & $\begin{array}{l}\text { Comprimento da zona de aquecimento do tubo de } \\
\text { evaporação }\end{array}$ & $\mathrm{m}$ \\
\hline$\dot{m}$ & Vazão mássica da solução líquida no evaporador & $\mathrm{kg} \cdot \mathrm{s}^{-1}$ \\
\hline$\dot{m}_{S A C}$ & Vazão mássica da sacarose no evaporador & $\mathrm{kg} \cdot \mathrm{s}^{-1}$ \\
\hline$m_{V}$ & $\begin{array}{l}\text { Velocidade de evaporação para alimentação com } \\
\text { líquido subresfriado }\end{array}$ & $\mathrm{kg} \cdot \mathrm{s}^{-1}$ \\
\hline$m_{V}^{\prime}$ & $\begin{array}{l}\text { Velocidade de evaporação para alimentação com } \\
\text { líquido saturado }\end{array}$ & $\mathrm{kg} \cdot \mathrm{s}^{-1}$ \\
\hline$P_{\text {sat }}$ & Pressão de saturação & $\mathrm{Pa}$ \\
\hline$q$ & Vazão do líquido no tubo de evaporação & $\mathrm{m}^{3} \cdot \mathrm{s}^{-1}$ \\
\hline$q_{0}$ & Vazão de alimentação do líquido & $\mathrm{m}^{3} \cdot \mathrm{s}^{-1}$ \\
\hline$Q$ & $\begin{array}{l}\text { Taxa de calor trocado entre o vapor de } \\
\text { aquecimento e o filme líquido }\end{array}$ & $J . s^{-1}$ \\
\hline$r$ & Velocidade de reação & mol. (L.s $)^{-1}$ \\
\hline$r_{p}$ & Velocidade de formação de produtos & mol.(L.s $)^{-1}$ \\
\hline$r_{S A C}$ & Velocidade de desaparição da sacarose & mol. $(\text { L.s. })^{-1}$ \\
\hline$R$ & Constante universal dos gases & J.K $\mathrm{K}^{-1} \cdot(\mathrm{mol})^{-1}$ \\
\hline $\operatorname{Re}_{\delta}$ & $\begin{array}{l}\text { Numero de Reynolds para filmes líquidos } \\
\text { descendentes }\end{array}$ & \\
\hline$T_{o}$ & $\begin{array}{l}\text { Temperatura da solução na entrada do tubo de } \\
\text { evaporação }\end{array}$ & ${ }^{\circ} \mathrm{C}$ \\
\hline$T_{c}$ & $\begin{array}{l}\text { Temperatura da câmara de separação líquido-vapor } \\
\text { (temperatura de saturação) }\end{array}$ & ${ }^{\circ} \mathrm{C}$ \\
\hline$T_{\text {sat }}$ & Temperatura de saturação & ${ }^{\circ} \mathrm{C}$ \\
\hline$T_{w 1}$ & Temperatura da parede interna do evaporador & ${ }^{\circ} \mathrm{C}$ \\
\hline$T_{w 2}$ & Temperatura da parede externa do evaporador & ${ }^{\circ} \mathrm{C}$ \\
\hline$T_{v}$ & Temperatura do vapor de aquecimento & ${ }^{\circ} \mathrm{C}$ \\
\hline$T_{\text {efa }}$ & $\begin{array}{l}\text { Temperatura efetiva na zona de aquecimento do } \\
\text { tubo de evaporação }\end{array}$ & ${ }^{\circ} \mathrm{C}$ \\
\hline
\end{tabular}




\begin{tabular}{|c|c|c|}
\hline Símbolo & Descrição & Unidade \\
\hline$T_{\text {efe }}$ & $\begin{array}{l}\text { Temperatura efetiva na zona de evaporação do } \\
\text { tubo de evaporação }\end{array}$ & ${ }^{\circ} \mathrm{C}$ \\
\hline$V$ & Volume total do líquido no tubo de evaporação & $\mathrm{m}^{3}$ \\
\hline$V_{a p r}$ & $\begin{array}{l}\text { Volume total do líquido no tubo de evaporação } \\
\text { calculado pelo modelo simplificado }\end{array}$ & $\mathrm{m}^{3}$ \\
\hline$V_{a q}$ & $\begin{array}{l}\text { Volume ocupado pelo líquido na zona de } \\
\text { aquecimento do tubo de evaporação }\end{array}$ & $m^{3}$ \\
\hline$V_{e v}$ & $\begin{array}{l}\text { Volume ocupado pelo líquido na zona de } \\
\text { evaporação do tubo de evaporação }\end{array}$ & $\mathrm{m}^{3}$ \\
\hline$V_{\text {num }}$ & $\begin{array}{l}\text { Volume total do líquido no tubo de evaporação } \\
\text { calculado por integração numérica do modelo }\end{array}$ & $m^{3}$ \\
\hline$x$ & Fração em massa de açúcares invertidos & \\
\hline$x_{0}$ & $\begin{array}{l}\text { Fração de açúcares invertidos na entrada do tubo } \\
\text { de evaporação }\end{array}$ & \\
\hline$x_{1}$ & $\begin{array}{l}\text { Fração de açúcares invertidos na saída da zona de } \\
\text { aquecimento }\end{array}$ & \\
\hline$x_{f}$ & Fração de açúcares invertidos saída do tubo & \\
\hline
\end{tabular}




\section{LISTA DE ABREVIATURAS}

$\begin{array}{ll}\exp & \text { Função exponencial } \\ \text { ln } & \text { Função logarítmica base "e" } \\ \text { RA } & \text { Reservatório Alimentador } \\ \text { RC } & \text { Reservatório Coletor } \\ \text { USDA } & \text { United States Department of Agriculture } \\ \text { ZA } & \text { Zona de aquecimento } \\ \text { ZE } & \text { Zona de evaporação }\end{array}$




\section{SUMÁRIO}

1. Introdução

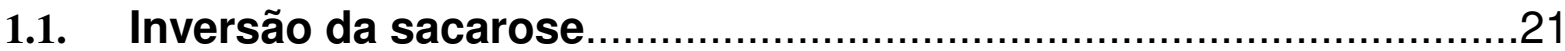

1.2. Concentração do caldo da cana ..................................................22

1.3. Abrangência da Dissertação.............................................................22

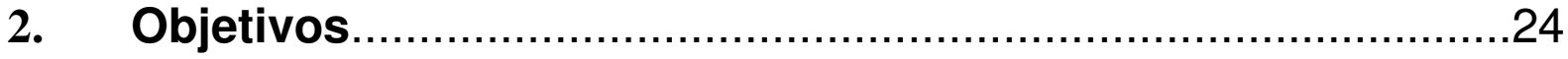

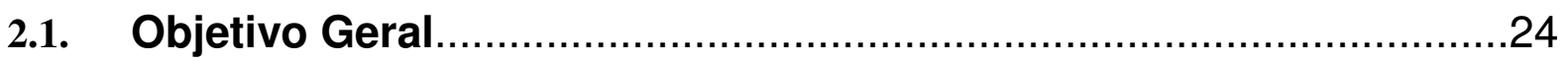

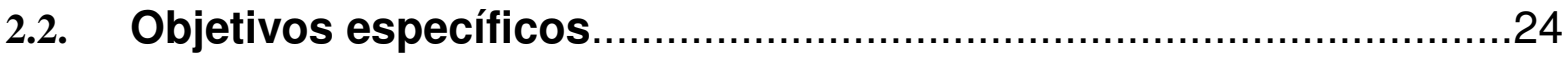

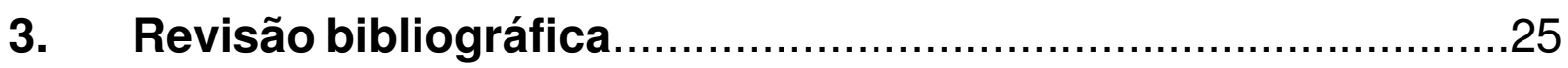

3.1. Fatores que determinam a velocidade de reação ............................25

3.2. Cinética da Inversão da Sacarose ..................................................25

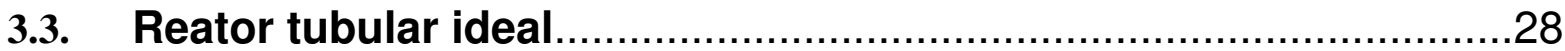

3.4. Transferência de calor na ebulição..................................................30

3.5. Propriedades da solução ..............................................................

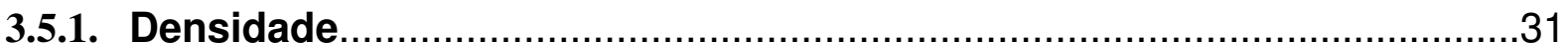

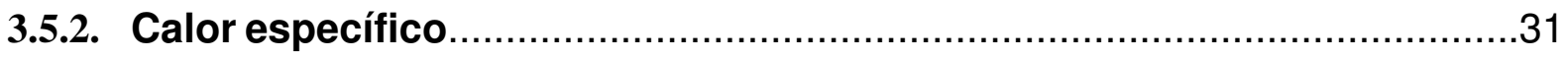

3.5.3. Viscosidade dinâmica ....................................................................

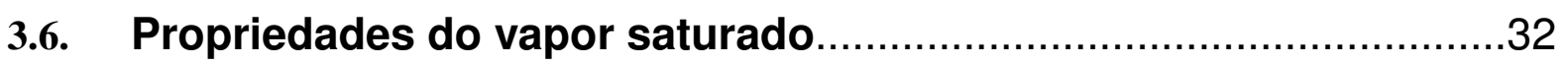

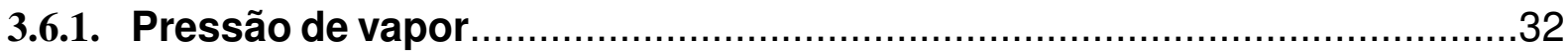

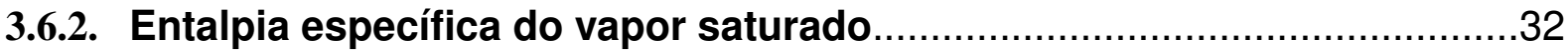

3.7. Evaporadores de filme descendente.............................................

4. Materiais e Métodos.............................................................

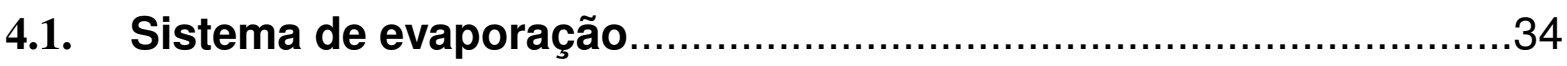

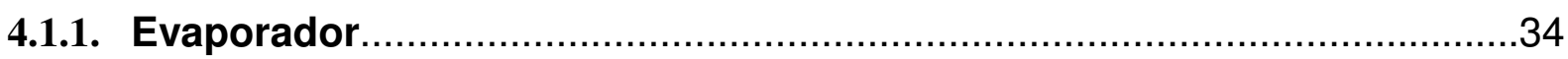

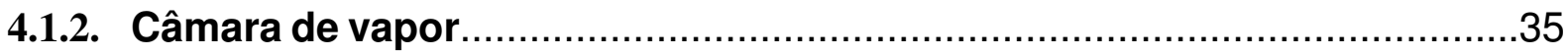

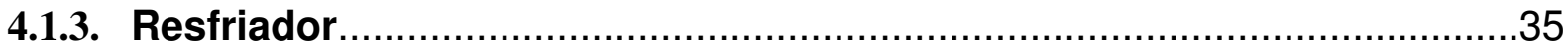

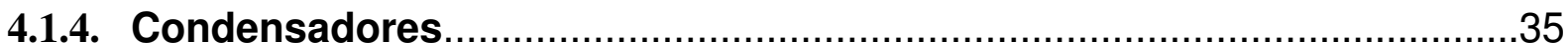

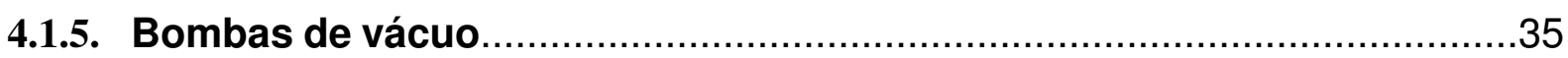

4.1.6. Reservatórios Alimentador e Coletor....................................................36 


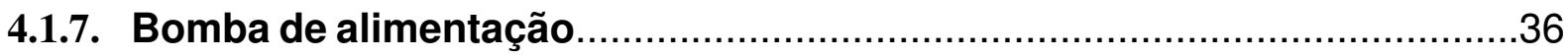

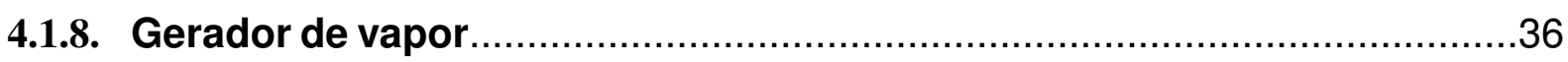

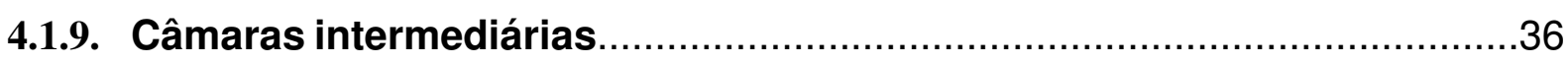

4.2. Método para a amostragem e a análise das amostras..................37

4.2.1. Procedimento para a amostragem dos experimentos no sistema de

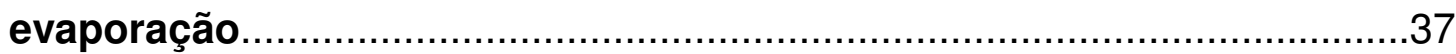

4.2.2. Procedimento para a análise das amostras.....................................39

4.2.3. Planilha para a coleta dos dados....................................................40

4.3. A inversão da sacarose no sistema de evaporação.....................40

4.3.1. Principais Hipóteses do modelo matemático para a avaliação da inversão da sacarose no sistema de evaporação.................................41

4.3.2. Modelagem matemática do tubo de evaporação...................................42

4.3.2.1. Balanço de massa global no evaporador............................................44

4.3.2.2. Balanço de massa parcial para a sacarose..........................................45

- $\quad$ Perfil de temperatura na direção radial no filme líquido...............................47

- $\quad$ Perfil de temperatura na direção axial z no filme líquido...........................48

4.3.2.3. Cálculo do volume do líquido (V) por integração numérica da concentração

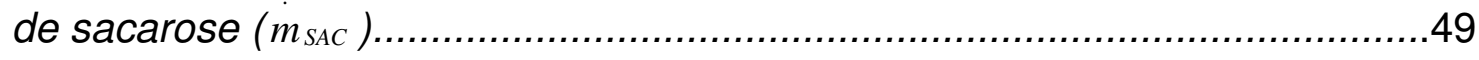

- Cálculo do tempo de residência do líquido no evaporador..........................52

- Cálculo do numero de Reynolds do líquido no evaporador.........................52

4.3.2.4. Cálculo do volume do líquido (V) com modelo simplificado........................53

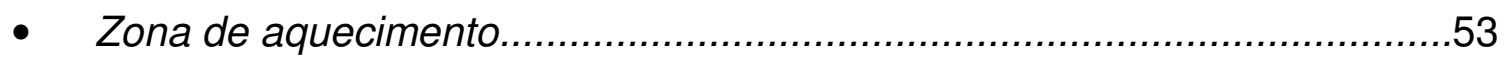

- Zona de evaporação.................................................................55

- Procedimento para o cálculo da temperatura efetiva na zona de

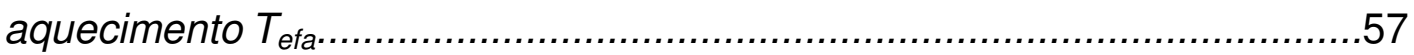

- Procedimento para o cálculo da temperatura efetiva da na zona de evaporação $T_{\text {efe }}$

4.3.2.5. Cálculo da temperatura na superfície da parede interna do tubo de evaporação. .59

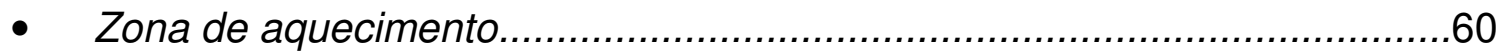

- Zona de evaporação..................................................................61

4.4. Cálculo das frações de volume ocupado pelo liquido na zona de aquecimento e na zona de evaporação do tubo 
4.4.1. Procedimento para determinação das frações do volume ocupado pelo líquido na zona de evaporação.

4.4.2. Planejamento experimental para a determinação da fração de volume ocupada pela zona de evaporação.

4.5. Planejamento experimental para a avaliação da inversão da sacarose 66

5. Resultados e discussões. .68

5.1. Resultados dos experimentos de medida da inversão da sacarose, taxa de evaporação, vazão de alimentação, $[H]$ e concentração da solução 68

5.2. Parâmetros cinéticos $k$ e $E_{a}$ usados para a avaliação da inversão da sacarose. .75

5.3. Resultados dos experimentos para a caracterização das zonas de aquecimento e de evaporação

5.4. Resultados dos roteiros do cálculo do volume $V$ por integração numérica $\left(V_{\text {num }}\right)$ e pelo modelo simplificado $\left(V_{\text {apr }}\right)$ 78

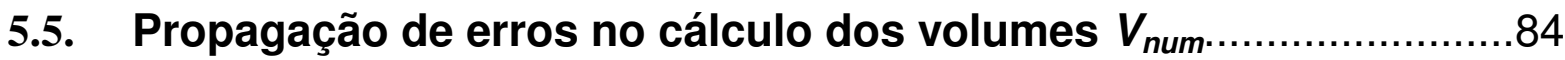

6. Conclusões, Resumo de Resultados e Recomendações........87

6.1. Conclusões e Resumo de Resultados...........................................87

6.2. Recomendações e Sugerencias................................................. 88

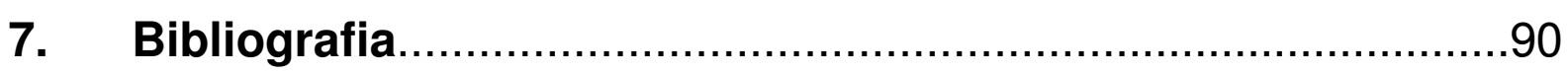

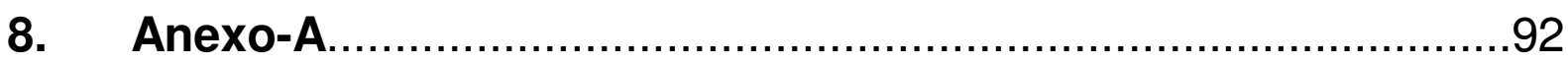

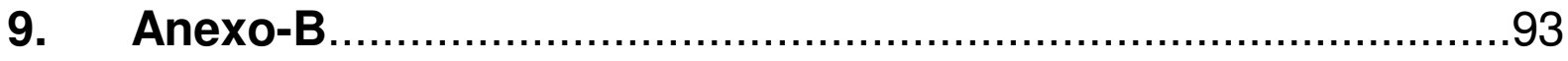




\section{Introdução}

Segundo o USDA Foreing Agricultural Service atualmente o Brasil é o maior produtor de cana de açúcar do mundo, com uma produção estimada de 420 milhões de toneladas na safra 2006/2007 (maio/abril), ocupando este setor um lugar importantíssimo na economia brasileira.

A cana de açúcar é utilizada como matéria-prima para a obtenção de açúcar (sacarose), álcool e energia elétrica.

A produção de açúcar brasileira atingiu 30,9 milhões de toneladas no período $2006 / 2007$, sendo quase $20 \%$ da produção mundial. Isto significou exportações por perto de 8 bilhões de dólares neste período.

O processamento do açúcar é uma série complexa de operações unitárias desenhadas para extrair a quantidade máxima de sacarose e com a mais alta qualidade da cana de açúcar ou da beterraba açucareira. Durante o processamento do açúcar os parâmetros físicos e químicos $(\mathrm{pH}$, concentração de açúcar, temperatura e concentração de açúcares invertidos) mudam nas linhas do processo, promovendo a formação da cor e causando perdas de sacarose, o que é uma conseqüência indesejável no processamento do açúcar.

Na figura 1.1 é apresentado o fluxograma do processamento do açúcar contendo cada uma das etapas do processo, www.engetecno.com.

Durante a concentração do caldo da cana ocorre a maior quantidade da inversão, devido a que o $\mathrm{pH}$ diminui por efeito deste processo causando maiores perdas da sacarose pela hidrólise ácida, Andrews (2002).

A avaliação da inversão que ocorre em um sistema de evaporação é de grande interesse, e envolve o estudo do processo de evaporação com seus parâmetros de operação característicos (vazão de alimentação, taxa de evaporação, concentrações de entrada e saída no tubo de evaporação, etc) a partir de um ponto de vista cinético. 


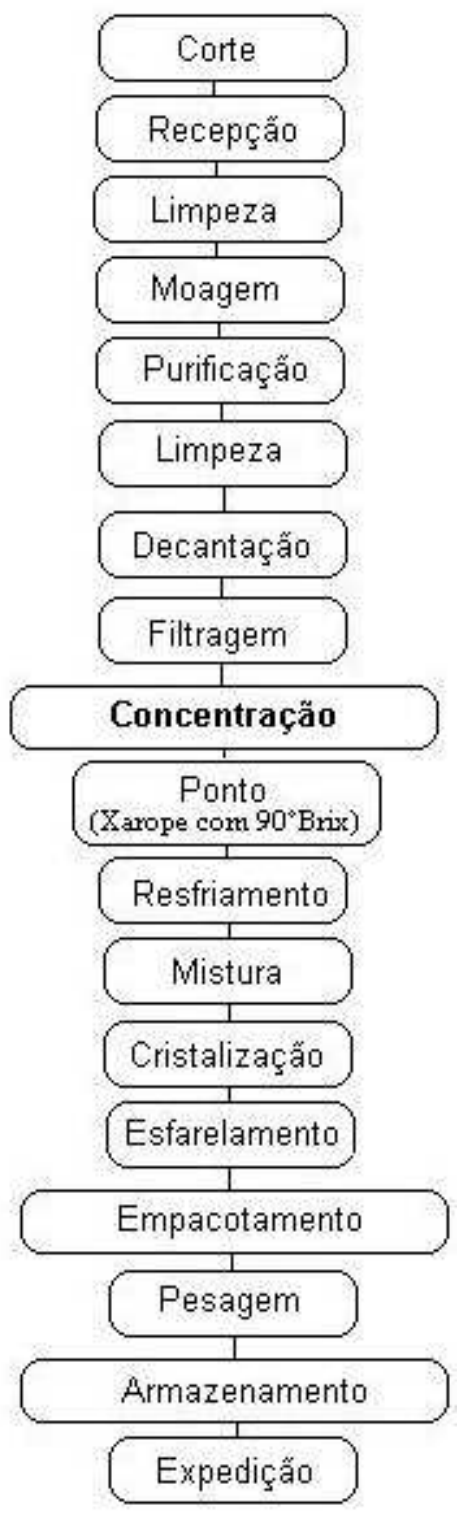

Figura1.1 Fluxograma da produção de açúcar

\subsection{Inversão da sacarose}

A Inversão da sacarose foi estudada por uma grande quantidade de pesquisadores os quais usaram diferentes métodos para a determinação da velocidade de reação, sendo o primeiro método para a determinação da concentração o de polarimetria no qual observaram-se as mudanças na rotação especifica da solução do açúcar.

A reação da inversão basicamente é a hidrólise do dissacarídeo sacarose que produz uma mistura dos monossacarídeos Glicose e Frutose. A velocidade desta reação é afetada principalmente pela temperatura, o pH e o tempo de residência da 
solução no processo e em menor grau por outros parâmetros tais como: concentração da sacarose, concentração de ácido não dissociado, presença de sais e não eletrólitos, (Falles and Morell (1922), Leininger and Kilpatrick (1938), Heidt and Purves (1938)).

A presença de açúcares invertidos é indesejável no processamento do açúcar, pois influencia na cor do açúcar obtido e dificulta a recuperação da sacarose.

\subsection{Concentração do caldo da cana}

Entre os evaporadores utilizados para a concentração do caldo da cana existe uma diversidade de tipos os quais apresentam vantagens e desvantagens no referente à operação, custo de manutenção, capacidade de evaporação, tempo de contato com o liquido, etc. Embora seja tão grande a diversidade dos evaporadores todos funcionam sob o mesmo princípio, a separação de uma parte da água contida na solução de açúcar por meio da evaporação. Inicialmente ocorre a transferência de calor do meio aquecedor para a solução por superfície sólida ou direta em seguida a transferência simultânea de calor e de massa do líquido para a fase vapor. A avaliação da inversão da sacarose durante o processo da evaporação ajudaria a prever as perdas causadas pela inversão as quais dependem dos parâmetros de projeto do evaporador (temperatura de operação, capacidade evaporativa, recirculação, acumulação do liquido no evaporador, etc.). Para a avaliação da inversão da sacarose em um sistema evaporativo, neste trabalho usou-se um evaporador de filme descendente com promotor de película cujos parâmetros mais importantes de estudo foram: vazão de alimentação $(q)$, taxa de evaporação $\left(m_{v}\right)$, temperatura da câmara de separação líquido-vapor $\left(T_{C}\right)$.

\subsection{Abrangência da dissertação}

A inversão da sacarose diminui o rendimento e a qualidade final do açúcar obtido. A temperatura da solução geralmente usada é inferior à temperatura da parede do tubo em contato com a solução e assim, a inversão da sacarose pode ser ainda mais 
acentuada. No presente trabalho foi estudada uma distribuição de temperaturas linear no sentido do eixo axial para a zona de aquecimento e linear no sentido do eixo radial para a zona de evaporação. A partir destes perfis de temperatura calcularam-se os volumes de liquido acumulado no tubo de evaporação $\left(V_{a q}\right.$ e $\left.V_{e v}\right)$ e em seguida os tempos de residência do liquido no tubo, finalmente foram avaliadas as espessuras do filme liquido em cada condição de operação.

Para o estudo da inversão da sacarose devido à hidrólise ácida, no presente trabalho alterou-se a concentração de hidrogênio $(H)$ da solução de açúcar, com o objetivo de amplificar o efeito da inversão, pois a característica principal do evaporador de filme descende é o seu curto tempo de residência.

Em cada uma das zonas do tubo de evaporação (zona de aquecimento e zona de evaporação) foram considerados os balanços de massa, de energia e cinética de inversão, elaborando-se, assim, os modelos matemáticos para a avaliação da inversão (ver figuras 4.1, pág.39 e 4.2, pág. 42) 


\section{Objetivos}

\subsection{Objetivo Geral}

O trabalho teve por objetivo avaliar a inversão da sacarose em um sistema de evaporação (Evaporador de filme descendente com promotor de película).

\subsection{Objetivos Específicos}

Os objetivos específicos foram:

a) Elaborar um modelo matemático para a avaliação da inversão da sacarose em um sistema de evaporação a partir dos balanços de massa e energia e de parâmetros cinéticos;

b) Estudar a influência das variáveis do processo de evaporação -concentração de sacarose de entrada, vazão e taxa de evaporação- na inversão da sacarose;

c) Calcular as áreas referentes às zonas de aquecimento e de evaporação no evaporador de filme descendente através de ensaios experimentais;

d) Desenvolver um critério de temperatura efetiva da solução a partir de um modelo de distribuição de temperatura no filme líquido;

e) Elaborar uma modelagem para calcular os tempos de residência da solução no sistema de evaporação; 


\section{Revisão bibliográfica}

Neste capítulo apresentam-se conceitos teóricos que são referidos à cinética de inversão da sacarose e ao fenômeno da evaporação, os quais serão necessários para a avaliação da inversão da sacarose em um sistema de evaporação.

\subsection{Fatores que determinam a velocidade de reação}

A velocidade de uma reação depende da composição das substâncias reagentes, assim como também de uma série de outros fatores. Entre os principais, estão: estado de agregação, nível de mistura dos reagentes, tamanho e concentração dos reagentes, temperatura, pressão, substâncias que afetam a reação sem serem elas nem reagentes nem produto (catalisadores) e de algumas condições especiais próprias do sistema como pode ser a radiação de luz visível, ultravioleta, raios $X$, nêutrons ou outras.

\subsection{Cinética da Inversão da Sacarose}

A velocidade de inversão da sacarose varia principalmente com: temperatura, concentração de íons hidrogênio e, em menor grau, com a concentração de ácido não dissociado, com a concentração de sacarose e com a presença de sais e não eletrólitos, Fales and Morell (1922).

A reação química da inversão da sacarose é dada por:

$$
\mathrm{C}_{12} \mathrm{H}_{22} \mathrm{O}_{11}+\mathrm{H}_{2} \mathrm{O} \stackrel{\mathrm{H}^{+}}{\longrightarrow} \mathrm{C}_{6} \mathrm{H}_{12} \mathrm{O}_{6}+\mathrm{C}_{6} \mathrm{H}_{12} \mathrm{O}_{6}
$$

E a sua equação cinética é expressa por: 


$$
\frac{d C_{S A C}}{d t}=-k \cdot\left[C_{S A C}\right]^{s} \cdot\left[\mathrm{H}_{2} \mathrm{O}\right]^{a} \cdot\left[H^{+}\right]^{h}
$$

Considerando-se a alta concentração de água, pode-se considerá-la constante. Sendo assim a equação de velocidade dessa reação pode ser descrita da forma:

$$
\frac{d C_{S A C}}{d t}=-k^{\prime} \cdot\left[C_{S A C}\right]^{s} \cdot\left[H^{+}\right]^{h}
$$

Além disso, para os íons de hidrogênio que atuam como catalisadores da reação, a concentração também permanece constante durante a reação. A equação 3.3 pode então ser expressa por:

$$
\frac{d C_{S A C}}{d t}=-k^{\prime \prime} \cdot\left[C_{S A C}\right]^{s}
$$

Os diferentes autores que estudaram esta reação concordam que esta se trata de uma reação de pseudo primeira ordem ou seja com um valor de $\boldsymbol{s}$ igual a 1, [Falles and Morell(1922), Leininger and Kilpatrick(1938), Heidt and Purves(1938), Buchanan and Kubler(1983) e Torres e Oliveira(1994)].

A variação da constante cinética com a temperatura obedece à lei de Arrhenius e se expressa por:

$$
k^{\prime \prime}=k_{o} * e^{-\frac{E_{a}}{R \cdot T}}
$$

sendo:

$E_{a}$ a Energia de ativação [kcal $\left./ \mathrm{mol}\right]$

T. a Temperatura [K]

$k_{0} \quad 0 \quad$ Coeficiente pré-exponencial [1/s]

$k^{\prime \prime} \quad$ o Coeficiente cinético de pseudoprimeiro ordem [1/s]

$R$ a Constante Universal dos Gases [kcal/mol-K] 
Em Hugot (1976) são apresentados dados de porcentagens de sacarose invertida por hora de acordo com o pH do meio, estes dados são transcritos na tabela 3.1.

Tabela 3.1. Porcentagens de sacarose invertida por hora

\begin{tabular}{ccccccc}
\hline $\mathbf{p H}$ & $\mathbf{6 , 0}$ & $\mathbf{6 , 2}$ & $\mathbf{6 , 4}$ & $\mathbf{6 , 6}$ & $\mathbf{6 , 8}$ & $\mathbf{7 , 0}$ \\
$\mathbf{T}\left[{ }^{\circ} \mathbf{C}\right]$ & & & & & & \\
\hline 50 & 0,00100 & 0,00063 & 0,00040 & 0,00025 & 0,00016 & 0,00010 \\
60 & 0,00350 & 0,00200 & 0,00140 & 0,00088 & 0,00056 & 0,00035 \\
70 & 0,01100 & 0,00700 & 0,00440 & 0,00260 & 0,00180 & 0,00110 \\
80 & 0,03300 & 0,02100 & 0,01300 & 0,00830 & 0,00520 & 0,00330 \\
85 & 0,05300 & 0,03400 & 0,02200 & 0,01300 & 0,00840 & 0,00530 \\
90 & 0,08900 & 0,05600 & 0,03500 & 0,02200 & 0,01400 & 0,00890 \\
95 & 0,14000 & 0,08800 & 0,05500 & 0,03500 & 0,02200 & 0,01400 \\
100 & 0,21000 & 0,13000 & 0,08400 & 0,05300 & 0,03400 & 0,02100 \\
105 & 0,35000 & 0,22000 & 0,14000 & 0,08800 & 0,05600 & 0,03500 \\
110 & 0,54000 & 0,34000 & 0,22000 & 0,14000 & 0,08600 & 0,05400 \\
120 & 1,00000 & 0,70000 & 0,44000 & 0,28000 & 0,18000 & 0,11000 \\
\hline
\end{tabular}

A partir destes dados e mediante um tratamento matemático, podem ser obtidos os parâmetros cinéticos da reação de inversão.

$$
\begin{aligned}
& E_{a}=25.52[\mathrm{kcal} / \mathrm{mol}] \\
& I n k_{o}=33.9 \\
& k_{o}=5,2793^{*} 10^{14}\left[\mathrm{~s}^{-1}\right]
\end{aligned}
$$

$\mathrm{Na}$ literatura, apresentam-se uma variedade de valores dos parâmetros cinéticos, e as diferenças que existem entre eles são, na maioria devido às técnicas empregadas na determinação das concentrações dos açúcares redutores ou açúcar invertido.

A tabela 3.2 apresenta um resumo dos valores de energia de ativação $\left(E_{a}\right)$ e do coeficiente pré-exponencial $\left(k_{o}\right)$, com uma descrição do autor e da técnica de determinação utilizada. 
Tabela 3.2: Parâmetros cinéticos para a inversão da sacarose

\begin{tabular}{|c|c|c|c|c|}
\hline Ano & Pesquisador/Concentração & Método & $\mathrm{E}_{\mathrm{a}}(\mathrm{kcal} / \mathrm{mol})$ & Ink \\
\hline 1934 & $\begin{array}{c}\text { Moelwyn-Hughes } \\
(0.20 \mathrm{M} \mathrm{HCl})\end{array}$ & Polarimetria & 24,90 & 33,21 \\
\hline 1938 & $\begin{array}{l}\text { Leiningerg-Kilpatrik } \\
\qquad(0.00 \mathrm{M} \mathrm{HCl})\end{array}$ & Dilatometria & 26,17 & 35,18 \\
\hline 1938 & $\begin{array}{l}\text { Leiningerg-Kilpatrik } \\
\qquad(0.20 \mathrm{M} \mathrm{HCl})\end{array}$ & Dilatometria & 25,97 & 34,94 \\
\hline 1938 & $\begin{array}{l}\text { Leiningerg-Kilpatrik } \\
\qquad(0.57 \mathrm{M} \mathrm{HCl})\end{array}$ & Dilatometria & 25,81 & 34,84 \\
\hline 1938 & $\begin{array}{l}\text { Heidt-Purves } \\
(0,01 \mathrm{M} \mathrm{HCl})\end{array}$ & Analise Química & 25,99 & 34,83 \\
\hline 1938 & $\begin{array}{l}\text { Heidt-Purves } \\
(0,57 \mathrm{M} \mathrm{HCl})\end{array}$ & Analise Química & 25,94 & 35,10 \\
\hline 1983 & $\begin{array}{l}\text { Buchanan-Clubler } \\
\qquad(0,57 \mathrm{M} \mathrm{HCl})\end{array}$ & Polarimetria & 25,04 & 33,59 \\
\hline 1983 & $\begin{array}{c}\text { Buchanan-Clubler } \\
(0,57 \mathrm{M} \mathrm{HCl}, \text { muta-rotação corrigida) }\end{array}$ & Polarimetria & 25,71 & 34,67 \\
\hline 1983 & $\begin{array}{l}\text { Buchanan-Clubler } \\
\qquad(0,57 \mathrm{M} \mathrm{HCl})\end{array}$ & HPLC & 25,76 & 34,87 \\
\hline 1983 & $\begin{array}{l}\text { Buchanan-Clubler } \\
\qquad(0,57 \mathrm{M} \mathrm{HCl})\end{array}$ & GLC & 25,71 & 34,80 \\
\hline 1976 & Hugot & $\begin{array}{l}\text { Ajuste dos dados } \\
\text { da tabela } 3.1\end{array}$ & 25,52 & 33,90 \\
\hline 1994 & $\begin{array}{c}\text { Pinheiros } \\
(\mathrm{pH} \text { de } 08 \text { a } 2,5)\end{array}$ & $\begin{array}{c}\text { DNS } \\
\text { Método } \\
\text { não-isotermico }\end{array}$ & 23,68 & 31,46 \\
\hline
\end{tabular}

\subsection{Reator tubular ideal}

O reator ideal de fluxo tubular é aquele no qual não há mistura na direção do fluxo e existe mistura perfeita na direção perpendicular à do fluxo, isto é na direção radial. As concentrações variam ao longo da coordenada do comprimento (eixo z) mas não ao longo da coordenada radial (eixo r) Smith (1989). Exceto quando é possível uma 
operação isotérmica, a temperatura também varia ao longo do eixo z. Pode-se deduzir que a velocidade de reação varia de acordo com a coordenada axial. Por conseguinte, o elemento de volume no balanço de massa, Equação 3.6, deve ser de comprimento diferencial, mas pode prolongar-se ao longo da totalidade do diâmetro do reator. $O$ balanço de massa aplicado ao elemento de volume $\Delta V$ para este tipo de operação em regime permanente é expresso por:

$$
\left.q C_{S A C}\right|_{V}-\left.q C_{S A C}\right|_{V+\Delta V}+r_{i} \Delta V=0
$$

Tomando o limite para $\Delta V \rightarrow 0$, obtém-se

$$
\frac{d\left(q C_{i}\right)}{d V}=r_{i}
$$

A vazão volumétrica $(q)$, assim como a concentração da sacarose $\left(C_{S A C}\right)$, pode variar de forma significativa ao longo do comprimento do reator, devido a mudanças de temperatura e do número total de moles no caso de reação em fase gasosa. Por estas razões é preferível expressar a equação 3.7 em termos de conversão em lugar de concentração conforme a equação 3.8. Em qualquer ponto do eixo z, ao longo do reator, a conversão x pode ser expressa como:

$$
x=\frac{q_{o} C_{S A C(i)}-q C_{S A C}}{q_{o} C_{S A C(i)}}
$$

Diferençando a conversão $x$ em função do volume $V$, a equação 3.8 pode-ser expressa na forma diferencial:

$$
\frac{d\left(q C_{S A C}\right)}{d V}=-q_{o} C_{S A C(i)} \frac{d x}{d V}
$$

A equação 3.7 pode se combinar com a equação 3.9 para obter o balanço de massa em termos da conversão. 


$$
\frac{d x}{d V}=-\frac{r_{S A C}}{q_{o} C_{S A C(i)}}=-\frac{r_{S A C}}{F_{S A C}}
$$

Em que $F_{S A C}$ é a vazão molar de sacarose na entrada do reator. A integração da equação 3.10 fornece:

$$
\frac{V}{F_{S A C}}=\int_{x_{i}}^{x}-\frac{d x}{r_{S A C}}=\int_{x_{i}}^{x} \frac{d x}{r_{p}}
$$

Esta última igualdade mostra que o sinal negativo pode ser suprimido se a velocidade $r_{P}$ corresponder à formação do produto e não ao reagente. As Equações 3.9 e 3.10 são os modelos comuns do balanço de massa para o reator de fluxo pistonado.

\subsection{Transferência de calor na ebulição}

A revisão apresentada no presente item é baseada no trabalho de Kurosawa (2002). Segundo Stephan (1988), a transferência de calor puramente convectiva pode ser descrita através de propriedades físicas, tais como viscosidade, densidade, condutividade térmica, coeficientes de expansão térmica e de parâmetros geométricos. Já em processos que envolvem mudanças de fase, como a ebulição, deve se dar adicional importância a variáveis ligadas à mudança de fase, tais como a entalpia de vaporização, temperatura de ebulição, densidade do vapor e tensão superficial.

Neste caso, devido à multiplicidade de variáveis, é mais difícil sugerir equações para o cálculo do coeficiente de troca de calor. Além das várias influências, devem ser considerados os diferentes tipos de troca de calor resultantes de diferentes padrões de escoamento e também o grau de superaquecimento do líquido. 


\subsection{Propriedades da solução}

As propriedades da solução a ser concentrada (no caso, a de sacarose) podem ser determinadas através de correlações descritas por Peacock (1995), a partir do Brix médio da solução $\left(C\right.$, em \%) e de sua temperatura média $\left(T\right.$, em $\left.{ }^{\circ} \mathrm{C}\right)$.

\subsubsection{Densidade}

A densidade da solução ( $\rho_{S}$, em $\left.\mathrm{kg} \cdot \mathrm{m}^{-3}\right)$ é dada por:

$$
\rho_{S}=1000\left[1+C \cdot \frac{(C+200)}{54000}\right] \cdot\left[1-0,036 \cdot \frac{T-20}{160-T}\right]
$$

Para $\mathrm{T}<100^{\circ} \mathrm{C}$ e $\mathrm{C}$ com faixa de aplicabilidade desconhecida.

\subsubsection{Calor específico}

O calor específico da solução ( $\mathrm{c}_{\mathrm{S}}$, em J.(kg.K) $\left.{ }^{-1}\right)$ é dado por:

$C_{p}=\left(4,12553-0,024804 \cdot C+6,7 \cdot 10^{-5} \cdot C \cdot T+1,8691 \cdot 10^{-3} \cdot T-9,271 \cdot 10^{-6} \cdot T^{2}\right) \cdot 1000$

Para $40^{\circ} \mathrm{C}<\mathrm{T}<100^{\circ} \mathrm{C}$ e $0 \%<\mathrm{C}<80 \%$.

\subsubsection{Viscosidade dinâmica}

A viscosidade dinâmica da solução $\left(\mu_{S}\right.$, em $\left.c P\right)$ é dada por:

$$
\mu=10^{\left[22,46 \frac{\mathrm{C}}{1900-18 \cdot \mathrm{C}}-0,114+\frac{(30-\mathrm{T})}{(91+\mathrm{T})} \cdot\left(1,1+43,1 \cdot\left(\frac{\mathrm{C}}{1900-18 . \mathrm{C}}\right)^{1,25}\right)\right]}
$$

Para $10^{\circ} \mathrm{C}<\mathrm{T}<80^{\circ} \mathrm{C}$ e $0 \%<\mathrm{C}<85 \%$. 
No S.I., a viscosidade dinâmica em $\mathrm{cP} \cdot 10^{-3}$ resulta em viscosidade dinâmica em Pa.s.

\subsection{Propriedades do vapor saturado}

As propriedades do vapor saturado podem ser determinadas através de correlações mostradas por Kurokawa (2002), a partir da temperatura da solução $T$ e da temperatura de saturação $T_{\text {sat }}\left(T\right.$ e $T_{\text {sat }}$ em $\left.{ }^{\circ} \mathrm{C}\right)$.

\subsubsection{Pressão de vapor}

Utilizando a equação de Antoine, a pressão de vapor da água ( $P_{\text {sat }}$, em $\left.\mathrm{Pa}\right)$ pode ser obtida através da seguinte equação, dependendo de sua temperatura de saturação $\left(\mathrm{T}_{\text {sat }}, \mathrm{em}^{\circ} \stackrel{\circ}{\mathrm{C}}\right)$ :

$$
P_{\text {sat }}=2,21 \cdot 10^{7} \cdot \mathrm{e}^{\left(6,53247-\frac{7173,79}{1,8 . T_{\text {sat }}+421,4747}\right)}
$$

\subsubsection{Entalpia de vaporização/condensação}

A entalpia de vaporização da água ( $\lambda$, em J. $\left.\mathrm{kg}^{-1}\right)$ ou condensação do vapor $\left(\lambda, \mathrm{J}_{\mathrm{kg}}{ }^{-1}\right)$ é dada em função de sua temperatura $\left(T\right.$, em $\left.{ }^{\circ} \mathrm{C}\right)$ através da seguinte relação:

$$
\lambda=4186,8(607-0,7 \mathrm{~T})
$$

\subsection{Evaporadores de filme descendente}

Os evaporadores de filme descendente podem ser operados com diferenças de temperatura muitos baixas entre a superfície de aquecimento e o líquido em ebulição, com altos coeficientes de transferência de calor e com curtos tempos de 
residência (alguns segundos), Salvagnini e Taqueda, (2004). Estas características tornam o evaporador de filme descendente particularmente adequado para produtos termo-sensiveis. Atualmente este tipo de evaporador é o de maior uso para o processamento deste tipo de produtos.

A concentração de sucos é geralmente feita a vácuo para reduzir a temperatura de ebulição e evitar a decomposição dos compostos sensíveis ao calor. As altas velocidades de escoamento evitam a incrustação do produto nas paredes.

$\mathrm{Na}$ industria açucareira o uso deste tipo de evaporadores ajudaria na minimização das perdas de sacarose por inversão, pois pelas características destes evaporadores a solução de sacarose é mantida em contato por pouco tempo na superfície aquecedora (alguns segundos), www.niroinc.com. 


\section{Materiais e Métodos}

\subsection{Sistema de evaporação}

Descreve-se o sistema de evaporação adequado ao modelo matemático proposto para a avaliação da inversão da sacarose durante o processo de evaporação. 0 sistema de evaporação consiste de um evaporador de filme descendente com promotor de película situado no Laboratório de Separações Térmicas e Mecânicas (LSTM) do Departamento de Engenharia Química, Escola Politécnica da USP, o qual esta composto de um evaporador, uma câmara de vapor, um resfriador, dois condensadores, duas bombas de vácuo, uma bomba de alimentação, um gerador de vapor, dois reservatórios de liquido e duas câmaras intermediarias.

$\mathrm{Na}$ seqüência descrevem-se detalhadamente partes do sistema de evaporação esquematizado na figura 4.1 (pagina 39).

\subsubsection{Evaporador}

O evaporador consiste de dois tubos de vidro pirex concêntricos onde o vapor que é utilizado como fluido de aquecimento flui pela parte anular dos tubos e a solução a ser concentrada flui no tubo interno escoando em forma de película. As dimensões do evaporador são descritas na tabela 4.1 (ver figura 4.1, pág.39);

Tabela 4.1: Descrição do evaporador

\begin{tabular}{lccc}
\hline & Unidade & Tubo interno & Tubo externo \\
\hline Diâmetro interno & $\mathrm{cm}$ & 5,00 & 7,14 \\
Diâmetro externo & $\mathrm{cm}$ & 5,36 & 7,50 \\
Comprimento & $\mathrm{cm}$ & 150,00 & 150,00 \\
Espessura da parede & $\mathrm{cm}$ & 0,18 & 0,18 \\
\hline
\end{tabular}




\subsubsection{Câmara de vapor}

A câmara de vapor consiste de um balão de vidro com volume de 5 litros de capacidade, conectado com a parte inferior do evaporador. Nesta parte a mistura líquido-vapor que sai do tubo de evaporação é separada, o liquido escoa pela parte inferior do balão sendo conduzido até o reservatório coletor e o vapor levado a um trocador de calor onde o vapor de água é condensado (ver figura 4.1, pág.39).

\subsubsection{Resfriador}

O resfriador está situado entre a câmara de vapor e o reservatório coletor ( $R C)$. $O$ objetivo deste resfriador é o de congelar a reação de inversão por meio da diminuição da temperatura da solução atingindo temperaturas bem próximas daquela do meio ambiente (ver figura 4.1, pág.39).

\subsubsection{Condensadores}

São utilizados dois condensadores para a condensação do vapor: o primeiro, de maior área de troca de calor, o qual opera com água a temperatura ambiente e onde se condensa a maior parte do vapor gerado durante a evaporação; e o outro de menor área de troca de calor, que opera com água gelada cujo principal objetivo é assegurar a não passagem de água para a bomba de vácuo. Este sistema de condensação possui um recipiente de coleta de água condensada e um dispositivo para a extração da mesma assim facilitando o cálculo da taxa de evaporação para cada experimento (ver figura 4.1, pág.39).

\subsubsection{Bombas de vácuo}

O sistema de evaporação opera com duas bombas de vácuo: uma ajusta a pressão de operação do sistema até que a temperatura da câmara atinja a temperatura de operação desejada; a outra bomba é utilizada para fazer a extração da solução 
concentrada do Reservatório Coletor e transferi-la para o Reservatório Alimentador (ver figura 4.1, pág.39).

\subsubsection{Reservatórios Alimentador e Coletor}

O Reservatório Coletor $(\mathrm{RC})$ é um frasco de vidro de um litro de capacidade mantido na pressão do sistema e conectado ao resfriador, este reservatório possui também uma saída na parte inferior por onde a solução concentrada pode ser extraída. $\mathrm{O}$ Reservatório Alimentador (RA) é onde se carrega a solução diluída, ele opera a pressão atmosférica e também possui uma saída na parte inferior a qual esta conectada à bomba de alimentação (ver figura 4.1, pág.39).

\subsubsection{Bomba de alimentação}

Para manter uma vazão de alimentação constante é utilizada uma bomba peristáltica modelo A-1860V-61, Flex Flo, Blue White industries, USA, a qual esta conectada ao reservatório alimentador, ela leva a solução diluída do experimento até o evaporador, a vazão pode ser mudada por meio de um regulador (ver figura 4.1, pág.39).

\subsubsection{Gerador de vapor}

O gerador de vapor consiste de um Erlenmeyer de 5 litros de capacidade, no interior do qual água destilada é evaporada por meio de uma resistência elétrica. A taxa de evaporação é controlada por meio de um reostato que se encontra conectado à resistência elétrica (ver figura 4.1, pág.39).

\subsubsection{Câmaras intermediárias}

São utilizadas duas câmaras intermediárias, uma para permitir a separação dos experimentos durante o ensaio e a outra para permitir a passagem do liquido do 
Reservatório Coletor, operando a uma pressão menor que a atmosférica, para o Reservatório Alimentador que opera à pressão atmosférica (ver figura 4.1, pág.39).

\subsection{Método para a amostragem e a análise das amostras}

A método utilizado para a tomada de amostras durante a experiência contempla a medição e ou registro de uma série de variáveis que afetam ao grau de inversão da sacarose. As variáveis são: concentrações da sacarose, [H] (indiretamente pelo pH), vazão de alimentação, temperatura na câmara de vapor e taxa de evaporação.

O método para a amostragem de cada experimento é apresentado a seguir.

\subsubsection{Procedimento para a amostragem dos experimentos no sistema de evaporação}

a) Pesar 250 gramas de sacarose (açúcar de mesa);

b) adicionar $2000 \mathrm{~mL}$ de água para solubilizar esta quantidade de sacarose,

c) em um outro recipiente preparar 250 gramas de uma solução de $\mathrm{HCl}$, a quantidade de $\mathrm{HCl}$ deve ser tal que a solução resultante da mistura das soluções de açúcar e $\mathrm{HCl}$ produzam uma solução de [H] igual a 0.005623 (valor mínimo da concentração de íons hidrogênio para que a mudança nas concentrações de açúcares invertida possa ser percebida pela análise, esta concentração correspondendo a pH igual a 2,25);

d) misturar as duas soluções e homogeneizar;

e) ligar o gerador de vapor, (já que é utilizado o vapor de água como fluido de aquecimento);

f) ligar as correntes de água e água gelada que são utilizadas nos condensadores e o resfriador;

g) ligar a bomba de vácuo a qual estabelece a pressão do sistema;

h) mediante o controle da pressão do sistema pode-se atingir a temperatura de evaporação desejada ( $T_{c}$, temperatura da câmara de separação liquido/vapor) a qual será motivo de estudo; 
i) utilizar 500 gramas da solução de sacarose para estabilizar a taxa de evaporação e para formação da película descendente no tubo de evaporação, estas 500 gramas são introduzidas no Reservatório Alimentador (RA) e são conduzidas ao tubo de evaporação mediante a bomba de alimentação;

j) uma vez gastos as 500 gramas de solução introduzir as restantes 2000 gramas no RA e acionar o cronômetro, isso tendo cuidado de não interromper a alimentação da solução;

k) tomar duas amostras da solução de alimentação uma de $2 \mathrm{ml}$ e a outra de $4 \mathrm{ml}$, a primeira será usada para a determinação do açúcar invertida e a outra para a medição da concentração de hidrogênio $([\mathrm{H}]$, a partir do pH);

l) ao escoar pelo evaporador a mistura liquido/vapor é separada na câmara de vapor (CV), a parte liquida é conduzida ao Reservatório Coletor (RC), mas previamente a sua temperatura é abaixada próxima à temperatura ambiente por meio de um resfriador. O vapor gerado durante a evaporação é condensado e colhido num recipiente a qual deve ser pesada posteriormente;

m) medir o tempo no qual a solução no RA é esgotada já que este define o tempo final do experimento;

n) terminado o experimento, tomar novamente duas amostras de 2 e $4 \mathrm{ml}$ para as medições do açúcar invertido e [H];

o) usar a solução concentrada deste experimento como solução de alimentação do próximo experimento e repetir os passos anteriormente mencionados. Considerando-se a estabilidade da taxa de evaporação e a película já formada do anterior experimento;

p) a solução concentrada deve ser reusada quantas vezes for possível, isso só é limitado pelo volume da solução resultante já que para volumes menores que um litro de solução o controle do sistema torna-se difícil de operar pelo curto tempo do experimento.

Para a análise das amostras o seguinte procedimento deve ser seguido para determinação das concentrações de glicose e das $[H] s$ nas soluções (de alimentação e de saída) para cada experimento. 


\subsubsection{Procedimento para a análise das amostras}

a) Fazer as medições da [H] das soluções nas amostras de $4 \mathrm{ml}$, está medição é feita diretamente por meio de um $\mathrm{pH}$-metro previamente calibrado;

b) as amostras de $2 \mathrm{ml}$ devem ser condicionadas, se for o caso, no referente ao $\mathrm{pH}$ e à concentração dos açúcares por meio da adição de uma solução básica e água destilada. Por exemplo, neste trabalho optou-se por usar um auto-analisador de fluxo continuo de marca Technicon, que usa um método enzimático para a determinação de glicose, mas as amostras devem encontrar-se em um pH bem perto de 7 e em um intervalo de concentrações de glicose entre 0 a 1 grama por litro de solução;

c) uma vez obtidas as concentrações de glicose lembrando que a glicose representa $50 \%$ da sacarose invertida total de cada amostra é calculado o grau de inversão a partir da concentração de sacarose original da amostra;

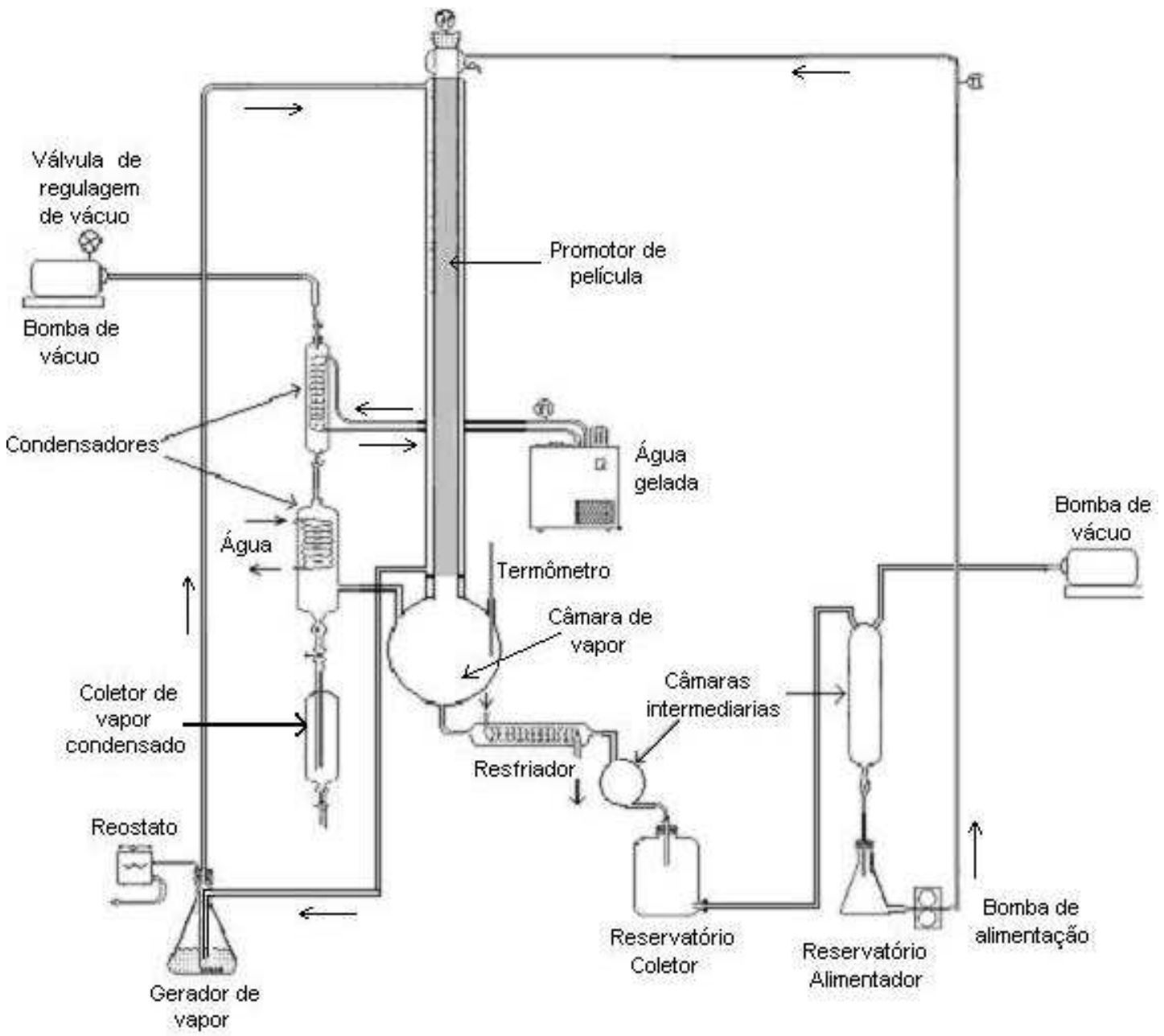

Figura 4.1. Esquema do sistema de evaporação. Em anexo B são mostrados fotos do evaporador com o promotor de película, o distribuidor de alimentação e a câmara de vapor. 


\subsubsection{Planilha para a coleta dos dados}

Para o controle das variáveis durante os ensaios criou-se uma planilha de ensaios na qual são registradas as suas mudanças, tais como: concentração de açúcares totais, temperaturas dos reservatórios e da câmara de evaporação, tempo de duração do experimento, massa de água evaporada, volumes de água e de solução de hidróxido de sódio agregados, etc. Além das variáveis que incidem diretamente na inversão da sacarose também são registradas: data de realização do ensaio, horas de inicio e de finalização do ensaio, potência da resistência do refervedor, etc. Em anexos $A$ é mostrada a planilha utilizada para a coleta destes dados.

\subsection{A inversão da sacarose no sistema de evaporação}

Para a modelagem matemática da inversão da sacarose no sistema de evaporação deve-se observar o conjunto dos processos intervenientes. $O$ esquema do sistema de evaporação é apresentado na Fig. 4.2.

Este esquema pode ser simplificado conforme Fig. 4.2 em dois Reservatórios (RA e RC) e o tubo de evaporação que é onde se evapora a solução de sacarose e portanto onde pode acontecer a reação da inversão da sacarose. Neste esquema pode-se observar que a solução de alimentação contida no RA é levada por meio da bomba de alimentação até o topo do tubo de evaporação, a solução atravessa o tubo e na saída são divididas duas correntes uma de vapor de água e a outra da solução de sacarose concentrada que é conduzida para o RC. Neste diagrama não são incluídos os recipientes intermediários já que estes são utilizados,um deles para a transferência da solução concentrada do RC para o RA e o outro para cortar por um curto tempo a vazão do líquido e assim poder usar a solução concentrada como uma nova solução de alimentação para o inicio da outra experiência. 


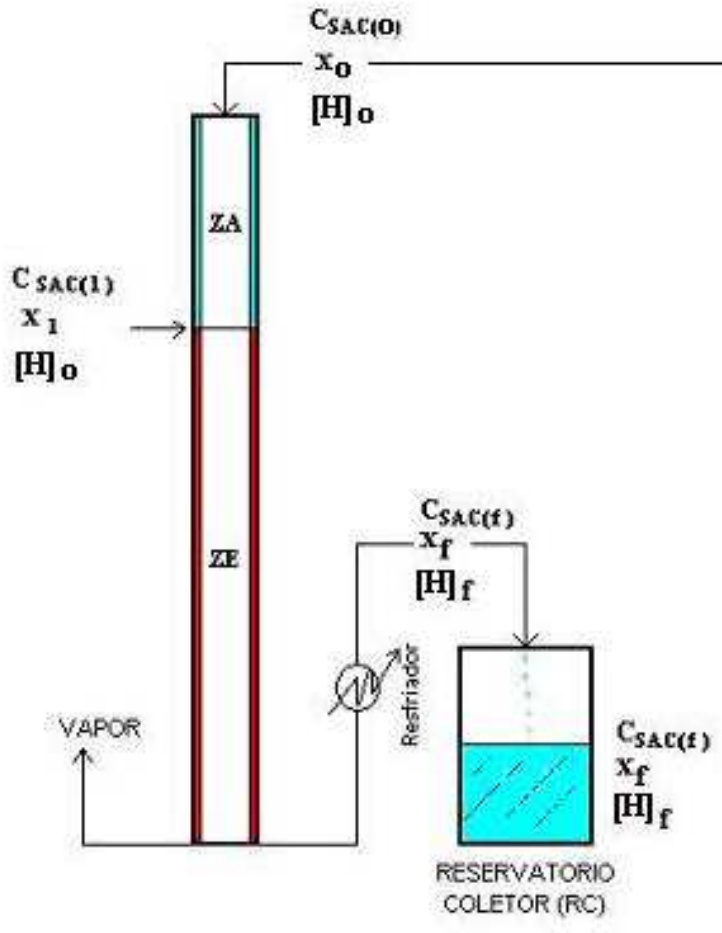

ZA - ZONA DE AQUECIMENTO

ZE = ZONA DE EVAPORAÇÃO

Figura 4.2. Sistema de evaporação simplificado.

A partir do esquema de evaporação pode-se formular as hipóteses com o fim de caracterizar as condições da solução nos diferentes pontos do sistema.

\subsubsection{Principais Hipóteses do modelo matemático para a avaliação da inversão da sacarose no sistema de evaporação}

1) A solução no Reservatório Alimentador (RA) apresenta uma concentração de sacarose $C_{S A C(0)}$ e um grau de inversão $x_{0}$. Esta concentração, o grau de inversão e a vazão de alimentação são considerados constantes no tempo. A primeira devido a que a temperatura da solução é mantida baixa (inferior a $25^{\circ} \mathrm{C}$ ), situação em que a velocidade de inversão da sacarose é de ordem de $0,13 \%$ daquela que ocorre na temperatura do evaporador (superior a $80^{\circ} \mathrm{C}$ ).

2) Considerando-se que a solução ingressa no tubo de evaporação como um líquido subresfriado supõe-se uma divisão do tubo em duas regiões, uma de aquecimento e outra de evaporação. 
3) O evaporador na sua região de aquecimento da solução desde a temperatura do líquido subresfriado $\left(T_{0}\right)$ até a temperatura de ebulição $\left(T_{\mathrm{c}}\right)$ é considerado com taxa de evaporação desprezível em relação à região subseqüente. Como conseqüência a $[H]$ da solução nesta região é considerado constante e igual a $[H]$, que também não se altera significativamente devido a esta variação da temperatura da solução. Nesta região de aquecimento a temperatura da solução é função das posições radiais e axiais $T(r, z)$. Este fato introduz uma complexidade na avaliação da taxa de inversão. Junto à parede a vazão é menor e a temperatura maior. O oposto ocorre na superfície do filme.

4) O evaporador na região de evaporação é suposto possuir uma temperatura constante na superfície do filme igual a $T_{\mathrm{c}}$. Esta temperatura varia radialmente $T=T(r)$ com $T\left(r_{\text {parede }}\right)=T_{\mathrm{w}}$ mantendo o perfil ao longo do eixo z. Como nesta região a evaporação é significativa a $[H]$ varia entre o valor $[H]$ o na entrada da seção até $[H]_{f}$ na saída da seção. A mudança desta concentração é função da taxa de evaporação e da vazão mássica do líquido no tubo.

5) A solução deixa o evaporador na temperatura $T_{\mathrm{c}},[H]$ igual a $[H]_{\mathrm{f}}$ e o grau de inversão $x_{f}$ e passa imediatamente por um resfriador que muda sua temperatura para o valor de $T_{0}$ (inferior a $25^{\circ} \mathrm{C}$ ) e a partir deste instante seu grau de inversão é suposto inalterado e igual a $x_{\mathrm{f}}$.

Com base nas hipóteses estabelecidas apresenta-se a seguir a modelagem matemática do tubo de evaporação incluindo-se os processos de evaporação e de inversão da sacarose.para a modelagem da inversão da sacarose.

\subsubsection{Modelagem matemática do tubo de evaporação}

A divisão do tubo de evaporação em duas zonas (zona de aquecimento, ZA e zona de evaporação ZE) facilita a modelagem da inversão, pois ambas zonas podem ser tratadas como reatores tubulares em série item 4.3.2.4 (Cálculo do volume do líquido (V) pelo método simplificado). A figura 4.3 ilustra as condições destas zonas. 


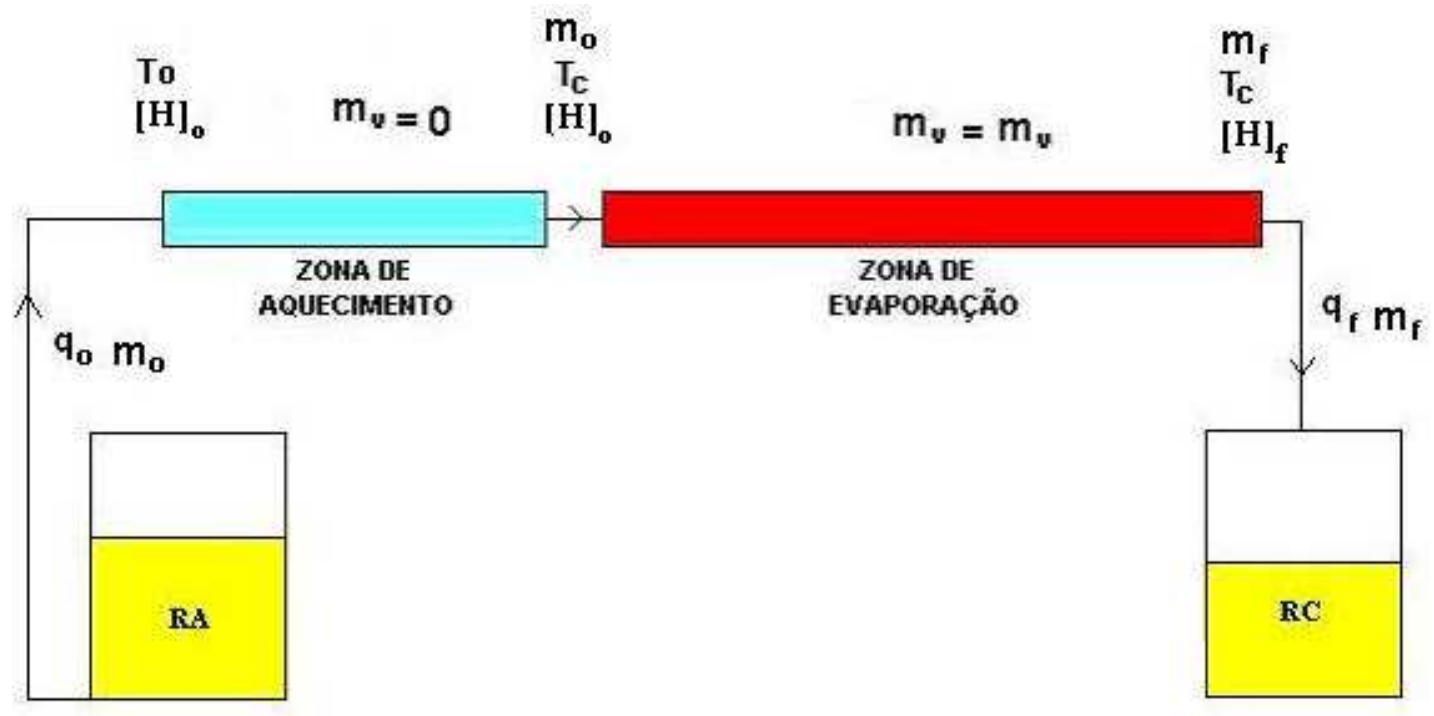

Figura 4.3 Divisão do tubo de evaporação

A inversão da sacarose que ocorre durante a evaporação está ligada diretamente com parâmetros evaporativos como são a taxa de evaporação $\left(m_{\mathrm{v}}\right)$, e a vazão de alimentação $\left(q_{0}\right)$, pois as variações destes parâmetros ocasionam mudanças na temperatura, concentrações do fluido, $[H]$, e tempo de residência do fluido no tubo das quais o grau de inversão é dependente. Os balanços de massa e de energia permitem a incorporação destes parâmetros na cinética da inversão.

Para o balanço diferencial esquematizado na figura 4.4, foi considerada uma distribuição homogênea do líquido sobre a superfície de escoamento.

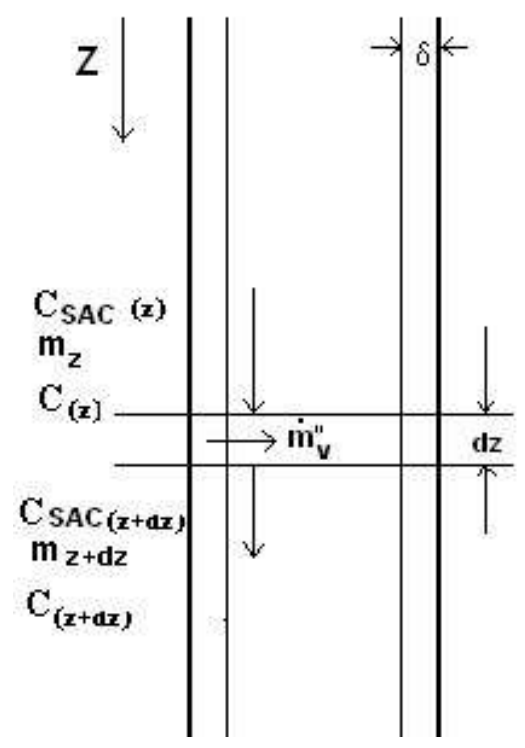

Figura 4.4 Balanço diferencial do tubo de evaporação 
Sendo:

$\begin{array}{lll}d A & = & \pi^{*} D^{*} d z \quad \text { (Diferencial de área de evaporação) } \\ m & \text { a } & \text { Vazão mássica do líquido }[\mathrm{g} / \mathrm{s}] \\ \rho & \text { a } & \text { Densidade da solução }[\mathrm{g} / \mathrm{ml}] \\ \bar{\rho} & \text { a } & \text { Densidade média da solução }[\mathrm{g} / \mathrm{ml}] \\ m_{v}{ }^{\prime \prime} & \text { o } & \text { Fluxo de água evaporada }\left[\mathrm{g} / \mathrm{s}-\mathrm{mm}^{2}\right] \\ q & \text { a } & \text { Vazão volumétrica da solução }[\mathrm{ml} / \mathrm{s}] \\ D & \text { o } & \text { Diâmetro interno [mm] } \\ \delta & \text { a } & \text { Espessura do filme [mm] } \\ C_{S A C} & \text { a } & \text { Concentração da sacarose [g-sacarose } / 100 \mathrm{~g} \text {-solução] } \\ C & \text { a } & \text { Concentração de açucares totais [g-açucares } / 100 \text { g-solução] } \\ x & \text { a } & \text { fração em peso de sacarose invertida }\end{array}$

\subsubsection{Balanço de massa global no evaporador}

O balanço de massa global do líquido no tubo de evaporação na condição de regime permanente tem como objetivo estudar as mudanças da vazão mássica ao longo do comprimento. Este balanço é deduzido da figura 4.4 e pode ser expresso como:

$$
\dot{m}_{z}=\dot{m}_{z+d z}+m_{v}^{I I} d A
$$

Considerando-se que o fluxo de evaporação $\left(m_{V}^{I I}\right)$ é constante e sendo a taxa de evaporação $\left(\dot{m}_{v}\right)$ igual a $m_{V}^{I I} \cdot \pi \cdot D \cdot L$, a equação 4.1 pode ser escrita na forma diferencial:

$$
\frac{d \dot{m}}{d z}=-\frac{\dot{m}}{L}
$$

Isolando as vaiáveis da equação 4.2 e integrando tem-se: 


$$
\dot{m}=-\frac{m_{v}}{L} z+B_{1}
$$

Em que $B_{1}$ é a constante de integração. Avaliando a vazão mássica na entrada do tubo $(z=0)$ tem-se:

$$
B_{1}=\dot{m}_{o}
$$

Substituindo a equação 4.4 na equação 4.3 esta pode ser reescrita como:

$$
\dot{m}=-\frac{\dot{m}_{v}}{L} z+\dot{m}_{o}
$$

E também a vazão mássica é igual a:

$$
\dot{m}=q \cdot \rho
$$

\subsubsection{Balanço de massa parcial para a sacarose}

O balanço de massa parcial da sacarose no filme líquido na condição de regime permanente é expressa por:

$$
\rho_{z} \cdot C_{S A C z} \cdot q_{z}=\rho_{z+d z} \cdot C_{S A C z+d z} \cdot q_{z+d z}+r_{S A C} \cdot d V
$$

O elemento diferencial do volume é definido como:

$$
d V=\pi \cdot D \delta \cdot d z
$$

A equação 4.7 pode escrever-se na forma diferencial: 


$$
\frac{d\left(\rho \cdot q \cdot C_{S A C}\right)}{d z}=-k \cdot \rho \cdot C_{S A C} \cdot \pi \cdot D \cdot \delta
$$

Em que a vazão mássica da sacarose é definida como:

$$
\dot{m}_{S A C}=\rho \cdot q \cdot \frac{C_{S A C}}{100}
$$

Substituindo a equação 4.10 na equação 4.9 e sabendo que o volume ocupado pelo líquido no evaporador ( $V$ ) igual a $D^{*} \pi * \delta * L$, assim a equação 4.9 pode ser reescrita como:

$$
\frac{d \dot{m}_{S A C}}{d z}=-\frac{k \cdot \dot{m}_{S A C} \cdot V}{q \cdot L}
$$

Lembrando também que:

$$
C_{S A C}=C \cdot(1-x)
$$

As concentrações de açúcares totais $C$ e de hidrogênio $[H]$ podem ser colocadas como função da vazão mássica, da taxa de evaporação e da posição axial $z$ como:

$$
\begin{aligned}
& C=C_{o} \frac{m_{o}}{m_{o}-\frac{\dot{m}_{v}}{L} z} \\
& {[H]=[H]_{o} * \frac{\dot{m}_{o}-\dot{m}_{o} \frac{C_{o}}{100}}{\dot{m}_{o}-\dot{m}_{o} \frac{C_{o}}{100}-\frac{\dot{m}_{v}}{L} z}}
\end{aligned}
$$


- Perfil de temperatura na direção radial no filme líquido

Considerando um perfil de temperatura linear ao longo da espessura do filme líquido na zona de evaporação e dividindo-se a espessura em S pontos, a temperatura para qualquer ponto $s$ da espessura pode ser calculada pela equação 4.15 como:

$$
T_{s}=T_{W}-\frac{\left(T_{W}-T_{C}\right)}{S} S
$$

sendo:

$S \quad 0 \quad$ Número de pontos na espessura

$s \quad$ a Posição do ponto $(0,1,2, \ldots \ldots, \mathrm{S})$

$T_{\mathrm{s}} \quad$ a $\quad$ Temperatura no ponto $\mathrm{s}\left[{ }^{\circ} \mathrm{C}\right]$

$T_{\mathrm{w}} \quad$ a $\quad$ Temperatura da parede do tubo $\left[{ }^{\circ} \mathrm{C}\right]$

Graficamente pode ser representado pela figura 4.5

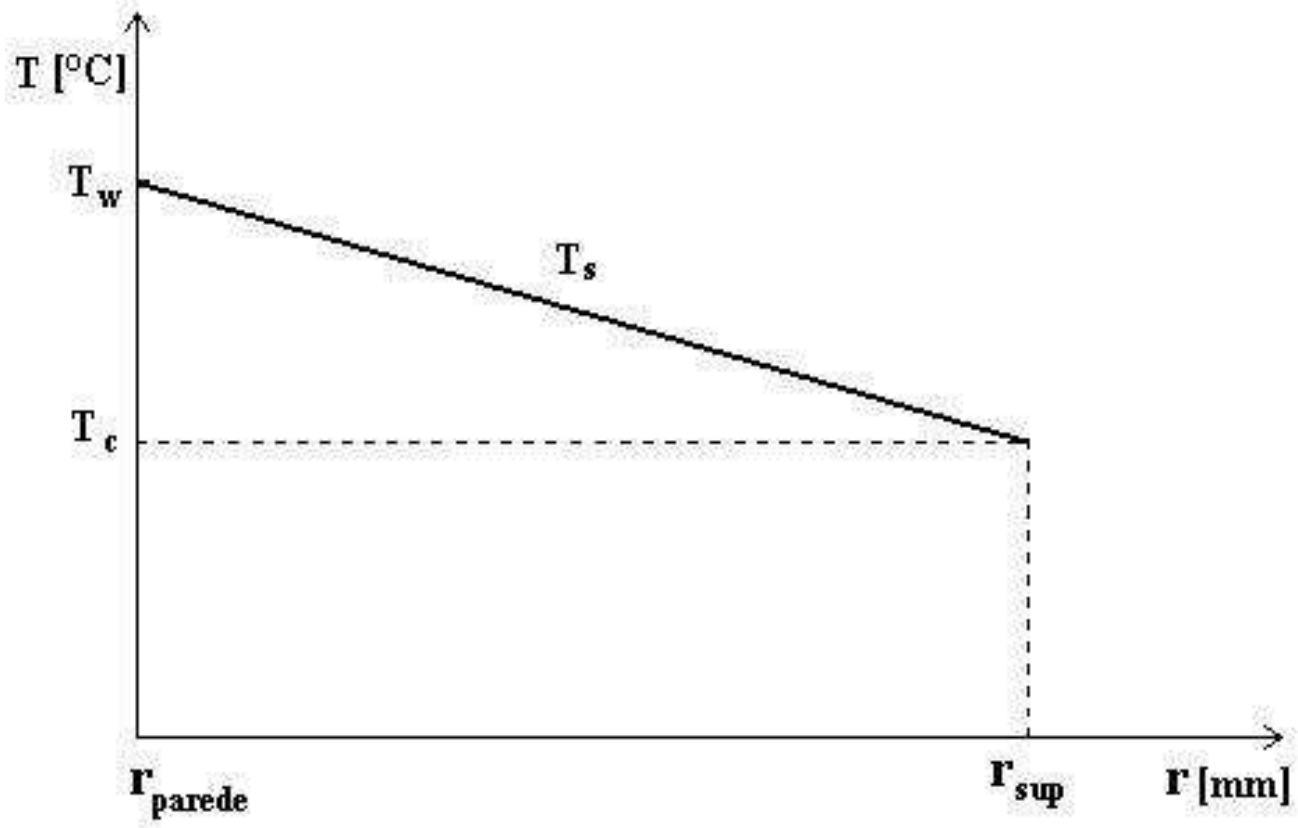

Figura 4.5 Perfil de temperatura na direção radial 
- Perfil de temperatura na direção axial z no filme líquido

Na zona de aquecimento o perfil de temperatura na direção z pode ser escrito como:

$$
T=T_{o}+\frac{\left(T_{s}-T_{o}\right)}{L_{a q}} z
$$

E na zona de evaporação o perfil é:

$$
T=T_{s}
$$

em que:

$T$ é a Temperatura do líquido no ponto s e posição $\mathrm{z}$ do tubo $\left[{ }^{\circ} \mathrm{C}\right]$

$T_{0}$ é a Temperatura inicial do líquido $\left[{ }^{\circ} \mathrm{C}\right]$

$L_{a q}$ é o Comprimento da zona de aquecimento [mm]

$L$ é o Comprimento do tubo de evaporação [mm]

$z \quad$ é a Posição axial qualquer na zona de aquecimento [mm]

Graficamente pode ser representado na figura 4.6

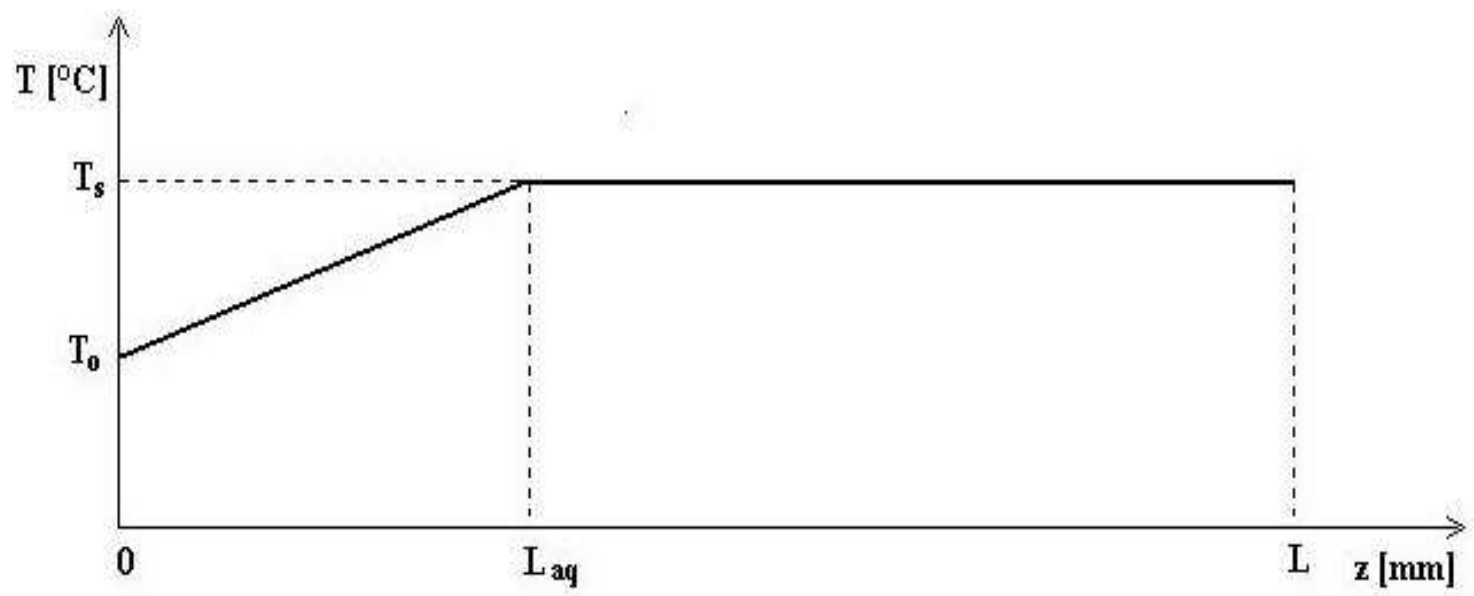

Figura 4.6 Perfil de temperatura na direção axial "z" 
4.3.2.3 Cálculo do volume do líquido (V) por integração numérica da concentração de sacarose $\left(\dot{m}_{S A C}\right)$.

Pela equação 4.11 pode-se calcular a vazão mássica e indiretamente a fração invertida final para um ponto " $s$ " do filme líquido $\left(x_{f(s)}\right)$. Como a equação 4.11 não é de integração direta (por meio de um método analítico), pois $\dot{m}_{S A C}$ é função da [H], temperatura, concentração de açúcares, a vazão, etc., esta tem que ser integrada por métodos numéricos. Assim utilizou-se o algoritmo de Runge Kutta de $4^{\text {ta }}$ ordem, cujo roteiro de cálculo é esquematizado na figura 4.7 .

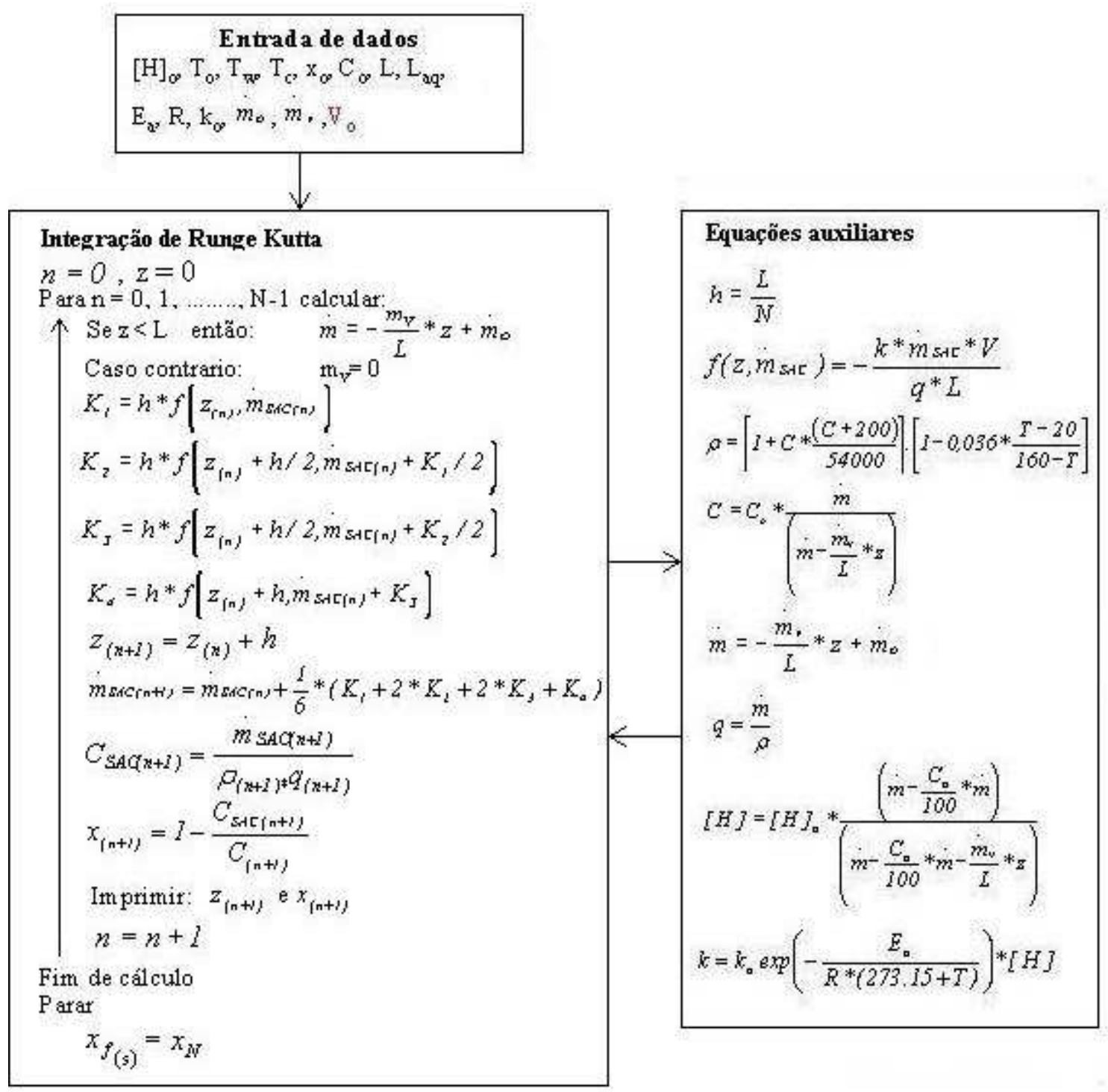

Figura 4.7 Algoritmo de cálculo de $\mathrm{x}_{\mathrm{f}(\mathrm{s})}$ por integração numérica 
Sendo:

$\begin{array}{lll}K_{1}, K_{2}, K_{3}, K_{4} & \text { os } & \text { Parâmetros de Integração de Runge Kutta } \\ N & 0 & \text { Número de divisões do comprimento do tubo } \\ h & 0 & \text { Comprimento de cada passo de integração [mm] } \\ n & \text { a } & \text { Posição do ponto }(0,1,2, \ldots \ldots ., \mathrm{N}) \\ V_{0} & 0 & \text { Valor inicial do volume do líquido }[\mathrm{ml}] \\ V & \text { o } & \text { Volume do líquido no tubo de evaporação [ml] } \\ T_{w} & \text { a } & \text { Temperatura na parede do tubo }\left[{ }^{\circ} \mathrm{C}\right] \\ T_{0} & \text { a } & \text { Temperatura do líquido na entrada do tubo }\left[{ }^{\circ} \mathrm{C}\right] \\ T_{c} & \text { a } & \text { Temperatura de saturação do líquido no tubo }\left[{ }^{\circ} \mathrm{C}\right] \\ x_{0} & \text { a } & \text { Fração invertida inicial } \\ {[H]} & \text { a } & \text { Concentração inicial de hidrogênio [mols } / \mathrm{L}] \\ C_{0} & \text { a } & \text { Concentração de açúcares totais [\%massa }]\end{array}$

No algoritmo são introduzidos os seguintes dados de entrada: $[H]_{o}, x_{o}, T_{w}, T_{o}, T_{c}, C_{o}$, $L_{a q}, \mathrm{~L}, \dot{m}, m_{v}, E_{a}, k_{o}, R$ e uma primeira aproximação do valor do volume ocupado $\left(V_{o}\right)$ e os parâmetros de integração $\left(K_{1}, K_{2}, K_{3}, K_{4}\right)$ que são calculados a partir das equações auxiliares.

Os valores de $X_{f(S)}$ para cada um dos $S$ pontos sobre a espessura podem ser integrados por meio do método de Simpson para calcular a fração invertida final média $\left(X_{f(c a l)}\right)$ como é mostrado na equação 4.18 a seguir:

$$
x_{f(c a l)}=\frac{1}{3 \cdot S} \cdot\left(A_{1}+2 * A_{2}+4 * A_{3}\right)
$$

Sendo:

$$
\begin{aligned}
& A_{1}=\left(x_{f(0)}+x_{f(S)}\right) \\
& A_{2}=\left(x_{f(2)}+x_{f(4)}+\ldots \ldots .+x_{f(S-2)}\right) \\
& A_{3}=\left(x_{f(3)}+x_{f(5)}+\ldots \ldots .+x_{f(S-1)}\right)
\end{aligned}
$$



$A_{1}, A_{2}, A_{3}$
os Parâmetros de integração de Simpson
$S$
- $\quad$ Número de pontos (Número inteiro par)
$X_{f(\text { cal })}$
a Fração invertida final média calculada

O valor de $x_{f(c a l)}$ para o valor inicial do volume do líquido $\left(V_{o}\right)$ é comparado com o valor de $x_{f(\exp )}$ por meio da função \%Erro como mostrado na equação 4.22:

$$
\% \text { Erro }=\left(\left(\frac{\left(x_{f(\exp )}-x_{f(c a l)}\right)}{x_{f(\exp )}}\right)^{2}\right)^{\frac{1}{2}}
$$

O valor do volume do líquido no tubo ( $V$ é ajustado mediante o SOLVER do Excel até atingir um valor do \%Erro menor ou igual a $10^{-5}$. O Roteiro para o cálculo do volume (V) é apresentado na figura 4.8 a seguir:

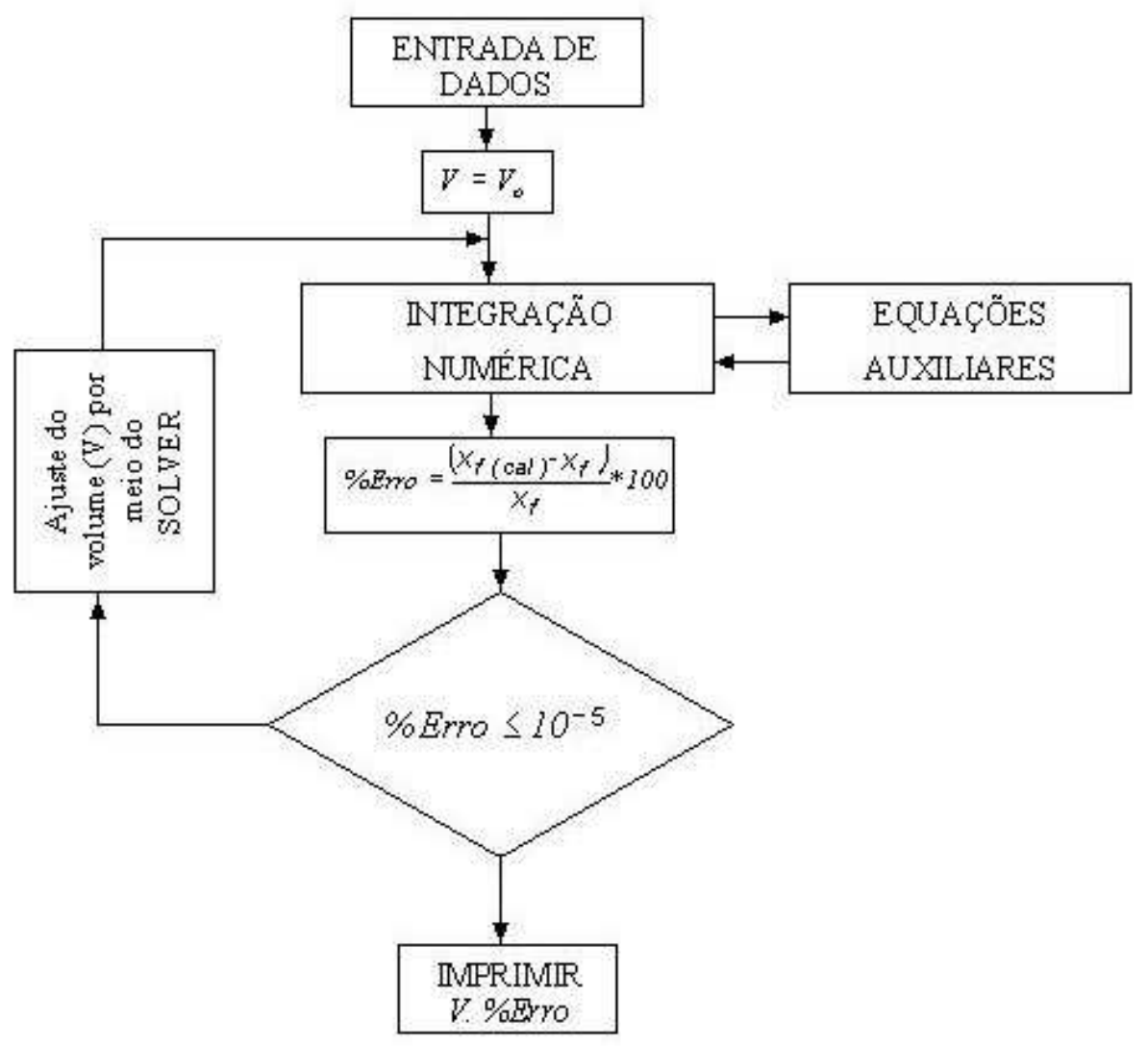

Figura 4.8 Roteiro do cálculo de $\vee$ pelo método rigoroso 
Assim é obtido o valor de $V$ levando em consideração as variações de $\rho, q,[H]$ e $k$ causados pelas mudanças na temperatura e na concentração nos diferentes pontos do tubo de evaporação.

- Cálculo do tempo de residência do líquido no evaporador

Encontrado o valor da convergência do $V$, o tempo de residência para do líquido no evaporador ( $\tau$ ) pode ser calculado como:

$$
\tau=\int_{0}^{L} \frac{A \cdot d z}{q}
$$

Sendo:

$$
\begin{array}{llll}
A & = & \pi \cdot D \cdot \delta \quad \text { Área perpendicular ao escoamento do líquido } \\
q & \text { a } & \text { Vazão do líquido }
\end{array}
$$

- Cálculo do número de Reynolds do líquido no evaporador

Segundo o Incropera (2003, pág. 434) o numero de Reynolds para filmes líquidos descendentes é definido como:

$$
\operatorname{Re}_{\delta}=\frac{4 \cdot m}{\mu \cdot b}
$$

em que:

$$
\begin{array}{lll}
\dot{m} & \text { é a } & \text { Vazão mássica } \\
b & = & \pi \cdot D \quad \text { (Perímetro molhado) } \\
\mu & \text { é a } & \text { Viscosidade do líquido }
\end{array}
$$


4.3.2.4 Cálculo do volume do líquido (V) com modelo simplificado

Uma opção ao cálculo rigoroso da integração numérica é a simplificação do equacionamento por meio do uso de valores médios e ou efetivos nas variáveis $\rho$, $[H]$ e $T$. A simplificação do equacionamento possibilita a integração analítica da equação 4.11. Assim usando-se a equação 4.5 que descreve a vazão mássica ( $m$ ) no tubo de evaporação e a equação 4.6 que relaciona a vazão mássica com a vazão (q), usando-se o valor médio da densidade ( $\bar{\rho}$ ) pode ser obtida a equação 4.25 que descreve a vazão do líquido no tubo de evaporação como:

$$
q=q_{o}-\frac{m_{v}}{L \cdot \rho} z
$$

diferenciando a equação 4.25 com relação a $z$ tem-se:

$$
\frac{d q}{d z}=-\frac{\dot{m}_{v}}{L \cdot \bar{\rho}}
$$

A equação 4.9 pode ser reescrita também como:

$$
\frac{d\left(q \cdot C_{S A C}\right)}{d z}=-\frac{k \cdot C_{S A C} \cdot V}{L}
$$

Derivando o termo esquerdo da equação 4.27 tem-se:

$$
q \frac{d C_{S A C}}{d z}+C_{S A C} \frac{d q}{d z}=-\frac{k \cdot C_{S A C} \cdot V}{L}
$$

Substituindo as equações 4.25 e 4.26 na equação 4.28 resulta em:

$$
\left(q_{o}-\frac{\dot{m}_{v}}{\bar{\rho} \cdot L} \cdot z\right) \frac{d C_{S A C}}{d z}+C_{S A C}\left(-\frac{\dot{m} v}{\bar{\rho} \cdot L}\right)=-\frac{k \cdot C_{S A C} \cdot V}{L}
$$


Isolando $d C_{S A C} / d z$ da equação 4.29:

$$
\frac{d C_{S A C}}{d z}=\frac{C_{S A C}\left(\frac{\dot{m_{v}}}{\bar{\rho} \cdot L}-\frac{k \cdot V}{L}\right)}{\left(q_{o}-\frac{\dot{m}_{v}}{\bar{\rho} \cdot L} z\right)}
$$

Separando as variáveis vem:

$$
\left.\frac{d C_{S A C}}{C_{S A C}}=\left(\frac{\dot{m}_{v}}{L \cdot \bar{\rho} \cdot q_{o}}-\frac{k \cdot V}{L \cdot q_{o}}\right) \frac{d z}{1-\frac{\dot{m}_{v}}{\bar{\rho} \cdot q_{o} \cdot L} z}\right)
$$

A equação 4.31 pode ser aplicada em ambas as zonas do tubo (zona de aquecimento e zona de evaporação).

- Zona de aquecimento

Aplicando a equação 4.31 na zona de aquecimento em que o valor de $\dot{m}_{v}$ tende a 0 , a equação transforma-se em:

$$
\frac{d C_{S A C}}{C_{S A C}}=-\frac{k_{a q} \cdot V_{a q}}{q_{o} \cdot L_{a q}} d z
$$

Em que $V_{a q}$ e $L_{a q}$ são o volume ocupado pelo líquido e o comprimento da zona de aquecimento respectivamente, $k_{a q}$ é a constante cinética avaliada à temperatura

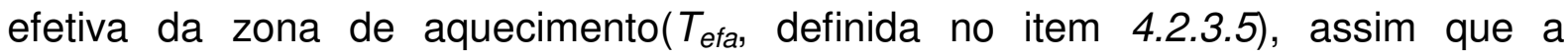
constante cinética $k_{a q}$ é independente da posição z e a equação 4.32 é integrada nos seus limites como: 


$$
\int_{C_{S A C(0)}}^{C_{S A C(1)}} \frac{d C_{S A C}}{C_{S A C}}=-\frac{k_{a q} \cdot V_{a q}}{L_{a q} \cdot q_{i}} \int_{0}^{L_{a q}} d z
$$

Em que $C_{S A C(0)}$ e $C_{S A C(1)}$ são as concentrações de sacarose na entrada do tubo e na saída da zona de aquecimento respectivamente. O resultado desta integração é dado pela equação 4.34:

$$
\ln \left(\frac{C_{S A C(1)}}{C_{S A C(0)}}\right)=-\frac{k_{a q} \cdot V_{a q}}{q_{o}}
$$

Substituindo a equação 4.12 na equação 4.34 tem-se:

$$
\ln \left(\frac{C_{1}\left(1-x_{1}\right)}{C_{o}\left(1-x_{o}\right)}\right)=-\frac{k_{a q} \cdot V_{a q}}{q_{o}}
$$

Isolando $x_{1}$ da equação 4.35 e sendo que $C_{1}=C_{0}$ já que a evaporação nesta zona é desprezível conclui-se que:

$$
x_{1}=1-\left(1-x_{o}\right) \exp \left(-\frac{k_{a q} \cdot V_{a q}}{q_{o}}\right)
$$

- Zona de evaporação

A equação 4.31 com limites de integração para zona de evaporação como:

$$
\left.\int_{C_{S A C(1)}}^{C_{S A C(f)}} \frac{d C_{S A C}}{C_{S A C}}=\left(\frac{\dot{m}_{v}}{L_{e v} \cdot \bar{\rho} \cdot q_{o}}-\frac{k_{e v} \cdot V_{e v}}{L_{e v} \cdot q_{o}}\right) \int_{0}^{L_{e v}} \frac{d z}{\left(1-\frac{\dot{m}_{v}}{\bar{\rho} \cdot q_{o} \cdot L_{e v}} \quad z\right.}\right)
$$


Em que $V_{e v}$ é o volume ocupado pelo líquido na zona de evaporação, $L_{e v}$ é o comprimento da zona de evaporação e igual a $L$ - $L_{a q}, C_{S A C(1)}$ e $C_{S A C(f)}$ são as concentrações de sacarose na entrada e na saída da zona de evaporação respectivamente e $k_{e v}$ é a constante cinética avaliada na temperatura efetiva da zona

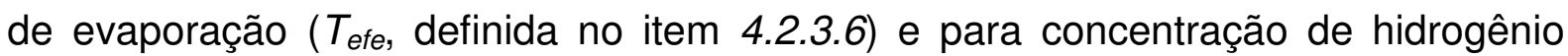
média entre a entrada e a saída do líquido no tubo de evaporação. O resultado desta integração é escrito como:

$$
\ln \left(\frac{C_{S A C(f)}}{C_{S A C(1)}}\right)=-\left(1-\frac{k_{e v} \cdot V_{e v} \cdot \bar{\rho}}{\dot{m}_{v}}\right) \ln \left(1-\frac{\dot{m}_{v}}{\bar{\rho} \cdot q_{o}}\right)
$$

Aplicando a equação 4.12 em 4.38:

$$
\ln \left(\frac{C_{f}\left(1-x_{f}\right)}{C_{1}\left(1-x_{1}\right)}\right)=-\left(1-\frac{k_{e v} \cdot V_{e v} \cdot \bar{\rho}}{m_{v}}\right) \ln \left(1-\frac{m_{v}}{\bar{\rho} \cdot q_{o}}\right)
$$

Lembrando que $C_{1}=C_{o}$ e isolando $x_{f}$ chega-se a:

$$
x_{f}=1-\frac{C_{o}}{C_{f}}\left(1-x_{1}\right) \cdot\left(1-\frac{m_{v}}{\rho^{*} q_{o}}\right)^{-\left(1-\frac{k_{e v}{ }^{*} V_{e v} * \bar{\rho}}{m_{v}}\right)}
$$

Das equações 4.36 e 4.40 derivadas da simplificação do equacionamento é feito o roteiro apresentado na figura 4.9 para o cálculo do volume $V$, a entrada de dados é a mesma daquela para a integração numérica mas o número de cálculos que envolvem a integração numérica é simplificado a duas equações (equações 4.36 e 4.40) que calculam diretamente as frações invertidas na saída da zona de aquecimento $\left(x_{1}\right)$ e a fração na saída do tubo de evaporação $\left(x_{f}\right)$. Também deve ser lembrado que a soma dos volumes $V_{a q}$ e $V_{e v}$ é igual a $V$ e que é considerado a espessura do filme constante ao longo do tubo. 


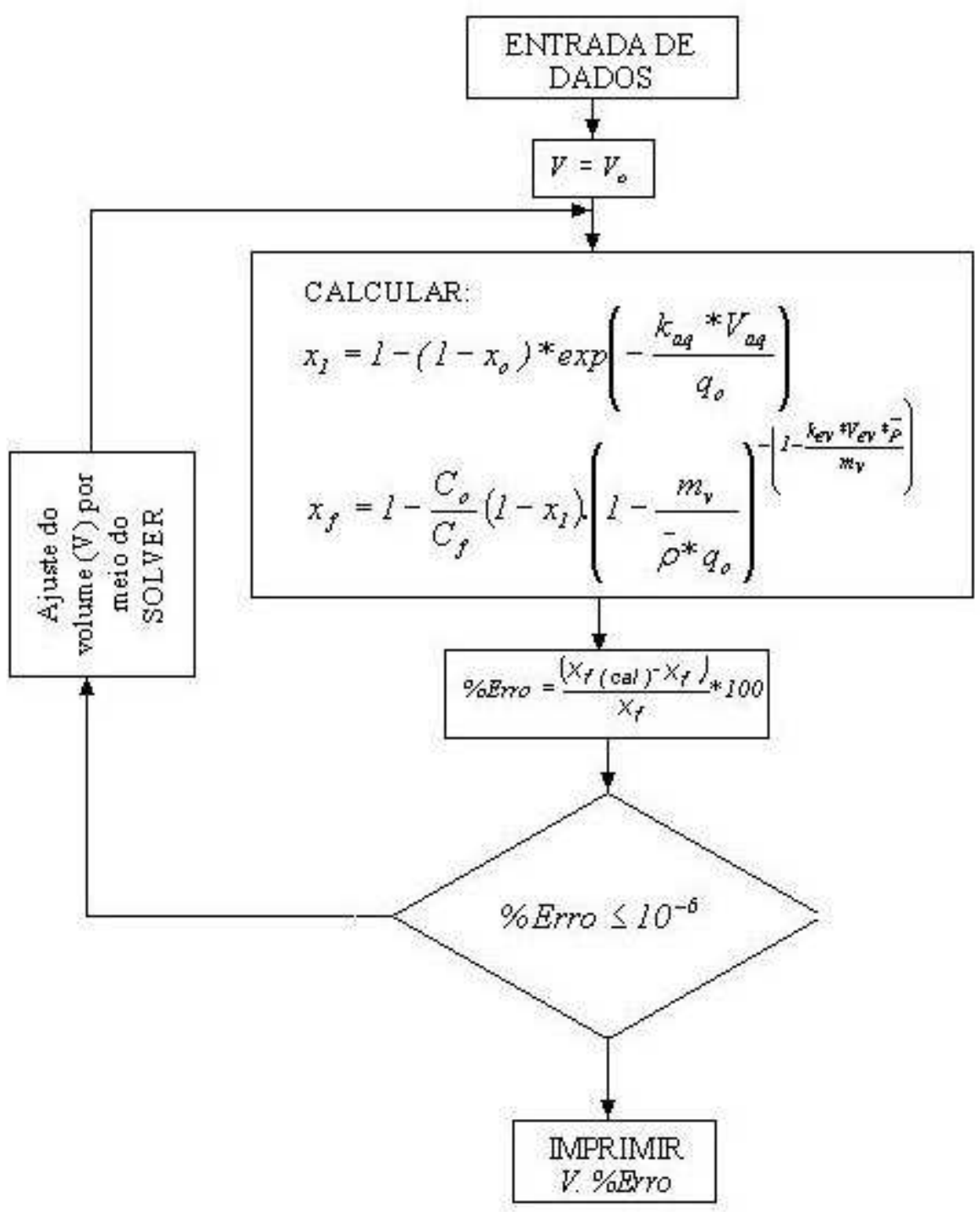

Figura 4.9 Roteiro do calculo de $\mathrm{V}$ com equacionamento simplificado

Nos próximos itens serão definidas $T_{\text {efa }}$ e $T_{\text {efe, }}$, as quais são necessárias para avaliação das constantes cinéticas em ambas as zonas.

- Procedimento para o cálculo da temperatura efetiva na zona de aquecimento $T_{\text {efa }}$

$\mathrm{Na}$ zona de aquecimento as variações de temperatura acontecem tanto na direção radial " $r$ " quanto na direção axial " $z$ ", estando o líquido nas temperaturas $T_{w}$ (temperatura da parede do tubo) e $T_{0}$ (temperatura inicial do líquido) na entrada do tubo de evaporação e entre $T_{w}$ e $T_{c}$ (temperatura de saturação do líquido) na saída 
da zona de evaporação. Para fins simplificadores o volume do líquido na zona de aquecimento $\left(V_{a q}\right)$ calculado pela equação 4.36 é ajustado ao $V_{a q}$ calculado pelo método rigoroso (usando a densidade média) mudando o valor da temperatura na qual é avaliada a constante cinética $k_{a q}$. A temperatura na que é atingida a convergência é chamada de temperatura efetiva na zona de aquecimento ( $\left.T_{\text {efa }}\right)$, e as temperaturas médias da entrada e da saída desta zona são relacionadas com $T_{\text {efa }}$ da seguinte maneira:

$$
T_{e f a}=\bar{T}_{\text {saida }}-\beta\left(\bar{T}_{\text {saida }}-\bar{T}_{\text {entrada }}\right)
$$

onde:

$$
\bar{T}_{\text {entrada }}=\frac{\left(T_{w i}+T_{o}\right)}{2}
$$

e;

$$
\bar{T}_{\text {saida }}=\frac{\left(T_{w i}-T_{c}\right)}{2}
$$

desta maneira é encontrado o valor da constante $\beta$ como:

$$
\beta=\frac{\left(\bar{T}_{\text {saida }}-T_{\text {efa }}\right)}{\left(\bar{T}_{\text {saida }}-\bar{T}_{\text {entrada }}\right)}
$$

- Procedimento para o cálculo da temperatura efetiva na zona de evaporação $T_{\text {efe }}$

O modelo assume um perfil linear de temperaturas ao longo da espessura do filme. Nesta zona e considerado também que a temperatura não sofrera mudanças significativas por causa da altura do líquido. Assim o líquido terá mudanças de temperatura só no eixo radial. A temperatura máxima do líquido encontra-se na parede do tubo $\left(T_{w}\right)$ e a mínima na superfície do filme ( $T_{C}$, temperatura de saturação 
do líquido). Da mesma forma do que na zona de aquecimento para fins simplificadores o valor calculado de $x_{f}$ calculado pela equação 4.40 é ajustado ao valor da fração invertida final experimental $\left(x_{f(\exp )}\right)$ usando o valor de $V_{e v}$ calculado pelo método rigoroso (usando a densidade e a concentração de hidrogênio médias entre a entrada e a saída da zona de concentração) mudando a temperatura de avaliação da constante cinética $k_{e v}$. A temperatura na que é atingida a convergência é chamada de temperatura efetiva da zona de evaporação $\left(T_{\text {efe }}\right)$, esta temperatura é relacionada às temperaturas $T_{w i}$ e $T_{c}$ da seguinte maneira:

$$
T_{e f e}=T_{w i}-\alpha\left(T_{w i}-T_{c}\right)
$$

E $\alpha$ pode ser expressa por:

$$
\alpha=\frac{\left(T_{w i}-T_{e f e}\right)}{\left(T_{w i}-T_{c}\right)}
$$

O critério para o cálculo da temperatura do líquido na parede interna do tubo é desenvolvida no item 4.3.2.7 a seguir:

4.3.2.5 Cálculo da temperatura na superfície da parede interna do tubo de evaporação

A transferência de calor no tubo de evaporação é realizada através de resistências compostas em serie: a primeira é dada pelo coeficiente de película do vapor condensado na superfície externa do tubo de evaporação $\left(h_{V}\right)$, a segunda pela condutividade térmica do vidro $\left(k_{W}\right)$ e a terceira pelo coeficiente de película do filme líquido $\left(h_{L}\right)$. Estas resistências produzem quedas de temperatura as quais são detalhadas na figura 4.10 a seguir: 


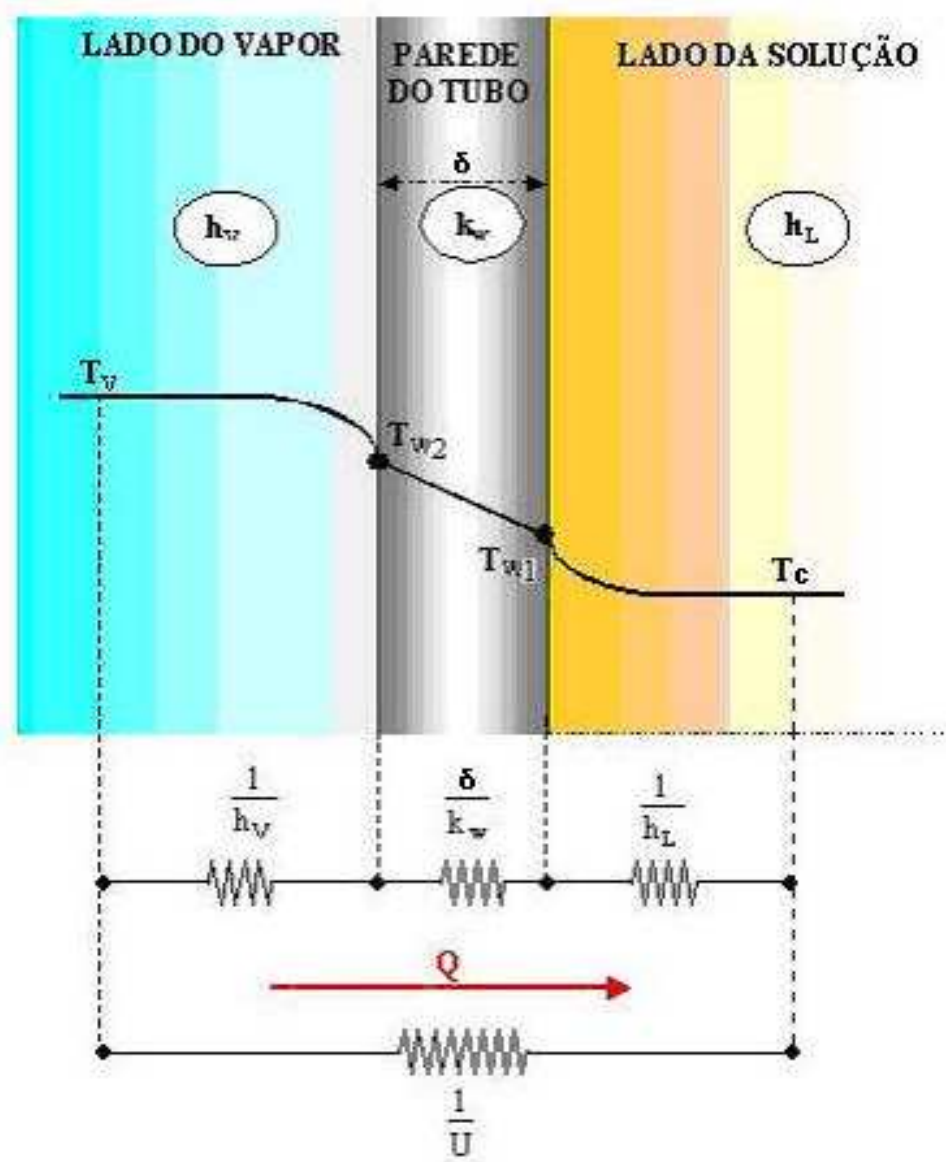

Figura 4.10 Transferência de calor no tubo de evaporação, KUROKAWA (2002)

A taxa de calor que atravessa a superfície do tubo pode ser expressa como:

$$
Q=h_{V} \cdot A \cdot\left(T_{V}-T_{W 2}\right)
$$

E também como:

$$
Q=\frac{k_{W}}{\delta_{W}} \cdot A \cdot\left(T_{W 2}-T_{W 1}\right)
$$

Aplicando o balanço de entalpia à solução em cada uma das zonas do evaporador tem-se:

- Zona de aquecimento

$$
Q=\rho \cdot q_{i} \cdot c_{p} \cdot\left(T_{c}-T_{o}\right)
$$


Igualando a equação 4.48 com a equação 4.49 considerando-se a temperatura interna da parede média para o trecho considerado é isolada a temperatura da superfície da parede interna $\left(T_{w 1}\right)$;

$$
\bar{T}_{w 1}=T_{w 2}-\frac{\rho \cdot q_{i} \cdot c_{p} \cdot \delta_{W} \cdot\left(T_{c}-T_{o}\right)}{k_{W} \cdot A_{a q}}
$$

A temperatura da superfície da parede externa do tubo de evaporação ( $\left.T_{W 2}\right)$ é assumida igual à temperatura do vapor $\left(T_{V}\right)$, pois os coeficientes de película de vapor condensando em uma superfície são bastante elevados e escrevendo $\bar{T}_{w 1}$ como $T_{W}$ a equação 4.50 fica como:

$$
\bar{T}_{W}=T_{V}-\frac{\rho \cdot q_{i} \cdot c_{p} \cdot \delta_{W}\left(T_{c}-T_{o}\right)}{k_{W} \cdot A_{a q}}
$$

- Zona de evaporação

$$
Q=m_{v} \cdot \lambda
$$

Da mesma maneira que na zona de aquecimento, a equação 4.52 é igualada a equação 4.48 para isolar o valor da temperatura da superfície da parede interna do tubo de evaporação ( $\left.\mathrm{T}_{\mathrm{W}_{1}}\right)$.

$$
\bar{T}_{W 1}=T_{W 2}-\frac{m_{v} \cdot \lambda \cdot \delta_{w}}{k_{W} \cdot A_{e v}}
$$

Assumindo $T_{W 2}$ igual a $T_{V}$ e expressando $\bar{T}_{W 1}$ como $T_{W}$ a equação 4.53 é expressa por:

$$
T_{W}=T_{V}-\frac{m_{v} \cdot \lambda \cdot \delta_{w}}{k_{W} \cdot A_{e v}}
$$




\subsection{Cálculo das frações de volume ocupado pelo líquido na zona de aquecimento e na zona de evaporação do tubo}

A figura 4.11 (a) mostra que, quando a vazão de alimentação ingressa no tubo de evaporação como líquido subresfriado à temperatura $T_{0}$ são formadas duas zonas a de aquecimento e a de evaporação (condições de operação para a avaliação da inversão da sacarose), mas quando a vazão de alimentação ingressa como líquido saturado na temperatura $T_{c}$ é formada somente a zona de evaporação, figura 4.11(b). Para o cálculo das frações do volume ocupado pela zona de aquecimento e da zona de evaporação são planejadas um número de experiências na que primeiramente a solução será alimentada ao tubo de evaporação como líquido subresfriado e depois a solução será pré-aquecido até a temperatura de saturação $\left(T_{c}\right)$. De cada uma das situações são determinadas as taxas de evaporação $m_{v}$ e $m_{v}^{\prime}$ quando a vazão de alimentação está como liquido subresfriado e líquido saturado respectivamente.

Do balanço de energia para a alimentação com líquido subresfriado tem-se:

$$
\begin{aligned}
& \dot{Q}=\dot{Q}_{a q}+\dot{Q}_{e v} \\
& \dot{Q}_{a q}=q_{o} \cdot c_{p} \cdot\left(T_{c}-T_{o}\right) \\
& \dot{Q}_{e v}=\dot{m}_{v} \cdot \lambda
\end{aligned}
$$




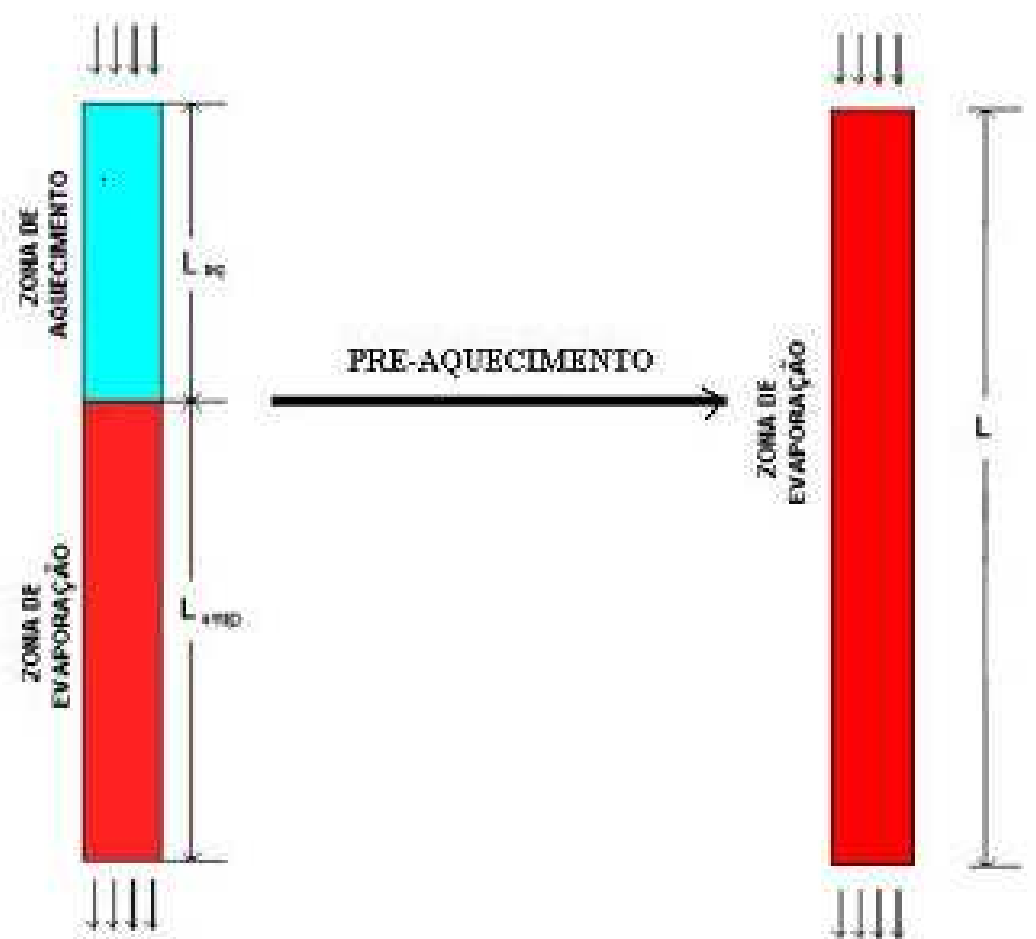

(a)

(b)

Figura 4.11: (a) vazão de alimentação como líquido subresfriado e formação das zonas de aquecimento e de evaporação. (b) vazão de alimentação com líquido na temperatura de saturação e formação da zona de evaporação.

O balanço de energia para a alimentação como líquido na temperatura de saturação é escrito como:

$$
\begin{aligned}
& \dot{Q}^{\prime}=\dot{Q}_{e v}^{\prime} \\
& \dot{Q}_{e v}^{\prime}=\dot{m}_{v}^{\prime} \cdot \lambda
\end{aligned}
$$

As taxas de calor $\dot{\mathrm{Q}}_{\mathrm{ev}}$ e $\dot{\mathrm{Q}}_{\mathrm{ev}}$ podem ser relacionadas com fluxos de calor correspondentes $\theta_{\mathrm{ev}}$ e $\theta_{\mathrm{ev}}^{\prime}$ como é visto a seguir:

$$
\theta_{e v}=\frac{\dot{Q}_{e v}}{A_{e v}}
$$




$$
\theta_{e v}^{\prime}=\frac{\dot{Q}_{e v}^{\prime}}{A_{e v}^{\prime}}
$$

Supondo que os fluxos de calor $\theta_{\mathrm{ev}}$ e $\theta_{\mathrm{ev}}^{\prime}$ sejam iguais, os termos à direita das equações 4.60 e 4.61 podem ser igualadas:

$$
\frac{\dot{Q}_{e v}^{\prime}}{A_{e v}^{\prime}}=\frac{\dot{Q}_{e v}}{A_{e v}}
$$

Substituindo as equações 4.57 e 4.59 na equação 4.62 tem-se:

$$
\frac{A_{e v}}{A_{e v}^{\prime}}=\frac{\dot{m}}{\dot{m}_{v}^{\prime}}
$$

A relação de $A_{e v} / A_{e v}^{\prime}$ proporciona a fração da área ocupada pela zona de evaporação nas condições de operação para a avaliação da inversão, pois a área $A_{e v}^{\prime}$ representa a área total de transferência de calor $A_{t}$ do tubo de evaporação. Assumindo que a espessura do filme líquido seja homogênea ao longo do tubo a fração da área ocupada pela zona de aquecimento é igual à fração do volume ocupado pela mesma assim tem-se:

$$
\frac{V_{e v}}{V_{t}}=\frac{\dot{m_{v}}}{\dot{m}^{\prime}{ }_{v}}
$$

Em que $V_{t}$ é o volume total ocupado pelo líquido, assim obtém-se a fração do volume ocupado pela zona de evaporação restando o valor da fração para a zona de aquecimento como complementar:

$$
\frac{V_{a q}}{V_{t}}=1-\frac{V_{e v}}{V_{t}}
$$




\subsubsection{Procedimento para determinação das frações do volume ocupado pelo líquido na zona de evaporação}

A seguir é apresentado o método para o levantamento dos dados e o planejamento experimental.

a) Pesar 500 gramas de sacarose (açúcar de mesa);

b) adicionar $4500 \mathrm{~mL}$ de água e homogeneizar a solução (à temperatura ambiente $\mathrm{T}_{0}$ - líquido subresfriado-);

c) dividir a solução em partes iguais de 2500 gramas cada;

d) ligar o gerador de vapor, (já que é utilizado o vapor de água como fluido de aquecimento);

e) ligar as correntes de água e água gelada que são utilizadas nos condensadores e o resfriador (usados neste caso para a proteção da bomba de vácuo);

f) ligar e regular a bomba de vácuo a qual estabelece a pressão do até atingir a temperatura de câmara estudada;

g) regular a vazão de alimentação por meio da bomba de alimentação ate a vazão de alimentação estudada;

h) utilizar 500 gramas da solução de sacarose para estabilizar a taxa de evaporação e para formação da película descendente no tubo de evaporação, estas 500 gramas são introduzidas no Reservatório Alimentador (RA) e são conduzidas ao tubo de evaporação mediante a bomba de alimentação;

i) uma vez gastas os 500 gramas de solução introduzir os restantes 2000 gramas no RA e acionar o cronômetro, isso tendo cuidado de não interromper a alimentação da solução;

j) tomar o tempo gasto para a passagem dos 2000 gramas de solução e pesar a evaporada durante o processo (condensada no condensador), com este valor se calcula a taxa de evaporação para alimentação com líquido sub-resfriado $\left(\dot{m}_{e v}\right)$;

k) os outros 2500 gramas de solução são pré-aquecidos até a temperatura de saturação ( $T_{c}$; temperatura da câmara);

I) usar 500 gramas desta solução pré-aquecida para estabilizar o sistema; 
m) uma vez gastos os 500 gramas de solução pré-aquecida são introduzidos os restantes 2000 gramas de solução pré-aquecida e é acionado o cronômetro;

n) esgotados os 2000 gramas de solução é tomado o tempo gasto e é pesada a água evaporada durante o processo, com este valor é calculada a taxa de evaporação para a alimentação com liquido saturado $\left(m_{e v}^{\prime}\right)$;

\subsubsection{Planejamento experimental para a determinação da fração de volume ocupada pela zona de evaporação}

Para a determinação da fração de volume ocupado pela zona de evaporação foram planejados o mesmo número de experimentos que para a avaliação da inversão da sacarose com condições de operação similares às mesmas $\left(T_{c}, q_{0}\right)$, já que os dados dos volumes das zonas de aquecimento e de evaporação são necessários na formulação das equações 4.11 (no método numérico) e as equações 4.32 e 4.36 (método simplificado "analítico)". Assim tem-se a tabela 4.2.

Tabela 4.2: Planejamento fatorial para a determinação da fração de volume ocupada pela zona de evaporação

\begin{tabular}{cccc}
\hline & $\begin{array}{c}\mathbf{q}_{\mathbf{o}} \text { (menor) } \\
\mathbf{1 , 0}[\mathbf{m l} / \mathbf{s}]\end{array}$ & $\begin{array}{c}\mathbf{q}_{\mathbf{o}}(\mathbf{m e ́ d i o}) \\
\mathbf{1 , 5}[\mathbf{m l} / \mathbf{s}]\end{array}$ & $\begin{array}{c}\mathbf{q}_{\mathbf{o}} \text { (maior) } \\
\mathbf{2 , 0}[\mathbf{m l} / \mathbf{s}]\end{array}$ \\
\hline $\begin{array}{c}\mathbf{T}_{\mathbf{c}} \text { (menor) } \\
\mathbf{7 0} \mathbf{C}\end{array}$ & Ensaio1 & Ensaio2 & Ensaio3 \\
$\begin{array}{c}\mathbf{T}_{\mathbf{c}} \text { (médio) } \\
\mathbf{7 5}^{\circ} \mathbf{C}\end{array}$ & Ensaio4 & Ensaio5 & Ensaio6 \\
$\mathbf{T}_{\mathbf{c}}$ (maior) & & & \\
$\mathbf{8 0}^{\circ} \mathbf{C}$ & Ensaio7 & Ensaio8 & Ensaio9 \\
\hline
\end{tabular}

\subsection{Planejamento experimental para a avaliação da inversão da sacarose}

Nesta parte é mostrado o planejamento experimental que foi seguido durante os ensaios de laboratório, para isto foram determinados primeiramente as variáveis que 
afetam à inversão. Sendo a inversão da sacarose função principalmente de: temperatura, $[H]$ e tempo de residência da solução, assim, são tomadas como varáveis de estudo a temperatura da câmara de separação líquido-vapor $\left(T_{c}\right)$ e a vazão de alimentação $\left(q_{0}\right)$ que estão diretamente relacionados com a temperatura e o tempo de residência respectivamente, a $[H]$ e a concentração da sacarose são mudados em cada experiência por efeito da evaporação. Assim, desse modo o número de variáveis é reduzido a dois $\left(T_{c} e q_{0}\right)$. A influência de cada variável é estudada em três níveis (valor superior, valor médio e valor inferior), o que leva a um desenho fatorial correspondente a $3^{\mathrm{n}}$, sendo $\mathrm{n}$ o número de ensaios (2), que são observados na tabela 4.3.

Tabela 4.3: Planejamento fatorial para a avaliação da inversão da sacarose

\begin{tabular}{cccc}
\hline & $\mathbf{q}_{\mathbf{o}}$ (menor) & $\mathbf{q}_{\mathbf{o}}$ (médio) & $\mathbf{q}_{\mathbf{o}}$ (maior) \\
& $\mathbf{1 , 0}[\mathbf{m l} / \mathbf{s}]$ & $\mathbf{1 , 5}[\mathbf{m l} / \mathbf{s}]$ & $\mathbf{2 , 0}[\mathbf{m l} / \mathbf{s}]$ \\
\hline $\begin{array}{c}\mathbf{T}_{\mathbf{c}} \text { (menor) } \\
\mathbf{7 0}^{\circ} \mathbf{C}\end{array}$ & Ensaio1 & Ensaio2 & Ensaio3 \\
$\begin{array}{c}\mathbf{T}_{\mathbf{c}} \text { (médio) } \\
\mathbf{7 5}^{\circ} \mathbf{C}\end{array}$ & Ensaio4 & Ensaio5 & Ensaio6 \\
$\mathbf{T}_{\mathbf{c}}$ (maior) & & & \\
$\mathbf{8 0}^{\circ} \mathbf{C}$ & Ensaio7 & Ensaio8 & Ensaio9 \\
\hline
\end{tabular}




\section{Resultados e Discussões}

\subsection{Resultados dos experimentos de medida da inversão da sacarose, taxa de evaporação, vazão de alimentação, [H] e concentração da solução.}

Seguindo o método desenvolvido no capítulo 4, neste capítulo são apresentados os resultados dos 9 ensaios nas tabelas de 5.1 a 5.9. Cada tabela apresenta os valores de entrada e saída de: grau de inversão $(x), p H$, concentração de açúcares totais $(C)$, e vazão mássica de entrada $\left(m_{0}\right)$ e taxa de evaporação $\left(m_{v}\right)$ os quais foram obtidos segundo os procedimentos 4.2.1 e 4.2.2 de Materiais e Métodos (capítulo 4). Cada tabela representa um ensaio com uma série de experiências.

Tabela 5.1: Ensaio1, $T_{c}=$ de $70^{\circ} \mathrm{C}, T_{0}=28^{\circ} \mathrm{C}$ e $q_{0}=1,03[\mathrm{ml} / \mathrm{s}]$

\begin{tabular}{ccccccccc}
\hline $\mathbf{N}{ }^{\circ}$ Exp. & xo ${ }^{*} \mathbf{1 0 3}$ & pHo & $\begin{array}{c}\text { Co } \\
{\left[{ }^{\circ} \text { Brix }\right]}\end{array}$ & xf $^{*} \mathbf{1 0 3}$ & pHf & $\begin{array}{c}\text { Cf } \\
{\left[{ }^{\circ} \text { Brix }\right]}\end{array}$ & $\begin{array}{c}\text { mv } \\
{[\mathbf{g} / \mathbf{s}]}\end{array}$ & $\begin{array}{c}\text { mo } \\
{[\mathbf{g} / \mathbf{s}]}\end{array}$ \\
\hline $\mathbf{1 . 1}$ & 3,44 & 2,25 & 10,0 & 38,66 & 2,00 & 16,4 & 0,42 & 1,07 \\
$\mathbf{1 . 2}$ & 38,66 & 2,00 & 16,4 & 91,88 & 1,74 & 26,5 & 0,42 & 1,09 \\
$\mathbf{1 . 3}$ & 91,88 & 1,74 & 26,5 & 180,30 & 1,42 & 42,6 & 0,43 & 1,12 \\
\hline
\end{tabular}

Tabela 5.2: Ensaio2, $T_{c}=$ de $70^{\circ} \mathrm{C}, T_{0}=23^{\circ} \mathrm{C}$ e $q_{o}=1,64[\mathrm{ml} / \mathrm{s}]$

\begin{tabular}{ccccccccc}
\hline $\mathbf{N}^{\circ}$ Exp. & xo ${ }^{*} \mathbf{1 0 3}$ & $\mathbf{p H o}$ & $\begin{array}{c}\text { Co } \\
{\left[{ }^{\circ} \mathrm{Brix}\right]}\end{array}$ & $\mathbf{x f}^{*} \mathbf{1 0 3}$ & $\mathbf{p H f}$ & $\begin{array}{c}\mathbf{C f} \\
{\left[{ }^{\circ} \mathrm{Brix}\right]}\end{array}$ & $\begin{array}{c}\mathbf{m v} \\
{[\mathbf{g} / \mathbf{s}]}\end{array}$ & $\begin{array}{c}\mathbf{m o} \\
{[\mathbf{g} / \mathbf{s}]}\end{array}$ \\
\hline $\mathbf{2 . 1}$ & 4,90 & 2,25 & 10,0 & 19,96 & 2,08 & 14,2 & 0,48 & 1,64 \\
$\mathbf{2 . 2}$ & 19,96 & 2,08 & 14,2 & 42,24 & 1,90 & 20,0 & 0,50 & 1,71 \\
$\mathbf{2 . 3}$ & 42,24 & 1,90 & 20,0 & 80,64 & 1,70 & 28,5 & 0,52 & 1,75 \\
\hline
\end{tabular}


Tabela 5.3: Ensaio3, $T_{c}=$ de $70^{\circ} \mathrm{C}, T_{0}=23^{\circ} \mathrm{C}$ e $q_{0}=1,97[\mathrm{ml} / \mathrm{s}]$

\begin{tabular}{ccccccccc}
\hline $\mathbf{N}{ }^{\circ}$ Exp. & xo ${ }^{*} \mathbf{1 0 3}$ & $\mathbf{p H o}$ & $\begin{array}{c}\text { Co } \\
{\left[{ }^{\circ} \mathrm{Brix}\right]}\end{array}$ & $\mathbf{x f}^{*} \mathbf{1 0 3}$ & $\mathbf{p H f}$ & $\begin{array}{c}\mathbf{C f} \\
{\left[{ }^{\circ} \mathrm{Brix}\right]}\end{array}$ & $\begin{array}{c}\mathbf{m v} \\
{[\mathbf{g} / \mathbf{s}]}\end{array}$ & $\begin{array}{c}\mathbf{m o} \\
{[\mathbf{g} / \mathbf{s}]}\end{array}$ \\
\hline $\mathbf{3 . 1}$ & 4,36 & 2,25 & 10,0 & 16,12 & 2,11 & 13,2 & 0,47 & 1,96 \\
$\mathbf{3 . 2}$ & 16,12 & 2,11 & 13,2 & 33,40 & 1,96 & 17,8 & 0,52 & 2,01 \\
$\mathbf{3 . 3}$ & 33,40 & 1,96 & 17,8 & 61,36 & 1,80 & 24,0 & 0,53 & 2,06 \\
$\mathbf{3 . 4}$ & 61,36 & 1,80 & 24,0 & 108,13 & 1,61 & 32,5 & 0,57 & 2,20 \\
\hline
\end{tabular}

Tabela 5.4: Ensaio4, $T_{\mathrm{c}}=$ de $75^{\circ} \mathrm{C}, \mathrm{T}_{\mathrm{o}}=22^{\circ} \mathrm{C}$ e $\mathrm{q}_{0}=1,14[\mathrm{ml} / \mathrm{s}]$

\begin{tabular}{ccccccccc}
\hline $\mathbf{N}^{\circ}$ Exp. & xo ${ }^{*} \mathbf{1 0 3}$ & $\mathbf{p H o}$ & $\begin{array}{c}\text { Co } \\
{\left[{ }^{\circ} \text { Brix }\right]}\end{array}$ & xf $^{*} \mathbf{1 0 3}$ & $\mathbf{p H f}$ & $\begin{array}{c}\mathbf{C f} \\
{\left[{ }^{\circ} \mathrm{Brix}\right]}\end{array}$ & $\begin{array}{c}\mathbf{m v} \\
{[\mathbf{g} / \mathbf{s}]}\end{array}$ & $\begin{array}{c}\mathbf{m o} \\
{[\mathbf{g} / \mathbf{s}]}\end{array}$ \\
\hline $\mathbf{4 . 1}$ & 1,92 & 2,25 & 10,0 & 23,39 & 2,11 & 13,3 & 0,29 & 1,16 \\
$\mathbf{4 . 2}$ & 23,39 & 2,11 & 13,3 & 50,14 & 1,97 & 17,6 & 0,28 & 1,16 \\
$\mathbf{4 . 3}$ & 50,14 & 1,97 & 17,6 & 88,20 & 1,80 & 23,8 & 0,31 & 1,21 \\
\hline
\end{tabular}

Tabela 5.5: Ensaio5, $\mathrm{T}_{\mathrm{c}}=$ de $75^{\circ} \mathrm{C}, \mathrm{T}_{\mathrm{o}}=22^{\circ} \mathrm{C}$ e $\mathrm{q}_{0}=1,51[\mathrm{ml} / \mathrm{s}]$

\begin{tabular}{ccccccccc}
\hline $\mathbf{N}^{\circ}$ Exp. & $\mathbf{x 0}{ }^{*} \mathbf{1 0 3}$ & $\mathbf{p H o}$ & $\begin{array}{c}\text { Co } \\
{\left[{ }^{\circ} \mathrm{Brix}\right]}\end{array}$ & $\mathbf{x f}^{*} \mathbf{1 0 3}$ & $\mathbf{p H f}$ & $\begin{array}{c}\mathbf{C f} \\
{\left[{ }^{\circ} \mathbf{B r i x}\right]}\end{array}$ & $\begin{array}{c}\mathbf{m v} \\
{[\mathbf{g} / \mathbf{s}]}\end{array}$ & $\begin{array}{c}\mathbf{m o} \\
[\mathbf{g} / \mathbf{s}]]\end{array}$ \\
\hline $\mathbf{5 . 1}$ & 4,36 & 2,25 & 10,0 & 23,91 & 2,13 & 12,8 & 0,33 & 1,50 \\
$\mathbf{5 . 2}$ & 23,91 & 2,13 & 12,8 & 45,02 & 2,00 & 16,5 & 0,34 & 1,54 \\
$\mathbf{5 . 3}$ & 45,02 & 2,00 & 16,5 & 74,75 & 1,87 & 21,1 & 0,34 & 1,57 \\
$\mathbf{5 . 4}$ & 74,75 & 1,87 & 21,1 & 110,55 & 1,72 & 27,2 & 0,37 & 1,64 \\
\hline
\end{tabular}

Tabela 5.6: Ensaio6, $\mathrm{T}_{\mathrm{c}}=$ de $75^{\circ} \mathrm{C}, \mathrm{T}_{\mathrm{o}}=22^{\circ} \mathrm{C}$ e $\mathrm{q}_{\mathrm{o}}=2,18[\mathrm{ml} / \mathrm{s}]$

\begin{tabular}{ccccccccc}
\hline $\mathbf{N}{ }^{\circ}$ Exp. & xo ${ }^{*} \mathbf{1 0 3}$ & pHo & $\begin{array}{c}\text { Co } \\
{\left[{ }^{\circ} \text { Brix }\right]}\end{array}$ & xf $^{*} \mathbf{1 0 3}$ & $\mathbf{p H f}$ & $\begin{array}{c}\mathbf{C f} \\
{\left[{ }^{\circ} \text { Brix }\right]}\end{array}$ & $\begin{array}{c}\mathbf{m v} \\
{[\mathbf{g} / \mathbf{s}]}\end{array}$ & $\begin{array}{c}\mathbf{m o} \\
{[\mathbf{g} / \mathbf{s}]}\end{array}$ \\
\hline $\mathbf{6 . 1}$ & 8,64 & 2,25 & 10,0 & 20,50 & 2,15 & 12,2 & 0,40 & 2,18 \\
$\mathbf{6 . 2}$ & 20,50 & 2,15 & 12,2 & 42,04 & 2,05 & 15,0 & 0,41 & 2,20 \\
$\mathbf{6 . 3}$ & 42,04 & 2,05 & 15,0 & 61,88 & 1,94 & 18,6 & 0,44 & 2,27 \\
$\mathbf{6 . 4}$ & 61,88 & 1,94 & 18,6 & 92,66 & 1,82 & 23,2 & 0,46 & 2,34 \\
\hline
\end{tabular}


Tabela 5.7: Ensaio7, $T_{c}=$ de $80^{\circ} \mathrm{C}, T_{0}=22^{\circ} \mathrm{C}$ e $q_{0}=1,22[\mathrm{ml} / \mathrm{s}]$

\begin{tabular}{|c|c|c|c|c|c|c|c|c|}
\hline$N^{\circ}$ Exp. & $x 0{ }^{*} 103$ & pHo & $\begin{array}{c}\text { Co } \\
{\left[{ }^{\circ} \text { Brix }\right]}\end{array}$ & $x f * 103$ & $\mathrm{pHf}$ & $\begin{array}{c}\mathrm{Cf} \\
{\left[{ }^{\circ} \mathrm{Brix}\right]}\end{array}$ & $\begin{array}{c}\mathrm{mv} \\
{[\mathrm{g} / \mathrm{s}]}\end{array}$ & $\begin{array}{c}\mathrm{mo} \\
{[\mathrm{g} / \mathrm{s}]}\end{array}$ \\
\hline 7.1 & 8,39 & 2,25 & 10,0 & 26,32 & 2,19 & 11,3 & 0,15 & 1,22 \\
\hline 7.2 & 26,32 & 2,19 & 11,3 & 49,83 & 2,12 & 13,0 & 0,15 & 1,22 \\
\hline 7.3 & 49,83 & 2,12 & 13,0 & 74,06 & 2,06 & 14,8 & 0,16 & 1,25 \\
\hline 7.4 & 74,06 & 2,06 & 14,8 & 113,97 & 1,98 & 17,0 & 0,16 & 1,25 \\
\hline 7.5 & 113,97 & 1,98 & 17,0 & 147,29 & 1,91 & 19,4 & 0,16 & 1,26 \\
\hline
\end{tabular}

Tabela 5.8: Ensaio8, $\mathrm{T}_{\mathrm{c}}=$ de $80^{\circ} \mathrm{C}, \mathrm{T}_{\mathrm{o}}=22^{\circ} \mathrm{C}$ e $\mathrm{q}_{0}=1,52[\mathrm{ml} / \mathrm{s}]$

\begin{tabular}{ccccccccc}
\hline $\mathbf{N}{ }^{\circ}$ Exp. & $\mathbf{x o}{ }^{*} \mathbf{1 0 3}$ & $\mathbf{p H o}$ & $\begin{array}{c}\text { Co } \\
{\left[{ }^{\circ} \text { Brix }\right]}\end{array}$ & xf $^{*} \mathbf{1 0 3}$ & $\mathbf{p H f}$ & $\begin{array}{c}\mathbf{C f} \\
{\left[{ }^{\circ} \mathbf{B r i x}\right]}\end{array}$ & $\begin{array}{c}\mathbf{m v} \\
{[\mathbf{g} / \mathbf{s}]}\end{array}$ & $\begin{array}{c}\mathbf{m o} \\
{[\mathbf{g} / \mathbf{s}]}\end{array}$ \\
\hline $\mathbf{8 . 1}$ & 6,87 & 2,25 & 10,0 & 23,40 & 2,20 & 11,1 & 0,16 & 1,53 \\
$\mathbf{8 . 2}$ & 23,40 & 2,20 & 11,1 & 39,75 & 2,15 & 12,4 & 0,15 & 1,54 \\
$\mathbf{8 . 3}$ & 39,75 & 2,15 & 12,4 & 64,23 & 2,10 & 13,7 & 0,15 & 1,53 \\
$\mathbf{8 . 4}$ & 64,23 & 2,10 & 13,7 & 94,32 & 2,04 & 15,2 & 0,15 & 1,53 \\
$\mathbf{8 . 5}$ & 94,32 & 2,04 & 15,2 & 122,09 & 1,99 & 16,9 & 0,15 & 1,54 \\
\hline
\end{tabular}

Tabela 5.9: Ensaio $9, \mathrm{~T}_{\mathrm{c}}=$ de $80^{\circ} \mathrm{C}, \mathrm{T}_{\mathrm{o}}=22^{\circ} \mathrm{C}$ e $\mathrm{q}_{\mathrm{o}}=1,94[\mathrm{ml} / \mathrm{s}]$

\begin{tabular}{ccccccccc}
\hline $\mathbf{N}{ }^{\circ}$ Exp. & $\mathbf{x o}{ }^{*} \mathbf{1 0 3}$ & $\mathbf{p H o}$ & $\begin{array}{c}\text { Co } \\
{\left[{ }^{\circ} \mathrm{Brix}\right]}\end{array}$ & $\mathbf{x f}{ }^{*} \mathbf{1 0 3}$ & $\mathbf{p H f}$ & $\begin{array}{c}\mathbf{C f} \\
{\left[{ }^{\circ} \mathrm{Brix}\right]}\end{array}$ & $\begin{array}{c}\mathbf{m v} \\
{[\mathbf{g} / \mathbf{s}]}\end{array}$ & $\begin{array}{c}\mathbf{m o} \\
{[\mathbf{g} / \mathbf{s}]}\end{array}$ \\
\hline $\mathbf{9 . 1}$ & 7,88 & 2,25 & 10,0 & 22,15 & 2,20 & 11,0 & 0,17 & 1,88 \\
$\mathbf{9 . 2}$ & 22,15 & 2,20 & 11,0 & 37,12 & 2,16 & 12,0 & 0,16 & 1,92 \\
$\mathbf{9 . 3}$ & 37,12 & 2,16 & 12,0 & 54,53 & 2,11 & 13,2 & 0,18 & 1,97 \\
$\mathbf{9 . 4}$ & 54,53 & 2,11 & 13,2 & 75,51 & 2,07 & 14,4 & 0,16 & 1,99 \\
$\mathbf{9 . 5}$ & 75,51 & 2,07 & 14,4 & 100,21 & 2,02 & 15,8 & 0,17 & 2,02 \\
\hline
\end{tabular}

A modificação do $p H$ pela adição de $\mathrm{HCl}$ (para o valor adotado de 2,25 ) possibilitou a amplificação das variações na fração de sacarose invertida $(x)$ causadas pela temperatura, pela concentração $(C)$ e pelo tempo de residência $(\tau)$. Nas condições de trabalho as concentrações de glicose (lembrando que a glicose representa $50 \%$ dos açúcares invertidos) mantiveram-se acima de $0.2 \mathrm{mg} / \mathrm{ml}$, já que a técnica de análise foi 
projetada para trabalhar com concentrações de 0,2 a 1,0 mg de glicose/ml de solução. Cabe ressaltar também que em alguns casos foi preciso diluir as soluções.

Das tabelas 5.1 a 5.9 pode-se observar que a inversão da sacarose $(x)$ tem uma forte influência da temperatura de saturação $\left(T_{c}\right)$. Isto pode ser observado nas figura 5.1 a 5.3 onde são colocadas as frações invertidas em função da concentração de açúcares totais para as distintas temperaturas $T_{c}$ para $q$ constante.

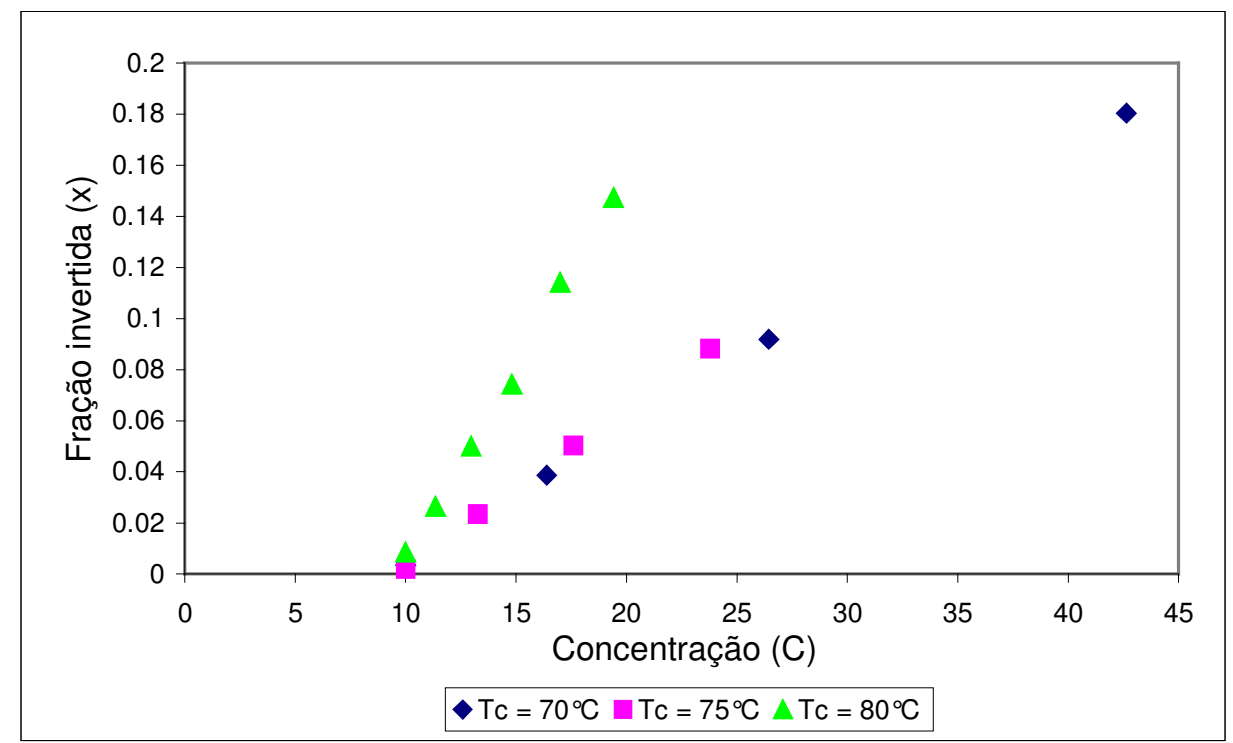

Figura 5.1 Influência da Temperatura $T_{c}$ no grau inversão para $q=1,1 \mathrm{ml} / \mathrm{s}$

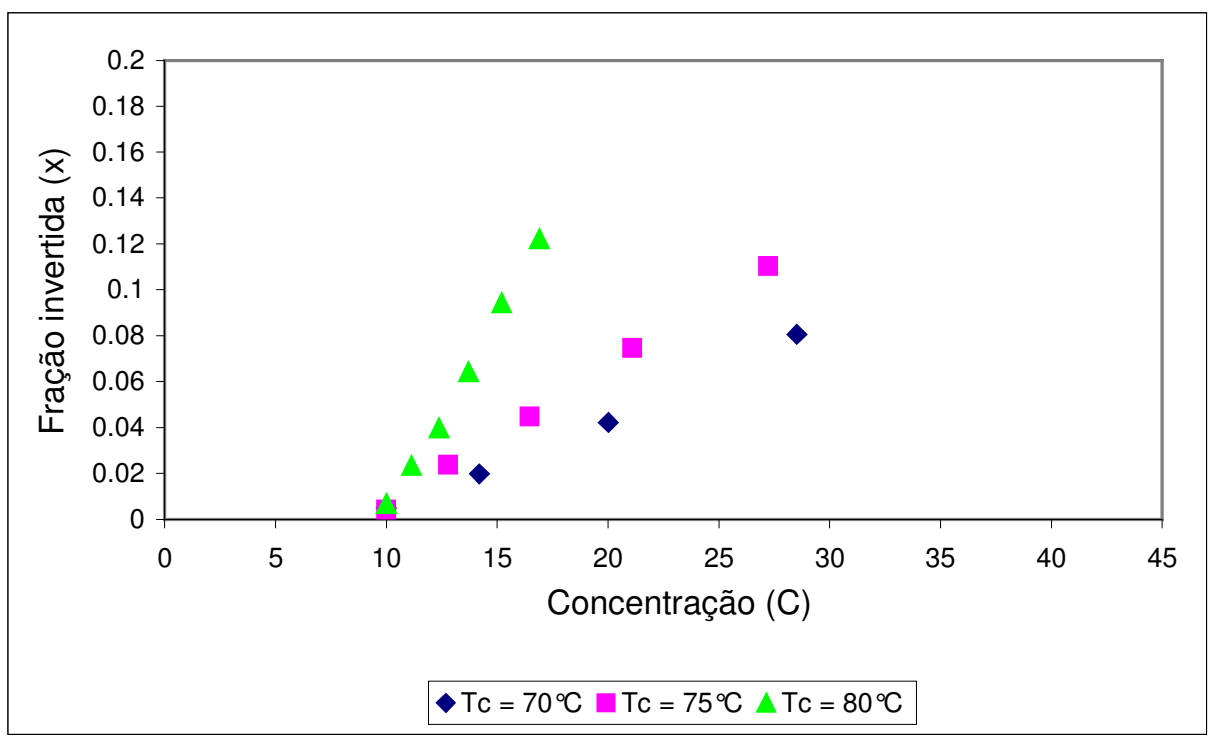

Figura 5.2 Influência da Temperatura $T_{c}$ no grau inversão para $q=1,6 \mathrm{ml} / \mathrm{s}$ 


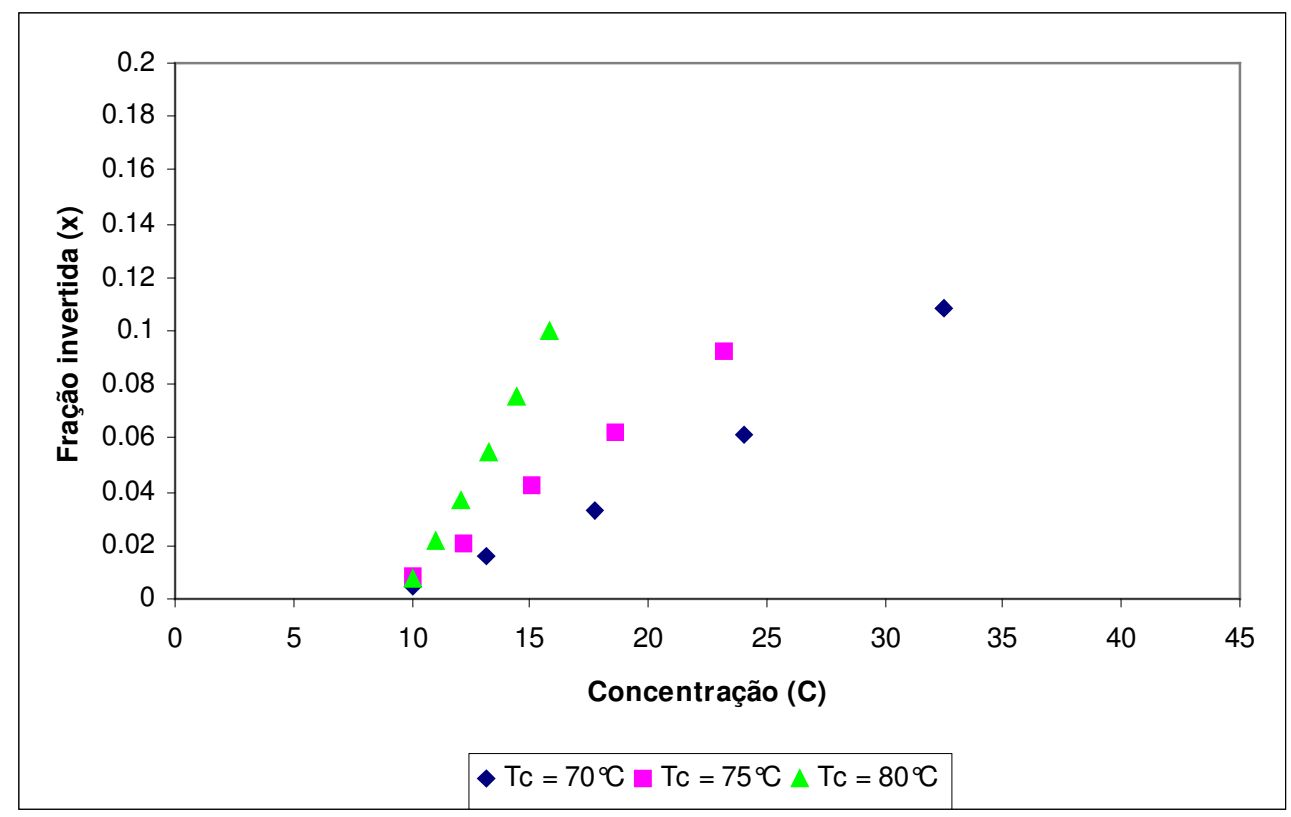

Figura 5.3 Influência da Temperatura $T_{c}$ no grau inversão para $q=2,0 \mathrm{ml} / \mathrm{s}$

Para avaliar a influência da vazão do liquido (q) dos dados apresentados nas tabelas 5.1 a 5.9 é colocado em um gráfico da fração invertida de sacarose $(x)$ como função da concentração $(C)$ para as distintas vazões de alimentação $\left(q_{0}\right)$ na temperatura $T_{C}$ constante. Isto pode ser observado nas figuras 5.4 a 5.6 a seguir:

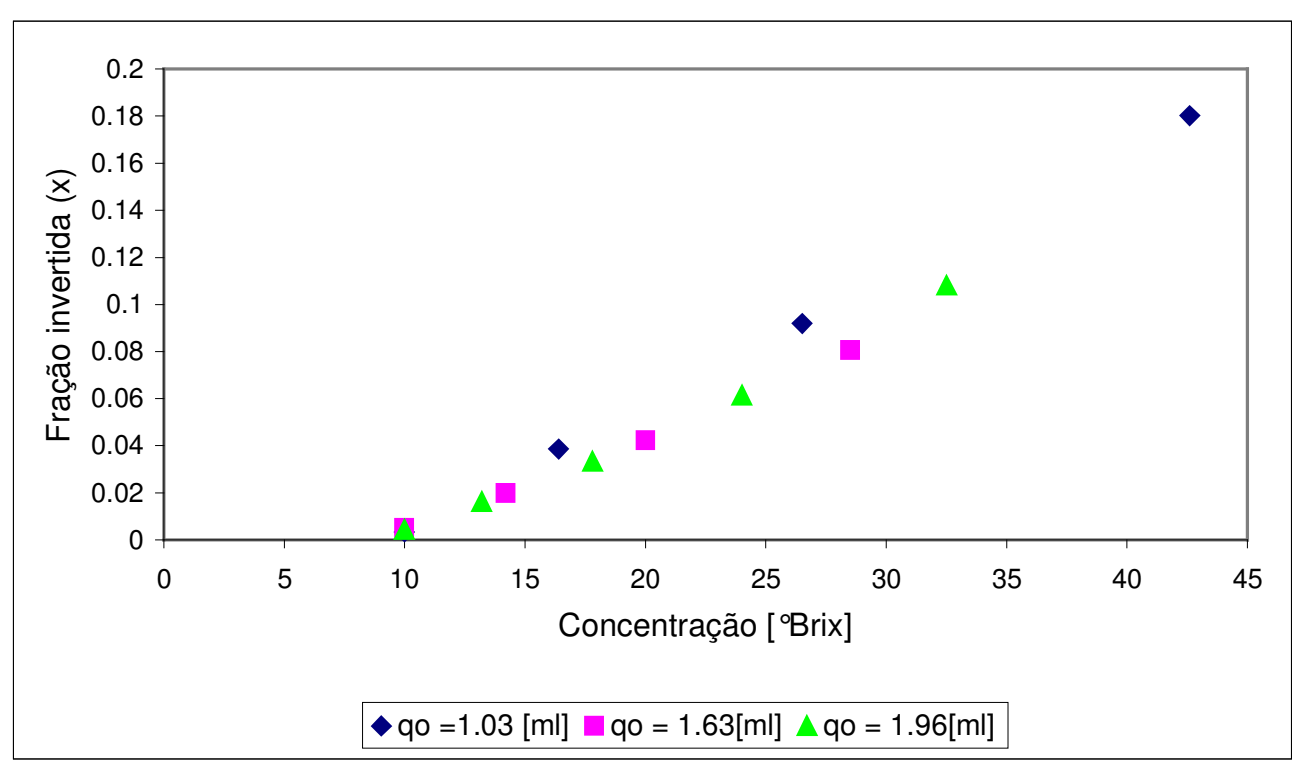

Figura 5.4 Influência da vazão do líquido no grau inversão para $T_{C}=70^{\circ} \mathrm{C}$ 


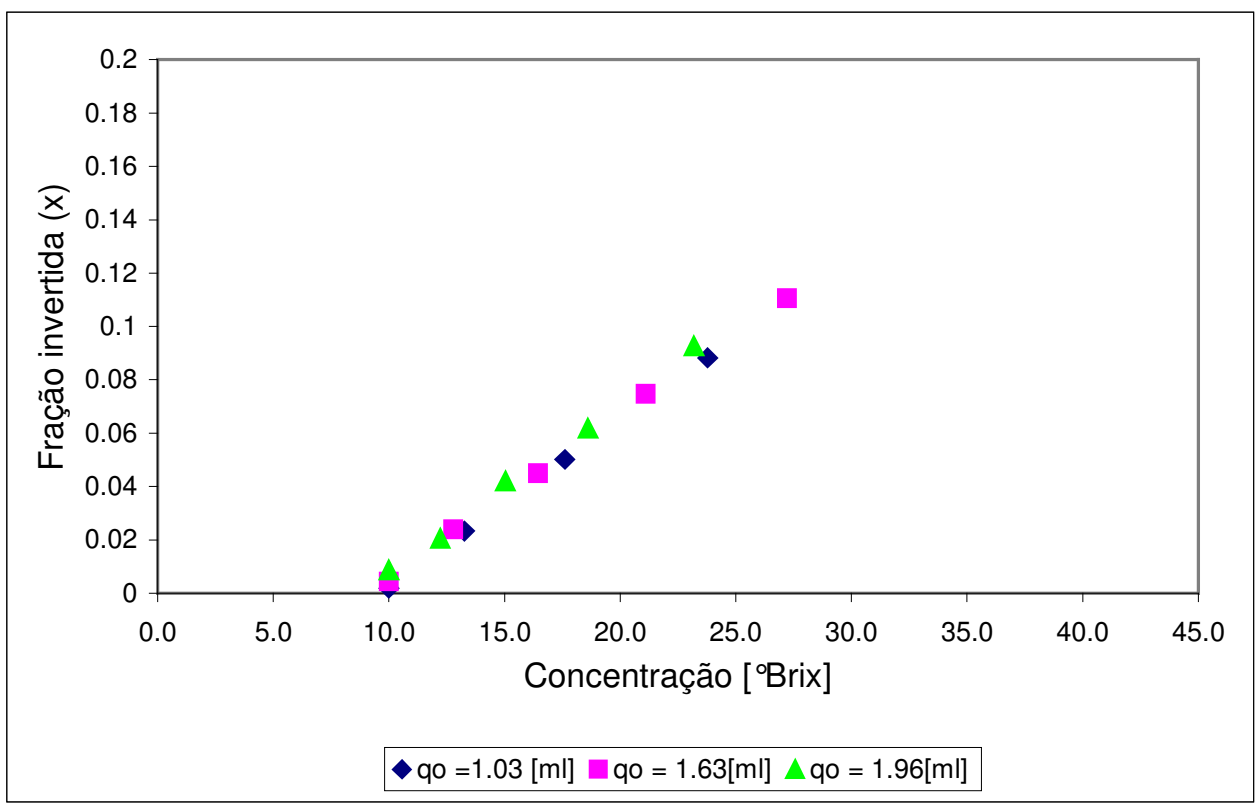

Figura 5.5 Influência da vazão do líquido no grau inversão para $T_{c}=75^{\circ} \mathrm{C}$

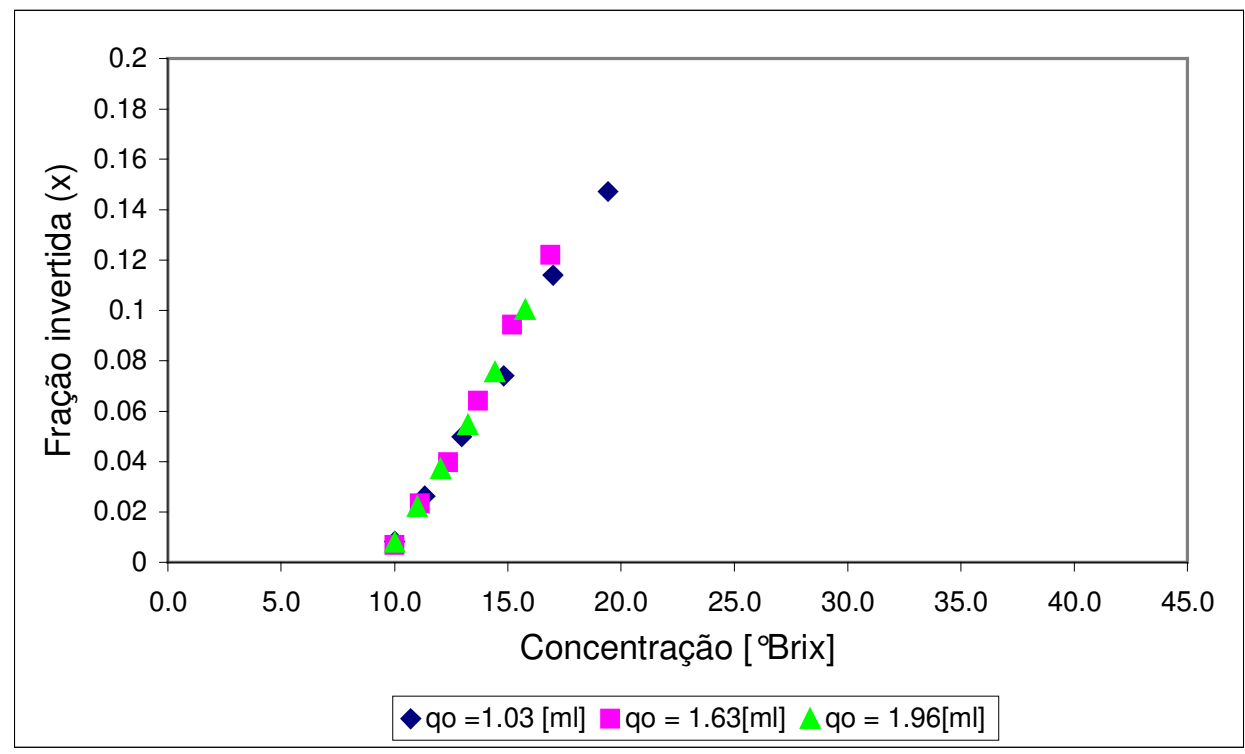

Figura 5.6 Influência da vazão do líquido no grau inversão para $T_{C}=80^{\circ} \mathrm{C}$

Dos gráficos 5.4 a 5.6 pode-se observar que a influência da vazão sob a inversão da sacarose é pouca, pois os pontos para as diferentes vazões operando na mesma temperatura $T_{c}$ se encontram confundidos em uma linha reta. 
Para corroborar estas observações são feitas as análises estatísticas dos dados apresentados nas figuras 5.4 a 5.6. Estas análises são apresentadas nas figuras 5.7 a 5.9 a seguir:

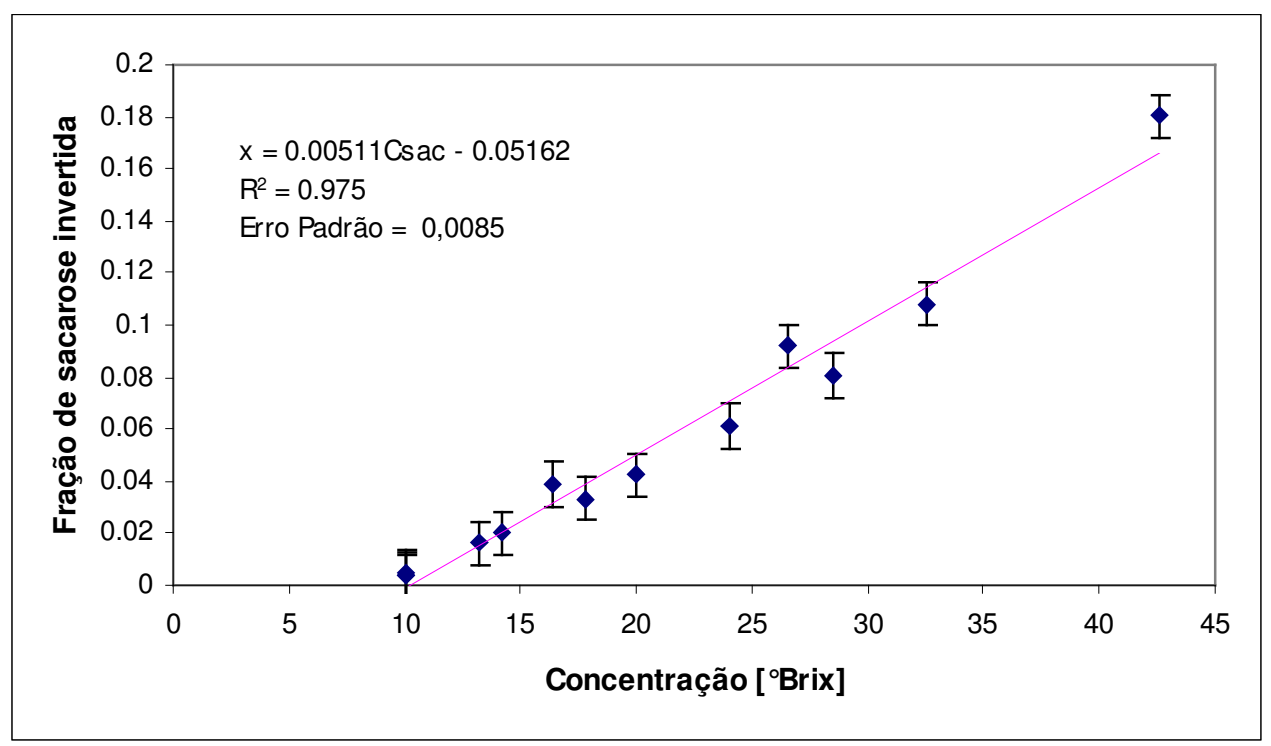

Figura 5.7 Análise estatística para a influência da vazão sob o grau inversão para $T_{c}=70^{\circ} \mathrm{C}$

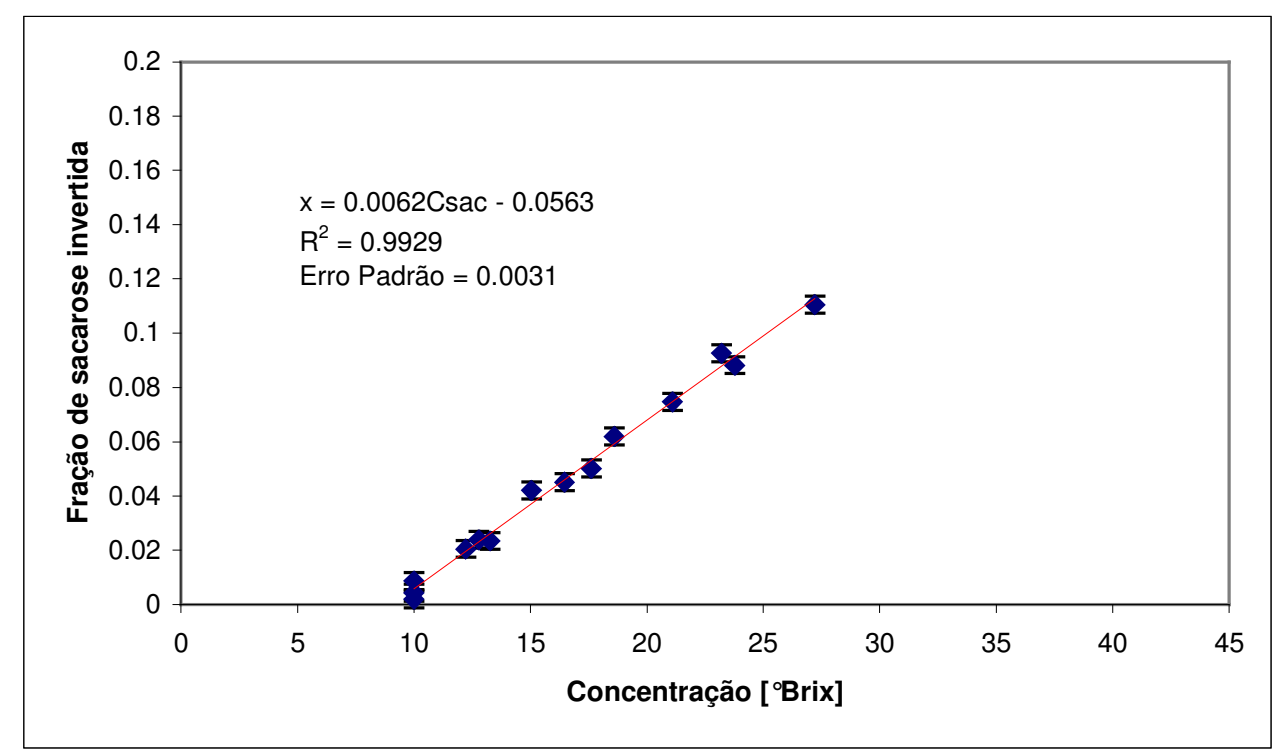

Figura 5.8 Análise estatística para a influência da vazão sob o grau inversão para $T_{c}=75^{\circ} \mathrm{C}$ 


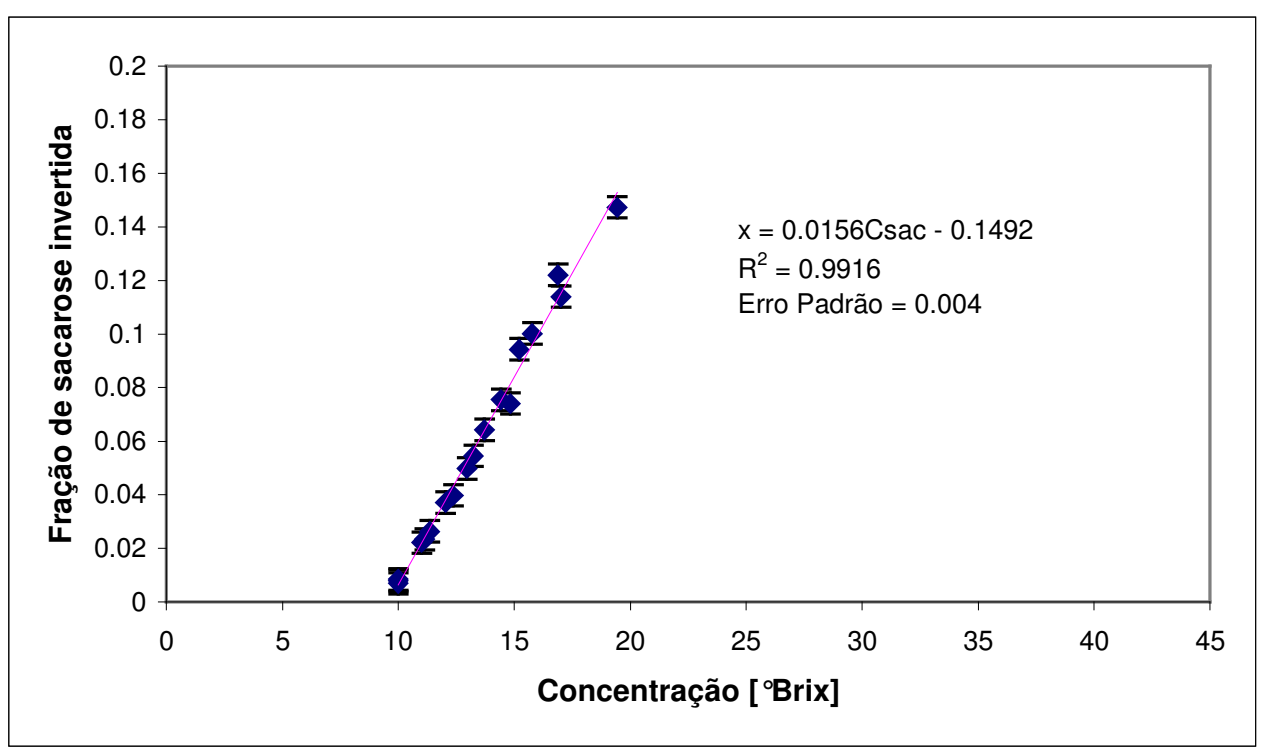

Figura 5.9 Análise estatística para a influência da vazão sob o grau inversão para $T_{c}=80^{\circ} \mathrm{C}$

A análise estatística verifica uma forte correlação entre os valores da fração invertida $(x)$ com a concentração $(C)$ para as diferentes vazões de alimentação $\left(q_{0}\right)$ com valores entre 0,98 a 0,99 e erros padrão entre 0,003 a 0,008 . Isto mostra que $q$ não tem influencia sob a inversão $x$ no intervalo das vazões na que foi avaliada.

\subsection{Parâmetros cinéticos $k$ e $E_{a}$ usados para a avaliação da inversão da sacarose}

Da revisão bibliográfica é observado que o estudo mais recente sob a inversão da sacarose foi feito por Pinheiro (1994). Este autor apresenta os seguintes valores:

$$
\begin{array}{ll}
E_{a} & =23,68 \mathrm{Kcal} / \mathrm{mole}-\mathrm{g} \\
K_{0} & =4,60 \cdot 10^{13}[\mathrm{~L} / \mathrm{mole}-\mathrm{g} / \mathrm{s}]
\end{array}
$$

Sendo a constante cinética $k$ igual a: $\quad k=k_{o} * \exp \left(-\frac{E_{a}}{R^{*} T}\right)$ 
Dados de inversão da sacarose como função do tempo foram gerados experimentalmente (isto sem evaporação da solução) para serem comparados com as frações invertidas calculadas com os valores dos parâmetros cinéticos apresentados por Pinheiros. Nas figuras 5.10 e 5.11 podem ser observados os ajustes das frações invertidas experimentais $\left(x_{\exp }\right)$ às frações invertidas calculadas dos parâmetros de Pinheiros $\left(x_{\text {teo }}\right)$

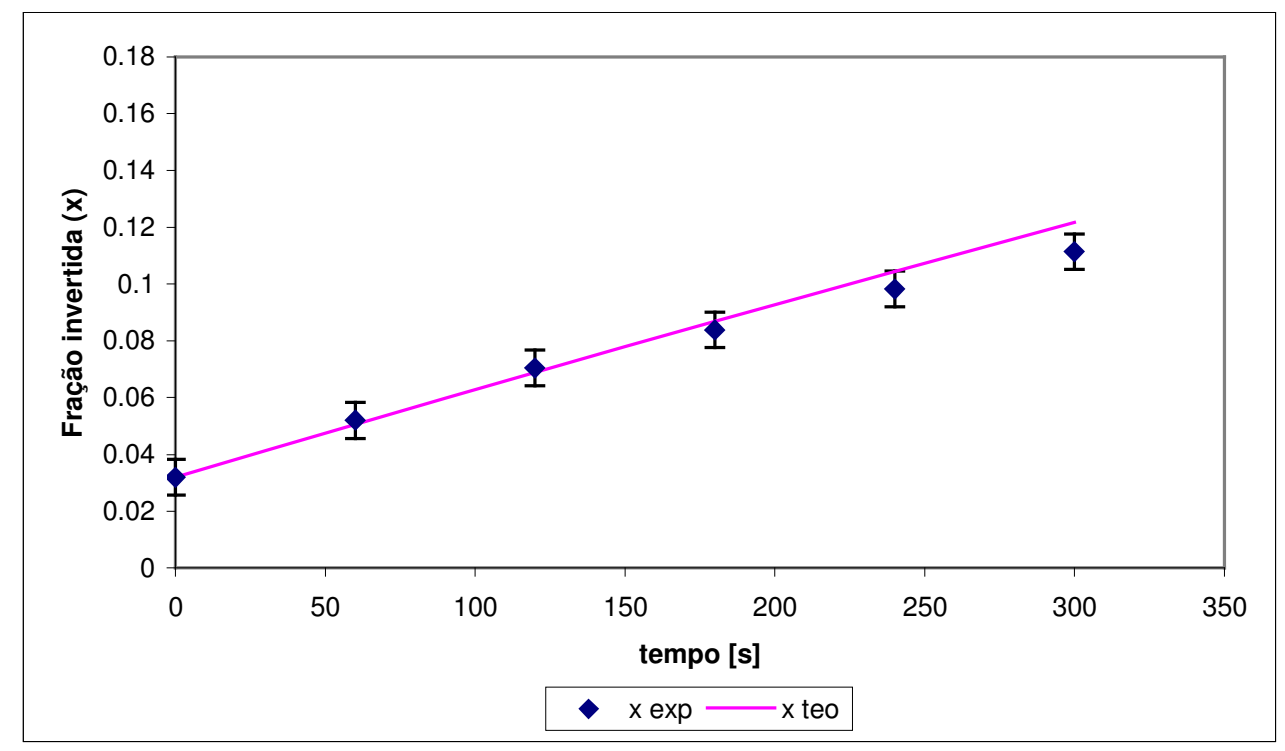

Figura 5.10 Fração invertida em função do tempo para $80^{\circ} \mathrm{C}$ e pH igual a 2,50

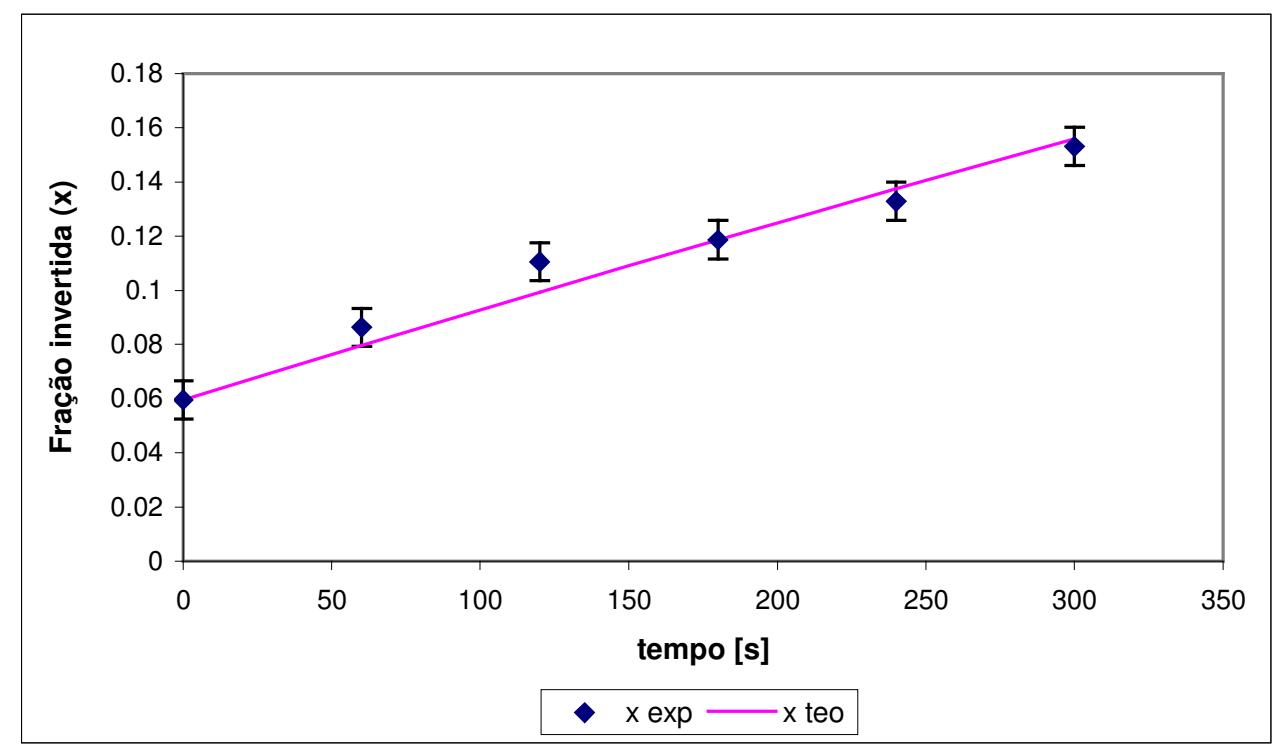

Figura 5.11 Fração invertida em função do tempo para $75^{\circ} \mathrm{C}$ e pH igual a 2,25 
Das figuras 5.10 e 5.11 pode-se observar que os dados experimentais apresentam aderência aos parâmetros de Pinheiros, assim os valores destes parâmetros podem ser usados para a avaliação da inversão no sistema de evaporação.

\subsection{Resultados dos experimentos para a caracterização das zonas de aquecimento e de evaporação}

Para caracterizar as zonas de aquecimento e de evaporação foram necessárias as medições das taxas de evaporação para a alimentação com líquido subresfriado $\left(m_{v}\right)$ e da taxa de evaporação com líquido saturado $\left(m_{v}^{\prime}\right)$ os quais foram obtidos experimentalmente e são apresentados na tabela 5.10.

Tabela 5.10: Medições das taxas de evaporação para a alimentação com líquido subresfriado $\left(m_{v}\right)$ e as taxas de evaporação com alimentação de liquido saturado $\left(m^{\prime}\right)$.

\begin{tabular}{ccccc}
\hline $\begin{array}{c}\mathbf{N}^{\circ} \\
\text { Experimento }\end{array}$ & $\begin{array}{c}\boldsymbol{T}_{c} \\
{\left[{ }^{\circ} \mathbf{C}\right]}\end{array}$ & $\begin{array}{c}\boldsymbol{q}_{o} \\
{\left[\mathbf{c m}^{3} / \mathbf{s}\right]}\end{array}$ & $\begin{array}{c}\boldsymbol{m}_{\boldsymbol{v}} \\
{[\mathbf{g} / \mathbf{s}]}\end{array}$ & $\begin{array}{c}\boldsymbol{m}^{\prime}{ }_{v} \\
{[\mathbf{g} / \mathbf{s}]}\end{array}$ \\
\hline $\mathbf{1}$ & 70 & 1,03 & 0,43 & 0,44 \\
$\mathbf{2}$ & 70 & 1,62 & 0,48 & 0,52 \\
$\mathbf{3}$ & 70 & 1,93 & 0,53 & 0,58 \\
$\mathbf{4}$ & 75 & 1,11 & 0,25 & 0,32 \\
$\mathbf{5}$ & 75 & 1,48 & 0,32 & 0,41 \\
$\mathbf{6}$ & 75 & 2,15 & 0,39 & 0,50 \\
$\mathbf{7}$ & 80 & 1,18 & 0,23 & 0,26 \\
$\mathbf{8}$ & 80 & 1,47 & 0,24 & 0,31 \\
$\mathbf{9}$ & 80 & 1,88 & 0,27 & 0,35 \\
\hline
\end{tabular}

A partir dos dados da tabela 5.10 são calculadas as frações do volume ocupado pela zona de evaporação para cada uma das condições de operação a partir das equações 4.64 e 4.65 do capítulo 4 de Materiais e Métodos.

$$
\frac{V_{e v}}{V_{t}}=\frac{\dot{m_{v}}}{\dot{m^{\prime}}{ }_{v}} \quad \text { e } \quad \frac{V_{a q}}{V_{t}}=1-\frac{V_{e v}}{V_{t}}
$$


Estes valores calculados são apresentados na tabela 5.11:

Tabela 5.11: Cálculo das frações do volume ocupado pela zona de evaporação

\begin{tabular}{ccccc}
\hline $\begin{array}{c}\mathbf{N}^{\circ} \\
\text { Experimento }\end{array}$ & $\begin{array}{c}\boldsymbol{T}_{\mathrm{c}} \\
{\left[{ }^{\circ} \mathbf{C}\right]}\end{array}$ & $\begin{array}{c}\boldsymbol{q}_{\mathrm{o}} \\
{\left[\mathbf{c m}^{3} / \mathbf{s}\right]}\end{array}$ & $\begin{array}{c}\boldsymbol{V}_{\mathrm{ev}} / \mathbf{V}_{\mathbf{t}} \\
{[\mathbf{g} / \mathbf{s}]}\end{array}$ & $\begin{array}{c}\boldsymbol{V}_{\mathrm{aq}} / \mathbf{V}_{\mathbf{t}} \\
{[\mathbf{g} / \mathbf{s}]}\end{array}$ \\
\hline $\mathbf{1}$ & 70 & 1,03 & 0,98 & 0,02 \\
$\mathbf{2}$ & 70 & 1,62 & 0,92 & 0,08 \\
$\mathbf{3}$ & 70 & 1,93 & 0,90 & 0,10 \\
$\mathbf{4}$ & 75 & 1,11 & 0,78 & 0,22 \\
$\mathbf{5}$ & 75 & 1,48 & 0,77 & 0,23 \\
$\mathbf{6}$ & 75 & 2,15 & 0,77 & 0,23 \\
$\mathbf{7}$ & 80 & 1,18 & 0,88 & 0,12 \\
$\mathbf{8}$ & 80 & 1,47 & 0,78 & 0,22 \\
$\mathbf{9}$ & 80 & 1,88 & 0,76 & 0,24 \\
\hline
\end{tabular}

Foi observado que $x$ aumenta com o acréscimo de $T_{c}$ e é independente de $q$ no intervalo de vazões na qual foi avaliada. Também foram estimadas as porcentagens dos volumes ocupados pelo líquido nas zonas (aquecimento e evaporação). Com esta caracterização da inversão podem ser usados os roteiros de cálculo do volume do líquido no tubo de evaporação que são indicados nas figuras 4.8 e 4.9, roteiros de cálculo por integração numérica e modelo simplificado respectivamente, do capitulo 4 de Matérias e Métodos.

Os resultados destes roteiros de cálculo são mostrados no item 5.4 a seguir.

\subsection{Resultados dos roteiros do cálculo do volume $V$ por integração numérica $\left(V_{\text {num }}\right)$ e pelo modelo simplificado $\left(V_{\text {apr }}\right)$}

O valor dos volumes calculados pelo roteiro de cálculo da figura 4.9 (integração numérica) e 4.10 (modelo simplificado) do capítulo 4 de Materiais e Métodos serão representados por $V_{\text {num }}$ e $V_{\text {apr }}$ respectivamente. 
Também são calculados os tempos de residência do líquido no tubo de evaporação $(\tau)$, a partir da equação 4.23, o número de Reynolds $(R e)$ da equação 4.24 e os parâmetros $\alpha$ e $\beta$. das equações 4.44 e 4.46 respectivamente.

Tabela 5.12: Resultados dos cálculos Ensaio1, $T_{c}=$ de $70^{\circ} \mathrm{C}$ e $q_{o}=1,03[\mathrm{ml} / \mathrm{s}]$

\begin{tabular}{cccccccccc}
\hline $\mathbf{N}^{\circ}$ Exp. & $\mathrm{x}_{\mathbf{0}} \times \mathbf{1 0}^{\mathbf{3}}$ & $\mathrm{x}_{\mathbf{1}} \times \mathbf{1 0}^{\mathbf{3}}$ & $\mathrm{x}_{\mathrm{f}}{ }^{*} \mathbf{1 0 ^ { 3 }}$ & $\begin{array}{c}\mathrm{V}_{\text {num }} \\
{\left[\mathbf{c m}^{3}\right]}\end{array}$ & $\begin{array}{c}\mathrm{V}_{\mathrm{apr}} \\
{\left[\mathbf{c m}^{3}\right]}\end{array}$ & $\boldsymbol{\alpha}$ & $\beta$ & $\mathbf{R e}$ & $\tau$ \\
\hline $\mathbf{1 . 1}$ & 3,44 & 3,56 & 38,66 & 36 & 35 & 0,43 & 0,74 & 26 & 44 \\
$\mathbf{1 . 2}$ & 38,66 & 38,84 & 91,88 & 32 & 31 & 0,43 & 0,74 & 21 & 39 \\
$\mathbf{1 . 3}$ & 91,88 & 92,16 & 180,30 & 29 & 28 & 0,43 & 0,74 & 12 & 36 \\
\hline
\end{tabular}

Tabela 5.13: Resultados dos cálculos Ensaio2, $T_{c}=$ de $70^{\circ} \mathrm{C}$ e $q_{0}=1,62[\mathrm{ml} / \mathrm{s}]$

\begin{tabular}{cccccccccc}
\hline $\mathbf{N}^{\circ}$ Exp. & $\mathbf{x}_{\mathbf{0}} * \mathbf{1 0}^{\mathbf{3}}$ & $\mathbf{x}_{\mathbf{1}} \times \mathbf{1 0}^{\mathbf{3}}$ & $\mathbf{x}_{\mathbf{f}}{ }^{*} \mathbf{1 0 ^ { 3 }}$ & $\begin{array}{c}\mathrm{V}_{\text {num }} \\
{\left[\mathbf{c m}^{3}\right]}\end{array}$ & $\begin{array}{c}\mathrm{V}_{\text {apr }} \\
{\left[\mathbf{c m}^{3}\right]}\end{array}$ & $\boldsymbol{\alpha}$ & $\boldsymbol{\beta}$ & $\mathbf{R e}$ & $\begin{array}{c}\tau \\
{[\mathbf{s}]}\end{array}$ \\
\hline $\mathbf{2 . 1}$ & 4,90 & 5,07 & 19,96 & 31 & 30 & 0,43 & 0,69 & 42 & 23 \\
$\mathbf{2 . 2}$ & 19,96 & 20,21 & 42,24 & 32 & 32 & 0,43 & 0,69 & 37 & 23 \\
$\mathbf{2 . 3}$ & 42,24 & 42,65 & 80,64 & 38 & 37 & 0,43 & 0,69 & 30 & 27 \\
\hline
\end{tabular}

Tabela 5.14: Resultados dos cálculos Ensaio3, $T_{c}=$ de $70^{\circ} \mathrm{C}$ e $q_{0}=1,93[\mathrm{ml} / \mathrm{s}]$

\begin{tabular}{|c|c|c|c|c|c|c|c|c|c|}
\hline $\mathrm{N}^{\circ}$ Exp. & $x_{0} \times 10^{3}$ & $x_{1} \times 10^{3}$ & $x_{f} * 10^{3}$ & $\begin{array}{c}V_{\text {num }} \\
{\left[\mathrm{cm}^{3}\right]}\end{array}$ & $\begin{array}{c}\mathrm{V}_{\mathrm{apr}} \\
{\left[\mathrm{cm}^{3}\right]}\end{array}$ & $\alpha$ & $\beta$ & $\mathbf{R e}$ & $\begin{array}{c}\tau \\
{[\mathbf{s}]}\end{array}$ \\
\hline 3.1 & 4,36 & 4,53 & 16,12 & 33 & 32 & 0,43 & 0,70 & 50 & 19 \\
\hline 3.2 & 16,12 & 16,36 & 33,40 & 37 & 36 & 0,43 & 0,70 & 46 & 22 \\
\hline 3.3 & 33,40 & 33,78 & 61,36 & 43 & 42 & 0,43 & 0,70 & 40 & 25 \\
\hline \multirow[t]{2}{*}{3.4} & 61,36 & 61,99 & 108,13 & 52 & 51 & 0,43 & 0,70 & 33 & 30 \\
\hline & & & & & & & & $\tau_{\text {(médio) }}$ & 24 \\
\hline
\end{tabular}


Tabela 5.15: Resultados dos cálculos Ensaio4, $\mathrm{T}_{\mathrm{c}}=$ de $75^{\circ} \mathrm{C}$ e $\mathrm{q}_{\mathrm{o}}=1,14[\mathrm{ml} / \mathrm{s}]$

\begin{tabular}{cccccccccc}
\hline $\mathbf{N}^{\circ}$ Exp. & $\mathrm{x}_{\mathbf{0}} * \mathbf{1 0}^{\mathbf{3}}$ & $\mathrm{x}_{\mathbf{1}} * \mathbf{1 0}^{3}$ & $\mathrm{x}_{\mathrm{f}}{ }^{*} \mathbf{1 0 ^ { 3 }}$ & $\begin{array}{c}\mathrm{V}_{\text {num }} \\
{\left[\mathbf{c m}^{3}\right]}\end{array}$ & $\begin{array}{c}\mathrm{V}_{\mathrm{apr}} \\
{\left[\mathbf{c m}^{3}\right]}\end{array}$ & $\boldsymbol{\alpha}$ & $\boldsymbol{\beta}$ & $\mathbf{R e}$ & $\begin{array}{c}\tau \\
{[\mathbf{s}]}\end{array}$ \\
\hline $\mathbf{4 . 1}$ & 1,92 & 2,63 & 23,39 & 28 & 27 & 0,43 & 0,66 & 31 & 27 \\
$\mathbf{4 . 2}$ & 23,39 & 24,28 & 50,14 & 25 & 24 & 0,43 & 0,66 & 28 & 25 \\
$\mathbf{4 . 3}$ & 50,14 & 51,36 & 88,20 & 28 & 27 & 0,43 & 0,66 & 25 & 27 \\
\hline
\end{tabular}

Tabela 5.16: Resultados dos cálculos Ensaio5, $T_{c}=$ de $75^{\circ} \mathrm{C}$ e $q_{0}=1,51[\mathrm{ml} / \mathrm{s}]$

\begin{tabular}{cccccccccc}
\hline $\mathbf{N}^{\circ}$ Exp. & $\mathrm{x}_{\mathbf{0}} * \mathbf{1 0}^{\mathbf{3}}$ & $\mathrm{x}_{\mathbf{1}} \times \mathbf{1 0}^{\mathbf{3}}$ & $\mathrm{x}_{\mathbf{f}}{ }^{*} \mathbf{1 \mathbf { 0 } ^ { 3 }}$ & $\begin{array}{c}\mathrm{V}_{\text {num }} \\
{\left[\mathbf{c m}^{3}\right]}\end{array}$ & $\begin{array}{c}\mathrm{V}_{\mathrm{apr}} \\
{\left[\mathbf{c m}^{3}\right]}\end{array}$ & $\boldsymbol{\alpha}$ & $\boldsymbol{\beta}$ & $\mathbf{R e}$ & $\begin{array}{c}\tau \\
{[\mathbf{s}]}\end{array}$ \\
\hline $\mathbf{5 . 1}$ & 4,36 & 5,08 & 23,91 & 36 & 35 & 0,43 & 0,65 & 40 & 27 \\
$\mathbf{5 . 2}$ & 23,91 & 24,68 & 45,02 & 31 & 30 & 0,43 & 0,65 & 38 & 23 \\
$\mathbf{5 . 3}$ & 45,02 & 46,10 & 74,75 & 34 & 32 & 0,43 & 0,65 & 34 & 25 \\
$\mathbf{5 . 4}$ & 74,75 & 76,03 & 110,55 & 32 & 31 & 0,43 & 0,65 & 30 & 23 \\
\hline
\end{tabular}

Tabela 5.17: Resultados dos cálculos Ensaio6, $T_{c}=$ de $75^{\circ} \mathrm{C}$ e $q_{0}=2,18[\mathrm{ml} / \mathrm{s}]$

\begin{tabular}{cccccccccc}
\hline $\mathbf{N}^{\circ}$ Exp. & $\mathrm{x}_{\mathbf{0}} \times \mathbf{1 0 ^ { 3 }}$ & $\mathrm{x}_{\mathbf{1}} \times \mathbf{1 0 ^ { 3 }}$ & $\mathrm{x}_{\mathrm{f}}{ }^{*} \mathbf{1 0 ^ { 3 }}$ & $\begin{array}{c}\mathrm{V}_{\text {num }} \\
{\left[\mathbf{c m}^{3}\right]}\end{array}$ & $\begin{array}{c}\mathrm{V}_{\mathrm{apr}} \\
{\left[\mathbf{c m}^{3}\right]}\end{array}$ & $\boldsymbol{\alpha}$ & $\boldsymbol{\beta}$ & $\mathbf{R e}$ & $\begin{array}{c}\tau \\
{[\mathbf{s}]}\end{array}$ \\
\hline $\mathbf{6 . 1}$ & 8,64 & 9,10 & 20,50 & 37 & 35 & 0,43 & 0,65 & 59 & 18 \\
$\mathbf{6 . 2}$ & 20,50 & 21,33 & 42,04 & 54 & 53 & 0,43 & 0,65 & 55 & 27 \\
$\mathbf{6 . 3}$ & 42,04 & 42,80 & 61,88 & 42 & 40 & 0,43 & 0,65 & 52 & 21 \\
$\mathbf{6 . 4}$ & 61,88 & 63,05 & 92,66 & 53 & 51 & 0,43 & 0,65 & 47 & 26 \\
\hline
\end{tabular}


Tabela 5.18: Resultados dos cálculos Ensaio7, $T_{c}=$ de $80^{\circ} \mathrm{C}$ e $q_{0}=1,22[\mathrm{ml} / \mathrm{s}]$

\begin{tabular}{|c|c|c|c|c|c|c|c|c|c|}
\hline $\mathbf{N}^{\circ}$ Exp. & $x_{0} \times 10^{3}$ & $x_{1} \times 10^{3}$ & $x_{f}^{*} 10^{3}$ & $\begin{array}{l}V_{\text {num }} \\
{\left[\mathrm{cm}^{3}\right]}\end{array}$ & $\begin{array}{c}\mathrm{V}_{\mathrm{apr}} \\
{\left[\mathrm{cm}^{3}\right]}\end{array}$ & $\alpha$ & $\beta$ & $\mathbf{R e}$ & $\begin{array}{c}\tau \\
{[\mathrm{s}]}\end{array}$ \\
\hline 7.1 & 8,39 & 9,06 & 26,32 & 20 & 19 & 0,43 & 0,63 & 35 & 17 \\
\hline 7.2 & 26,32 & 27,20 & 49,83 & 23 & 22 & 0,43 & 0,63 & 34 & 20 \\
\hline 7.3 & 49,83 & 50,74 & 74,06 & 21 & 21 & 0,43 & 0,63 & 33 & 18 \\
\hline 7.4 & 74,06 & 75,56 & 113,97 & 31 & 30 & 0,43 & 0,63 & 31 & 27 \\
\hline \multirow[t]{2}{*}{7.5} & 113,97 & 115,21 & 147,29 & 23 & 22 & 0,43 & 0,63 & 30 & 20 \\
\hline & & & & & & & & (médio) & 21 \\
\hline
\end{tabular}

Tabela 5.19: Resultados dos cálculos Ensaio8, $\mathrm{T}_{\mathrm{c}}=$ de $80^{\circ} \mathrm{C}$ e $\mathrm{q}_{\mathrm{o}}=1,52[\mathrm{ml} / \mathrm{s}]$

\begin{tabular}{cccccccccc}
\hline $\mathbf{N}{ }^{\circ}$ Exp. & $\mathbf{x}_{\mathbf{0}} * \mathbf{1 0}^{3}$ & $\mathbf{x}_{\mathbf{1} \times 10^{3}}$ & $\mathbf{x}_{\mathbf{f}}{ }^{*} \mathbf{1 0 ^ { 3 }}$ & $\begin{array}{c}\mathrm{V}_{\text {num }} \\
{\left[\mathbf{c m}^{3}\right]}\end{array}$ & $\begin{array}{c}\mathrm{V}_{\text {apr }} \\
{\left[\mathbf{c m}^{3}\right]}\end{array}$ & $\alpha$ & $\beta$ & $\mathbf{R e}$ & $\begin{array}{c}\tau \\
{[\mathbf{s}]}\end{array}$ \\
\hline $\mathbf{8 . 1}$ & 6,87 & 7,54 & 23,40 & 24 & 23 & 0,43 & 0,63 & 44 & 17 \\
$\mathbf{8 . 2}$ & 23,40 & 24,06 & 39,75 & 21 & 21 & 0,43 & 0,63 & 43 & 15 \\
$\mathbf{8 . 3}$ & 39,75 & 40,75 & 64,23 & 29 & 28 & 0,43 & 0,63 & 41 & 20 \\
$\mathbf{8 . 4}$ & 64,23 & 65,46 & 94,32 & 32 & 31 & 0,43 & 0,63 & 40 & 22 \\
$\mathbf{8 . 5}$ & 94,32 & 95,45 & 122,09 & 27 & 26 & 0,43 & 0,63 & 38 & 19 \\
\hline & & & & & & & & $\tau_{\text {(médio) }}$ & 19 \\
\hline
\end{tabular}

Tabela 5.20: Resultados dos cálculos Ensaio9, $\mathrm{T}_{\mathrm{c}}=$ de $80^{\circ} \mathrm{C}$ e $\mathrm{q}_{\mathrm{o}}=1,94[\mathrm{ml} / \mathrm{s}]$

\begin{tabular}{cccccccccc}
\hline $\mathbf{N}{ }^{\circ}$ Exp. & $\mathrm{x}_{\mathbf{o}} * \mathbf{1 0}^{\mathbf{3}}$ & $\mathrm{x}_{\mathbf{1}} * \mathbf{1 0}^{\mathbf{3}}$ & $\mathrm{x}_{\mathrm{f}}{ }^{*} \mathbf{1 0 ^ { 3 }}$ & $\begin{array}{c}\mathrm{V}_{\text {num }} \\
{\left[\mathbf{c m}^{3}\right]}\end{array}$ & $\begin{array}{c}\mathrm{V}_{\text {apr }} \\
{\left[\mathbf{c m}^{3}\right]}\end{array}$ & $\boldsymbol{\alpha}$ & $\beta$ & $\mathbf{R e}$ & $\begin{array}{c}\tau \\
{[\mathbf{s}]}\end{array}$ \\
\hline $\mathbf{9 . 1}$ & 7,88 & 8,50 & 22,15 & 27 & 26 & 0,43 & 0,62 & 54 & 15 \\
$\mathbf{9 . 2}$ & 22,15 & 22,80 & 37,12 & 26 & 25 & 0,43 & 0,62 & 54 & 14 \\
$\mathbf{9 . 3}$ & 37,12 & 37,88 & 54,53 & 28 & 27 & 0,43 & 0,62 & 54 & 15 \\
$\mathbf{9 . 4}$ & 54,53 & 55,45 & 75,51 & 31 & 30 & 0,43 & 0,62 & 53 & 17 \\
$\mathbf{9 . 5}$ & 75,51 & 76,59 & 100,21 & 35 & 34 & 0,43 & 0,62 & 52 & 18 \\
\hline & & & & & & & $\tau_{\text {(médio) }}$ & 16 \\
\hline
\end{tabular}


Dos resultados apresentados nas tabelas 5.12 a 5.20 têm-se as seguintes observações:

a) A quantidade de sacarose invertida na zona de aquecimento $\left(x_{0}\right.$ a $\left.x_{1}\right)$ representam entre 1 a $5 \%$ do total da sacarose invertida $\left(x_{0}\right.$ a $\left.x_{f}\right)$ durante a passagem no tubo de evaporação.

b) $O$ parâmetro $\beta$ utilizado para o cálculo da temperatura efetiva na zona de aquecimento ( $\left.T_{\text {efa }}\right)$ apresenta valores entre 0,62 a 0,72 nos 9 ensaios.

c) O parâmetro $\alpha$ utilizado para o cálculo da temperatura efetiva de na zona de evaporação ( $\left.T_{\text {efe }}\right)$ apresenta o valor constante de 0,43 para todos os ensaios.

d) Os valores dos volumes calculados pelo modelo simplificado $\left(V_{\text {apr }}\right)$ resultaram ser entre 3 a $6 \%$ menores do que aqueles calculados pelo método numérico $\left(V_{\text {num }}\right)$.

e) Os valores do Reynolds apresentaram valores entre 12 a 59 .

f) Os volumes médios calculados $\left(\bar{V}_{\text {num }}\right)$ apresentam uma dependência direta da vazão do líquido, pois o volume calculado aumenta para o acréscimo da vazão e para a diminuição da vazão o volume também diminui (para cada temperatura de câmara $T_{c}$ ) isto é observado na figura 5.12 a seguir.

g) Os valores do número de Reynolds achados entre 12 a 59, embora estejam contemplados na faixa do fluxo laminar (até 100, segundo Incropera 2003, pág.434), os fluxos do líquido foram considerados como sendo turbulentos, já que o evaporador usado é equipado com um promotor de filme, este dispositivo ajuda na turbulência do fluxo do líquido (Salvagnini 2004) 


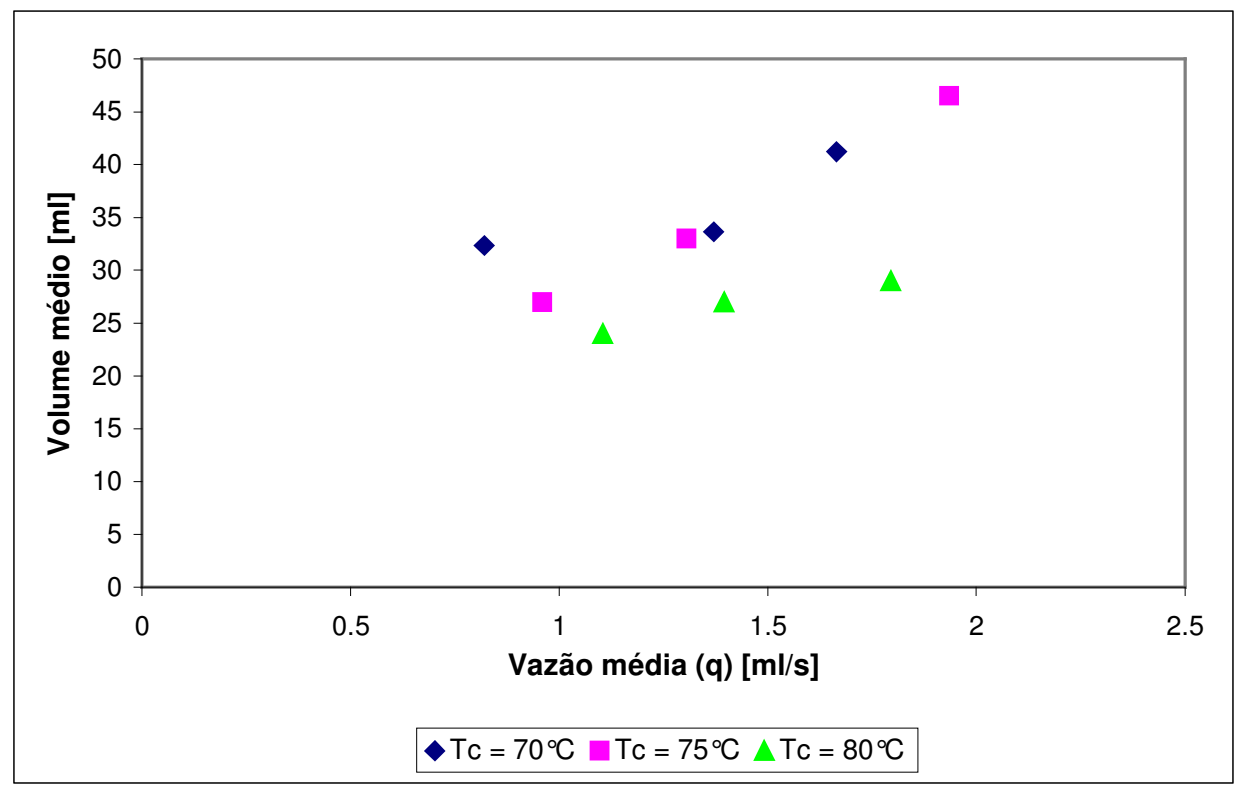

Figura 5.12: Influência da vazão do líquido sob o volume calculado (V)

- Da figura 5.12 pode-se observar que os volumes calculados se encontram entre 24 a $45 \mathrm{ml}$.

- O tempo médio de residência $(\bar{\tau})$ decresce com a vazão $(q)$. Isto pode-ser observado na figura 5.13 onde $\bar{\tau}$ é colocado como função de q para cada uma das temperaturas de câmara $\left(T_{c}\right)$.

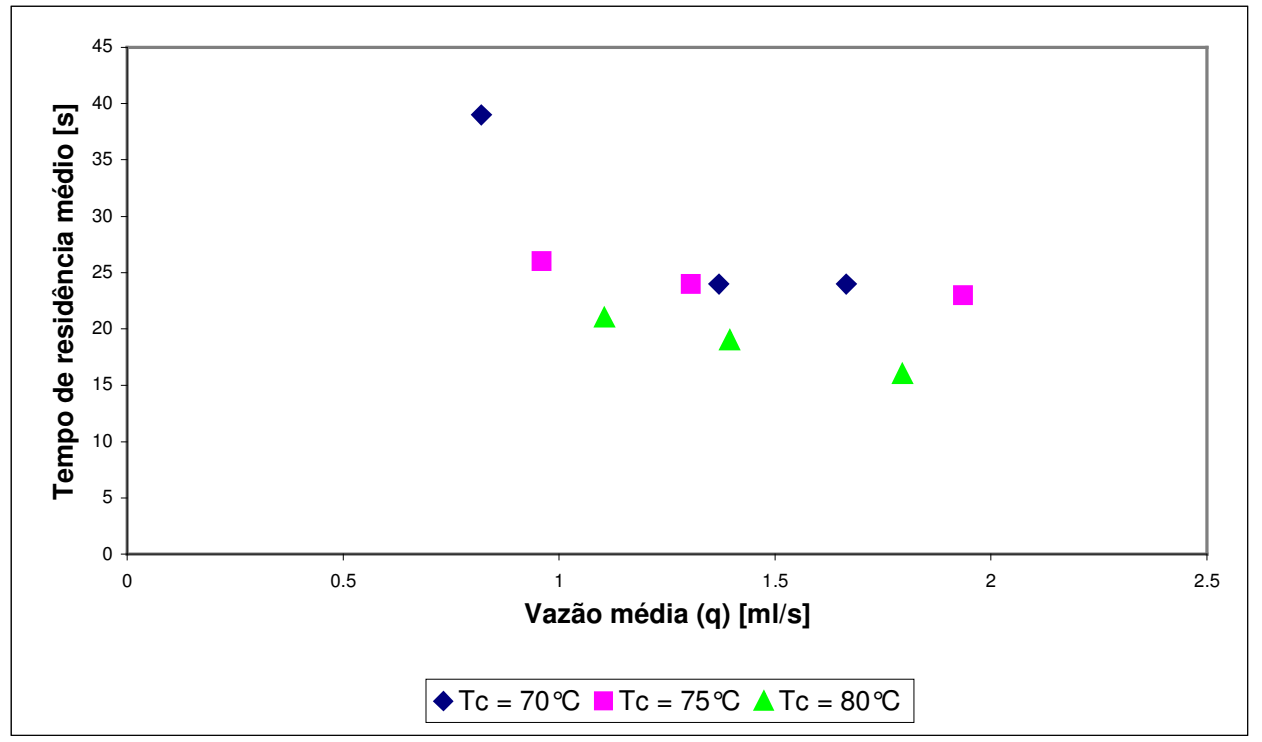

Figura 5.13: Influência da vazão do líquido sob o tempo de residência médio $(\bar{\tau})$ 
- Da figura 5.13 pode-se observar que os valores dos tempos de residência se encontram entre $16\left(T_{c}=70^{\circ} \mathrm{C}\right.$ e $\left.q=0,82[\mathrm{ml} / \mathrm{s}]\right)$ a 39 segundos $\left(T_{c}=80^{\circ} \mathrm{C}\right.$ e $q=$ $1,8[\mathrm{ml} / \mathrm{s}])$.

\subsection{Propagação de erros no cálculo dos volumes $V_{\text {num }}$}

O erro no cálculo dos volumes $\left(V_{\text {num }}\right)$ pode ser estimado por meio da propagação de erros como é mostrado nas equações 5.1 a seguir:

$e_{v}=\sqrt{\left(\left(\frac{\partial V}{\partial T_{c}} e_{T c}\right)^{2}+\left(\frac{\partial V}{\partial T_{o}} e_{T o}\right)^{2}+\left(\frac{\partial V}{\partial T_{W}} e_{T_{w}}\right)^{2}+\left(\frac{\partial V}{\partial x} e_{x}\right)^{2}+\left(\frac{\partial V}{\partial H} e_{H}\right)^{2}+\left(\frac{\partial V}{\partial L_{a q}} e_{L a q}\right)^{2}\right)}$

Sendo:

$\begin{array}{lll}e_{T c} & = & \pm 1{ }^{\circ} \mathrm{C} \text { (erro cometido na medição da temperatura } T_{c} \text { ) } \\ e_{T o} & = & \pm 1{ }^{\circ} \mathrm{C} \text { (erro cometido na medição da temperatura } T_{o} \text { ) } \\ e_{T w} & = & \pm 2{ }^{\circ} \mathrm{C} \text { (erro cometido na medição da temperatura } T_{w} \text { ) } \\ e_{H} & = & \pm 5 \% \text { (erro cometido na medição de }[H] \text { ) } \\ e_{X} & = & \pm 5 \% \text { (erro cometido na medição de } x \text { ) } \\ e_{L a q} & = & \pm 0.05^{*} V_{a q} / V_{e v} \text { (erro cometido na medição de } x \text { ) } \\ \partial V / \partial T_{C} & a & \text { Variação de } V \text { com a variação de } T_{C} \\ \partial V / \partial T_{C} & a & \text { Variação de } V \text { com a variação de } T_{o} \\ \partial V / \partial T_{C} & a & \text { Variação de } V \text { com a variação de } T_{w} \\ \partial V / \partial T_{C} & a & \text { Variação de } V \text { com a variação de } x \\ \partial V / \partial T_{C} & a & \text { Variação de } V \text { com a variação de }[H] \\ \partial V / \partial L_{a q} & a & \text { Variação de } V \text { com a variação de } L_{a q}\end{array}$


As tabelas 5.21 a 5.23 apresentam os erros dos volumes médios calculados para as diferentes temperaturas de saturação $T_{c}$ e as vazões $(q)$ e também as contribuições de cada uma das variáveis no erro do volume calculado.

Tabela 5.21: Cálculo dos erros dos volumes médios para os ensaios a $T_{c}=$ de $70^{\circ} \mathrm{C}$

\begin{tabular}{cccccccc}
\hline $\begin{array}{c}q \\
{[\mathrm{ml} / \mathrm{s}]}\end{array}$ & $\frac{\partial V}{\partial T_{c}} e_{T c}$ & $\frac{\partial V}{\partial T_{o}} e_{T o}$ & $\frac{\partial V}{\partial T_{W}} e_{T_{w}}$ & $\frac{\partial V}{\partial x} e_{x}$ & $\frac{\partial V}{\partial H} e_{H}$ & $\frac{\partial V}{\partial L_{a q}} e_{L a q}$ & $\begin{array}{c}e_{V} \\
{[\mathrm{ml}]}\end{array}$ \\
\hline 1,03 & 1,27 & 0,004 & 1,67 & 1,65 & 1,58 & 1,35 & 3,38 \\
1,64 & 1,36 & 0,013 & 1,78 & 1,71 & 1,50 & 1,31 & 3,45 \\
1,97 & 1,67 & 0,020 & 2,19 & 2,11 & 2,03 & 1,57 & 4,32 \\
\hline
\end{tabular}

Tabela 5.22: Cálculo dos erros dos volumes médios para os ensaios a $T_{c}=$ de $75^{\circ} \mathrm{C}$

\begin{tabular}{cccccccc}
\hline$q$ & $\frac{\partial V}{\partial T_{c}} e_{T c}$ & $\frac{\partial V}{\partial T_{o}} e_{T o}$ & $\frac{\partial V}{\partial T_{W}} e_{T_{w}}$ & $\frac{\partial V}{\partial x} e_{x}$ & $\frac{\partial V}{\partial H} e_{H}$ & $\frac{\partial V}{\partial L_{a q}} e_{L a q}$ & $\begin{array}{c}e_{V} \\
{[\mathrm{ml}]}\end{array}$ \\
\hline$[\mathrm{ml} / \mathrm{s}]$ & 1,02 & 0,03 & 1,36 & 1,35 & 1,20 & 0,85 & 2,63 \\
1,14 & 1,28 & 0,04 & 1,71 & 1,69 & 1,53 & 1,04 & 3,29 \\
1,51 & 1,80 & 0,06 & 2,40 & 2,35 & 2,23 & 1,44 & 4,65 \\
\hline
\end{tabular}

Tabela 5.23: Cálculo dos erros dos volumes médios para os ensaios a $T_{c}=$ de $80^{\circ} \mathrm{C}$

\begin{tabular}{cccccccc}
\hline $\begin{array}{c}q \\
{[\mathrm{ml} / \mathrm{s}]}\end{array}$ & $\frac{\partial V}{\partial T_{c}} e_{T c}$ & $\frac{\partial V}{\partial T_{o}} e_{T o}$ & $\frac{\partial V}{\partial T_{W}} e_{T_{w}}$ & $\frac{\partial V}{\partial x} e_{x}$ & $\frac{\partial V}{\partial H} e_{H}$ & $\frac{\partial V}{\partial L_{a q}} e_{L a q}$ & $\begin{array}{c}e_{V} \\
{[\mathrm{ml}]}\end{array}$ \\
\hline 1,22 & 0,89 & 0,03 & 1,20 & 1,23 & 1,15 & 0,75 & 2,38 \\
1,52 & 1,00 & 0,03 & 1,34 & 1,38 & 1,26 & 0,82 & 2,64 \\
1,94 & 1,11 & 0,04 & 1,53 & 1,50 & 1,44 & 0,89 & 2,95 \\
\hline
\end{tabular}

Das tabelas 5.21 a 5.23 pode-se observar que as maiores contribuições vêm das variáveis $[H], T_{c}, T_{w}$ e $x$ mudando entre 0,89 a 2,40 $\mathrm{ml}$ o valor do volume $V$ calculado e em menor grau das variáveis $T_{o}$ e $L_{a q}$ que mudam o valor de $V$ entre 0,03 a 1,57 ml. 
O gráfico do volume em função da vazão do líquido com os erros calculados para os volumes pode ser representado na figura 5.14 a seguir:

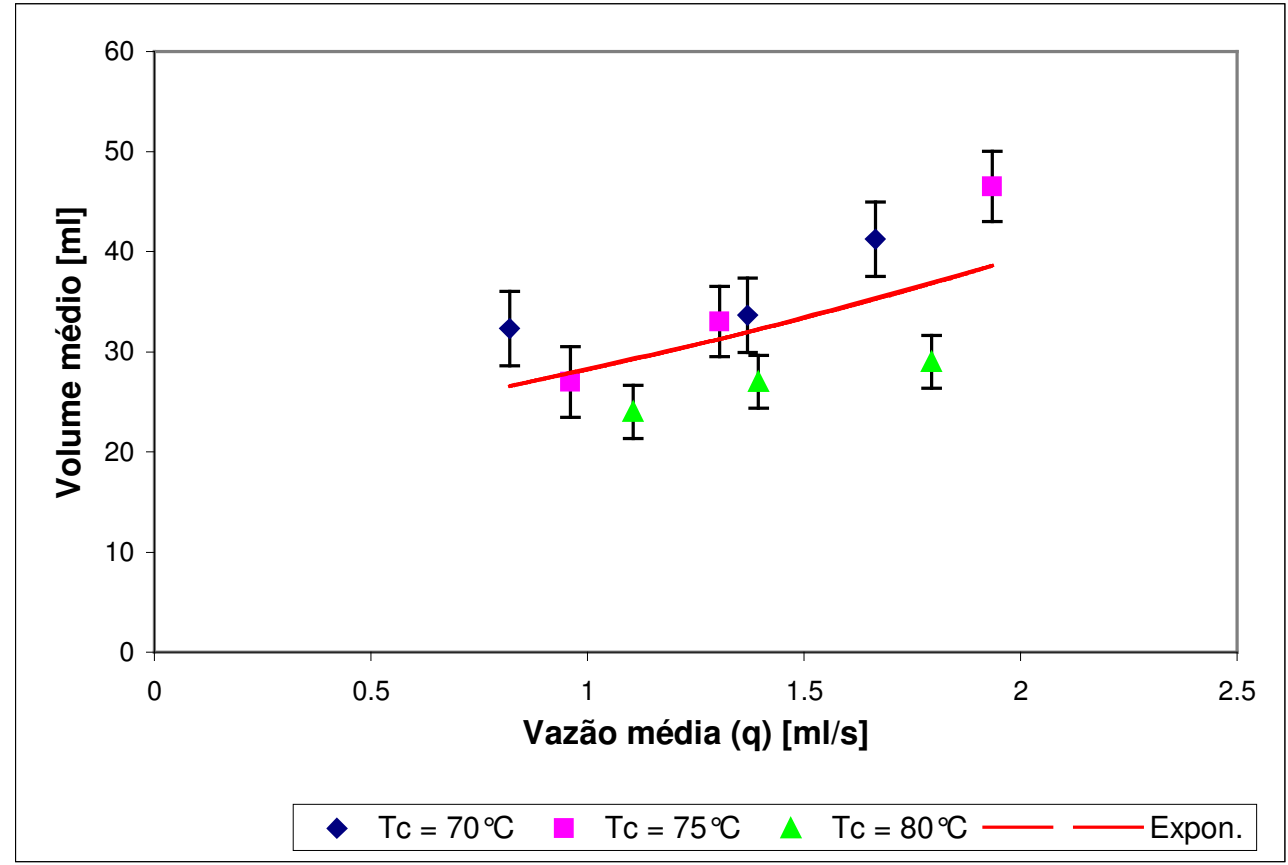

Figura 5.14:Ajuste do volume (V) médio com a vazão média do líquido (q) 


\section{Conclusões, Resumo de Resultados e Recomendações}

\subsection{Conclusões e Resumo de Resultados}

Dos resultados obtidos pode-se chegar as seguintes conclusões:

1. A inversão na zona de aquecimento $\left(x_{0}\right.$ a $\left.x_{1}\right)$ representam entre 1 a $5 \%$ do total da inversão da sacarose no tubo de evaporação $\left(x_{o}\right.$ a $\left.x_{f}\right)$.

2. A variação da inversão da sacarose $(x)$ com a concentração $(C)$ é incrementada com o acréscimo da temperatura de saturação do líquido $T_{c}$.

3. A variação da inversão da sacarose $(x)$ com a concentração $(C)$ é independente do $q_{o}$ no intervalo de vazões avaliado

4. As frações invertidas experimentais tiveram um bom ajuste às frações invertidas calculadas a partir dos parâmetros cinéticos apresentados por Pinheiros, isto deu a confiabilidade do uso destes parâmetros na avaliação da inversão no sistema de evaporação.

5. Foram desenvolvidos dois modelos matemáticos para a avaliação da inversão da sacarose a partir dos balanços de massa global e parcial para a sacarose feitos no tubo de evaporação, estes modelos calculam o volume do líquido no tubo de evaporação, considerado-se um perfil de velocidades plano no escoamento do líquido e um perfil de temperaturas linear ao longo da espessura do filme líquido.

6. Os valores de $V_{\text {apr }}$ foram muito próximos aos do $V_{\text {num }}$, isto possibilitaria o uso do modelo simplificado como uma boa aproximação, pois neste não é necessário um grande número de cálculos tal como é feito na integração numérica. Os valores de $V_{a p r}$ que resultaram ser entre 3 a $6 \%$ menores aos de $V_{\text {num. }}$ 
7. O parâmetro " $\beta$ " (usado no cálculo da temperatura efetiva na zona de aquecimento, $T_{\text {efa }}$ ) calculou-se ter valores entre 0,62 a 0,74, o valor médio deste parâmetro pode ser usado para poder calcular a fração invertida na saída da zona de aquecimento $\left(x_{1}\right)$ com bastante confiabilidade.

8. O parâmetro " $\alpha$ " (usado para o cálculo da temperatura efetiva na zona de evaporação, $T_{\text {efal }}$ ) calculou-se, resultando ser constante e de valor de 0,43, este parâmetro $\alpha$ leva em conta as variações da temperatura ao longo da espessura do filme líquido na zona de evaporação

9. Os volumes médios calculados $\left(\bar{V}_{\text {num }}\right)$ encontram-se entre 24 a 46 [ml] nos 9 ensaios. Estes volumes tendem a aumentar com o acréscimo da vazão média do líquido $(q)$.

10. Os valores do tempo de residência médio $\bar{\tau}$ tendem a diminuir com $o$ aumento da vazão média do líquido. Os valores do tempo de residência foram encontrados entre 16 a 39 [s] nos 9 ensaios.

11. Os erros do volume $\bar{V}_{\text {num }}$ encontrados através da propagação do erro acharam-se entre 2,38 a 4,65 [ml] para os 9 ensaios.

\subsection{Recomendações e Sugestões}

1. O modelo usado para avaliar a inversão no sistema de evaporação assumiu o fluxo do líquido com perfil de velocidade plano (fluxo turbulento). Em trabalhos posteriores podem ser provados outros tipos de perfis de velocidades como o perfil parabólico para o fluxo laminar ou equações empíricas para a zona de transição entre o fluxo laminar e o fluxo turbulento. 
2. Pode-se imaginar uma variação da taxa de evaporação entre as camadas do filme líquido. A camada mais próxima da parede do tubo, onde a temperatura é maior, teria uma taxa de evaporação maior do que a camada na superfície do filme, onde a temperatura é menor.

3. O modelo é bastante sensível à temperatura de avaliação da inversão, à medição do $\mathrm{pH}$, às determinações das frações invertidas (análise de laboratório), por esse motivo deve-se ter bastante cuidado já que erros na medição e/ou determinação destes parâmetros podem levar a consideráveis variações no cálculo do Volume. 


\section{$7 \quad$ Lista de referências}

ANDREWS L.S.; GODSHALL M.A.; MOORE S. Sucrose Degradation Under Model Processing Conditions. Journal of Food Science, v.67, n.5, p. 1621-24, 2002.

BUCHANAN, S.; KLUBER, D.G.; MEIGS,C.; OWENS, M.; TALLMAN, A. Energy of Activation and Temperature for the Hydrolysis of Sucrose. International Journal of Chemical Kinetics, v.15, n.11, p. 1229-34, 1983.

CHEN, J.C.P. Cane sugar handbook: a manual for cane sugar manufactures and their chemists. 11.ed. New York: John Wiley, 1985.

ENGETECNO, Tecnologia de fabricação de açúcar mascavo. Disponível em:< http://www.engetecno.com.br/acucar-mascavo.htm> . Acesso em 06/03/2008.

FALES, H.A.; MORREL, J.C. The velocity of inversion of sucrose as function of the Thermodynamic concentration of hydrogen. The Journal of the American Chemical Society, v.44, n.10, p. 2071-91, 1922.

GEA NIRO Inc., Falling Film Evaporators. Disponível em:

<www.niroinc.com/evaporators crystallizers/falling film evaporators.asp $>$.

Acesso em 12/02/2007.

HEIDT, L.J.; PURVES, C.B. The Unimolecular Rates of Hydrolysis of 0,01 Molar Methyl- and Benzyl fructo- furanocides and- Pyranosides and of sucrose in 0,0095 Molar Hydrochloric Acid at $20^{\circ}$ to $60^{\circ}$. The Journal American Chemical Society. v.60, n.5, p. 1206-10, 1938.

HUGOT, E. Handbook of Cane Sugar Engineering. Amsterdam: Elsevier Publishing Company, 1972. 
INCROPERA, F.P, Condensação em película turbulenta. In: Fundamentos de transferência de calor e de massa, Quinta Edição, Indiana/USA, Livros Técnicos e Científicos Editora S.A., 2003, capítulo 10, pág. 434.

KUROKAWA, E.C. Metodologia de estudo para melhoria do processo de evaporação de soluções de açúcar a partir dos coeficientes individuais de transporte de energia. 2002. 123p. Dissertação (Mestrado) - Escola Politécnica, Universidade de São Paulo, São Paulo.

LEININGER, P. M.; KILPATRICK, M. The inversion of sucrose. The Journal of the American Chemical Society, v.60, n.12, p. 2891-98, 1938.

PEACOCK, S. Predicting physical properties of factory juices and syrups. International Sugar Journal, v. 97, n. 1162, p. 571-7, 1995.

PINHEIRO TORRES, A.; OLIVEIRA, F.A.R.; SILVA, C.L.M.; FORTUNA, S.P. The Influence of $\mathrm{pH}$ on the Kinetics of Acid Hydrolysis of sucrose. Journal of Food Process Engineering, v.17, n.2, p. 191-208, 1994.

SALVAGNINI, W.M.; TAQUEDA, M.E. A Falling Film Evaporator with Film Promoters. Ind. Eng. Chem. Res., v. 43, n. 21, p. 6832-6835, 2004.

SARAVACOS, G.D.; MAYER, J.C.; WOOSTER, G.D. Concentration of Liquid Foods in a pilot-scale falling film evaporator. New York's Food and Sciences Bulletin, n.4, p. 1-14, 1970.

SMITH, J.M. Introdução na Engenharia das reações químicas. McGraw-Hill Book Company, Quarta Impressão, p. 143-145, 1989

STEPHAN, K. Heat transfer in condensation and boiling. New York: SpringerVerlag, 1988.

WARD, J.R. On the temperature dependence of the Activation Enthalpy for Sucrose Hydrolysis. International Journal of Chemical Kinetics, v.17, n.1, p. 11-15, 1985. 


\section{ANEXO A}

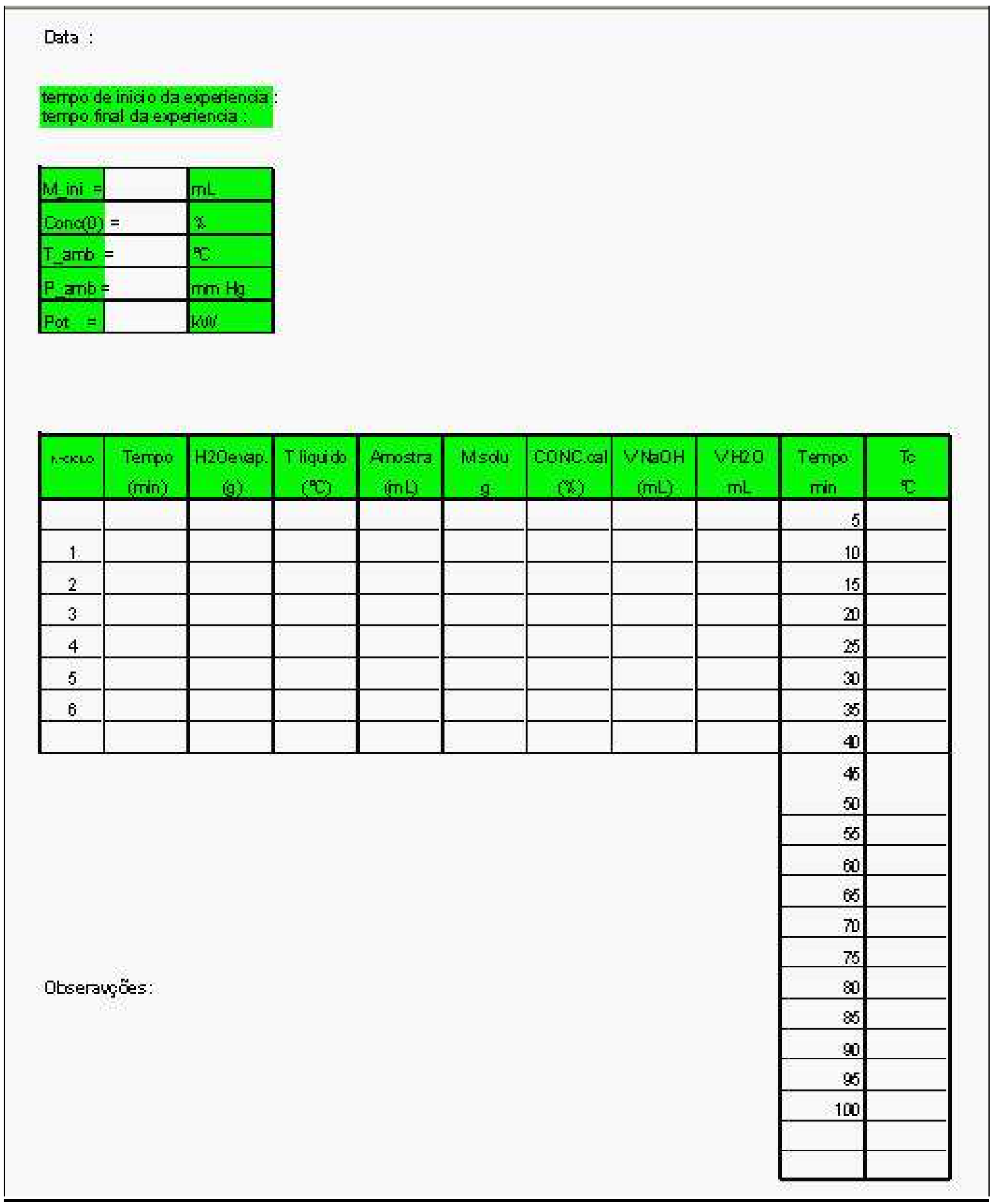

Figura A.1 Planilha usada para o registro das mudanças nas variáveis do processo de inversão. 


\section{ANEXO B - Fotos do sistema de evaporação}

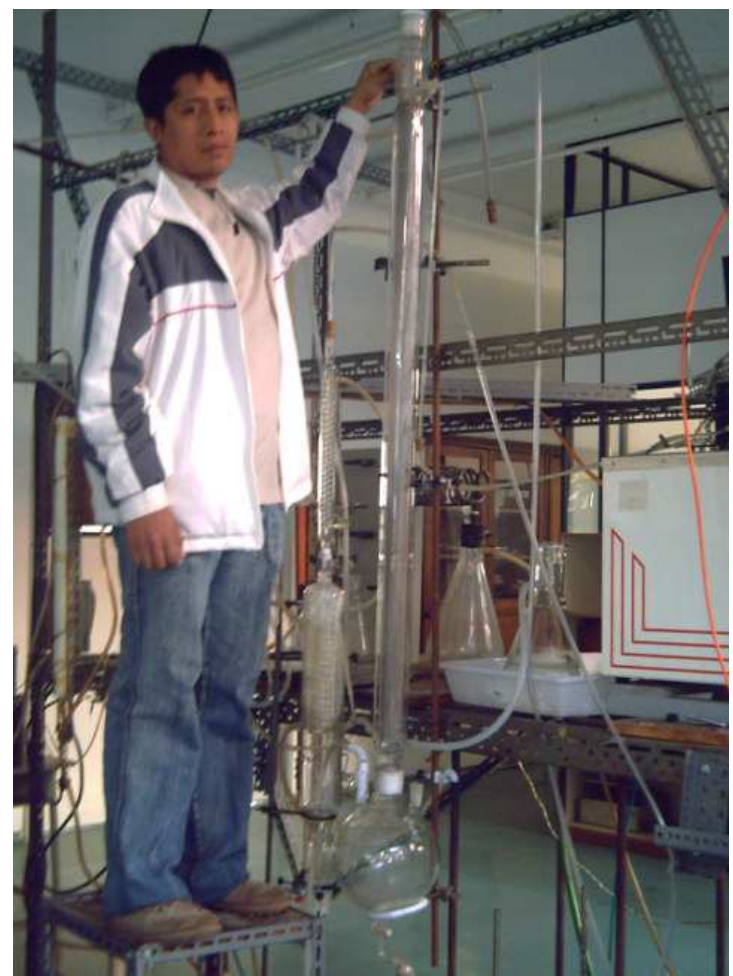

Figura B.1 Tubo de evaporação conectado com a câmara de vapor.

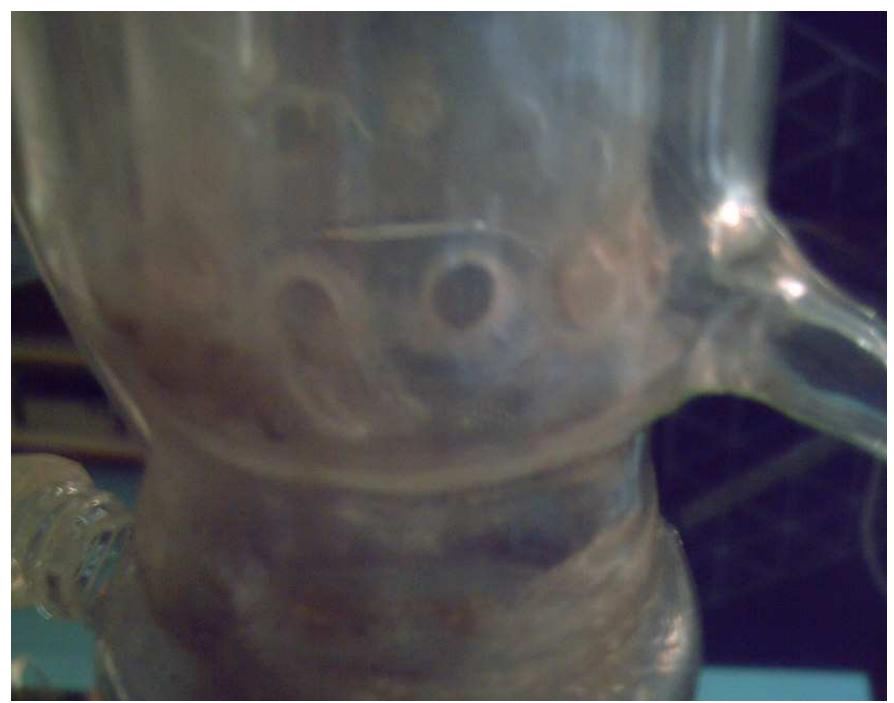

Figura B.2 Distribuidor de alimentação. Situado na parte superior do tubo de evaporação, este consistente de vários furos envolta da entrada do tubo interno que ajudam na formação do filme líquido no tubo de evaporação. 


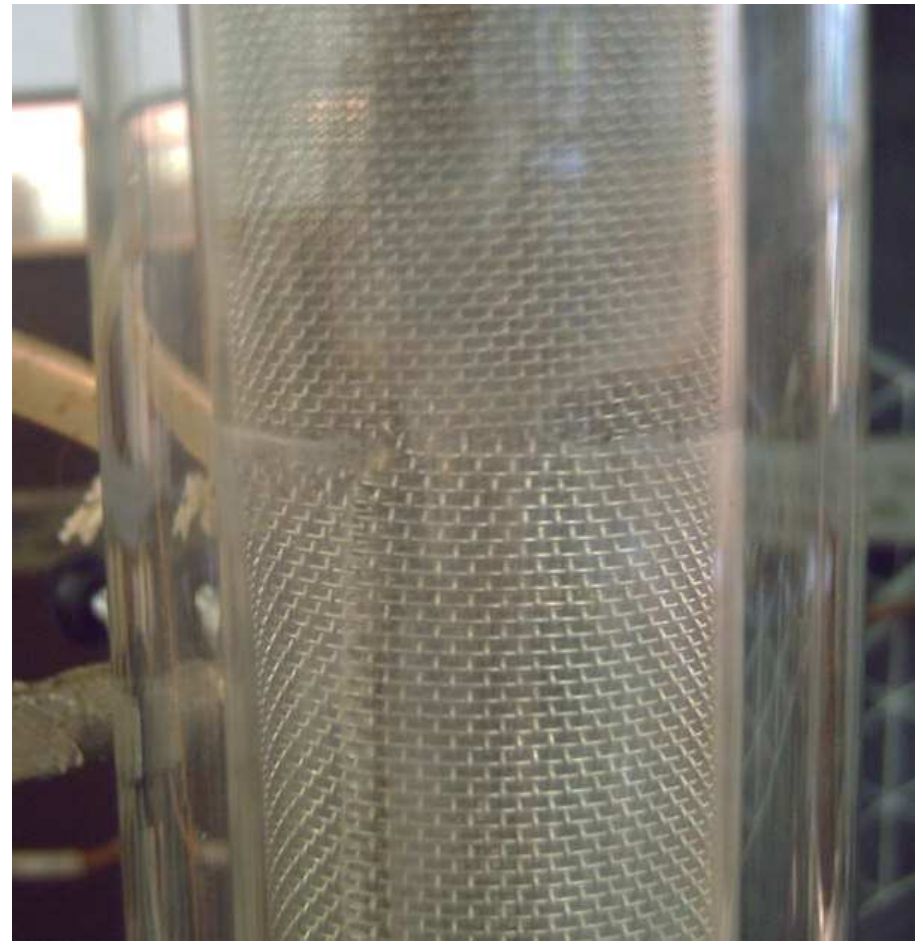

Figura B.3 Promotor de película. Situado dentro do tubo interno do evaporador, consistente de uma tela metálica pegada à parede do tubo que ajuda na estabilidade do filme.

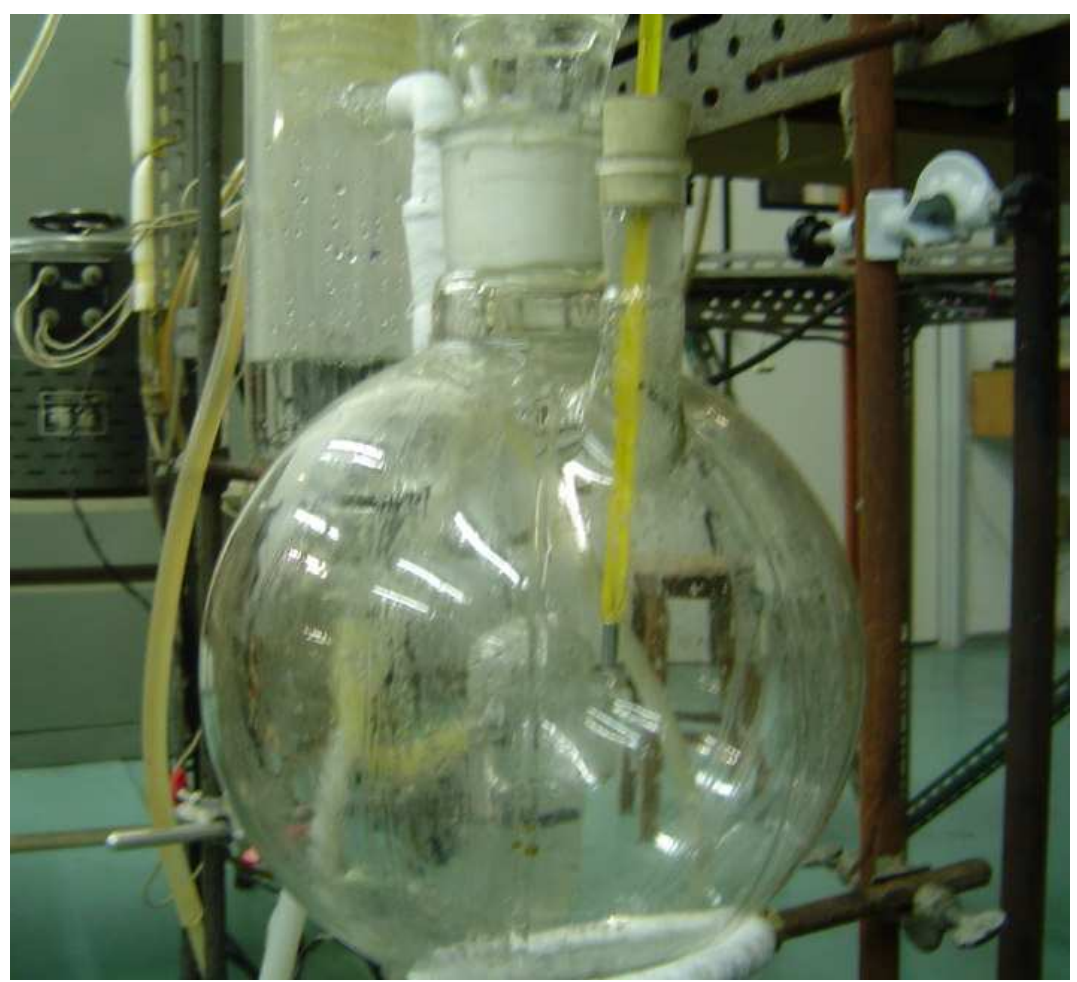

Figura B.4 Câmara de vapor em funcionamento. Conectado na parte inferior do tubo de evaporação. Em teoria esta câmara deve funcionar sem acumulo de líquido como pode ser observado na figura. 